Portland State University

PDXScholar

$1-1-2011$

\title{
Identifying Modifiable Factors associated with Depression across the Lifespan in Stroke Survivor- Spouse Dyads
}

Michael Joseph McCarthy

Portland State University

Follow this and additional works at: https://pdxscholar.library.pdx.edu/open_access_etds Let us know how access to this document benefits you.

\section{Recommended Citation}

McCarthy, Michael Joseph, "Identifying Modifiable Factors associated with Depression across the Lifespan in Stroke Survivor-Spouse Dyads" (2011). Dissertations and Theses. Paper 171.

https://doi.org/10.15760/etd.171

This Dissertation is brought to you for free and open access. It has been accepted for inclusion in Dissertations and Theses by an authorized administrator of PDXScholar. Please contact us if we can make this document more accessible: pdxscholar@pdx.edu. 
Identifying Modifiable Factors associated with Depression across the Lifespan in Stroke Survivor-Spouse Dyads

by

Michael Joseph McCarthy

A dissertation submitted in partial fulfillment of the requirements for the degree of

\author{
Doctor of Philosophy \\ in \\ Social Work and Social Research
}

Dissertation Committee:

Laurie E. Powers, Chair

Karen S. Lyons

Daniel Coleman

Victoria Cotrell

Thomas A. Kindermann

Portland State University

(C)2011 


\begin{abstract}
Depression is the most common psychological sequela associated with stroke, affecting approximately 33\% of stroke survivors (Hackett, Yapa, Parag, \& Anderson, 2005) with corresponding impacts on spouses, partners, or other informal caregivers (Han \& Haley, 1999; Low, Payne, \& Roderick, 1999). Although stroke is more common in older persons, persons of all ages are at risk for stroke and especially post-stroke depression (Centers for Disease Control and Prevention [CDC], 2007; Barker-Collo, 2007; Hughes, Giobbie-Hurder, Weaver, Kubal, \& Henderson, 1999). One of the factors which could explain increased risk of depression is "biographical disruption” (Bury, 1982), which happens when couples experience chronic illnesses that are developmentally off schedule or unexpected (Faircloth, Boylstei, Rittman, Young, \& Gubrium, 2004; Pound, Gompertz, \& Ebrahim, 1998; Roding, Lindstrom, Malms, \& Ohman, 2003). The goal of this dissertation study was to examine modifiable factors associated with depression in stroke survivor-spouse dyads, including the potential moderating effects of biographical disruption. This goal was accomplished by pursuing three specific aims: (1) investigating the extent to which dyad-level factors are associated with current depression in stroke survivor-spouse dyads, above and beyond the influence of individual-level factors; (2) investigating the extent to which biographical disruption associated with stroke moderates the strength of association between individual and dyad-level factors and depression; and (3) exploring additional individual- and dyad-level features of disruption from stroke not included in the structured portion of the interview, and to explore how the experience of stroke may be different for couples in different
\end{abstract}


developmental stages of life. Thirty-two recent stroke survivor-spouse dyads were interviewed using a combination of standardized measures and semi-structured interviews. Results showed that several dyad-level factors such as relationship quality, illness appraisal, and coping patterns were significant predictors of depression for survivors and spouses. The presence of biographical disruption did not statistically moderate these relationships, although the qualitative aspect of the study uncovered many aspects of disruption not addressed in the structured interview and the illness experience was clearly unique for couples in different developmental stages. These results have relevance for the development of effective interventions for post-stroke depression in couples, and are encouraging with respect to operationalizing and measuring the notion of biographical disruption from chronic illness across the lifespan. 


\section{DEDICATION}

This work is dedicated to my wife, Jennifer, whose support made the completion of this dissertation possible, and to our two amazing children, Macy and Peter. You have been, are, and will continue to be the most important people in my life. 


\section{ACKNOWLEDGEMENTS}

I would like to begin by acknowledging the couples who took part in this study. I am deeply appreciative for the trust you placed in me by opening up and sharing with me your most personal experiences with recovery from stroke. I also wish to thank my Dissertation Committee Members, Laurie Powers, Karen Lyons, Dan Coleman, Vicki Cotrell, and Thomas Kindermann, for all of your support throughout this entire process from study conceptualization, to participant recruitment, to data analysis and interpretation of findings - and my two Research Assistants, Jennifer Lawrence and Susan DeNight. Without your guidance, this study would certainly have never gotten off the ground. I would also like to acknowledge my major participant recruitment contacts, including the providers at the Oregon Stroke Center, Providence Stroke Center, and Rehabilitation Institute of Oregon, the staff at Meals on Wheels and Elders in Action, and the leaders of a number of Stroke Survivor Support Groups in the Portland metropolitan area. Thank you for your time and support of this study. Finally, I would like to express my appreciation to my extremely understanding and supportive friends and family. I have not seen you much in the past 12 months, but I hope to remedy that soon. Thank you. 
TABLE OF CONTENTS

$\begin{array}{lr}\text { ABSTRACT } & \text { i } \\ \text { DEDICATION } & \text { iii } \\ \text { ACKNOWLEDGEMENTS } & \text { iv } \\ \text { LIST OF TABLES } & \text { vii } \\ \text { LIST OF FIGURES } & \text { viii } \\ \text { CHAPTER I: INTRODUCTION } & 1\end{array}$

Significance of the Problem - Stroke and Depression

The Confluence of Stroke and Depression - Post-stroke Depression

Aims for Dissertation Research

Importance to the field of Social Work

CHAPTER II: REVIEW OF THE LITERATURE

Theoretical Frameworks

Interconnectedness of Spousal Depression

The Developmental-Contextual Model of Coping

Developmental Response to Stroke

Individual-level Factors associated with PSD in Stroke Survivors and

Spouses

Dyad-level Factors associated with PSD - An Emerging Area of Study

Dyad-level Factors associated with Depression in Other Illness Contexts

The Role of Biographical Disruption

Study Aims and Hypotheses

CHAPTER III: METHODOLOGY

Research Design

Setting and Sample

Procedures

Recruitment

Power Analysis

Data Collection

Measures

Overview of Data Analysis Approach

Quantitative Analysis

Qualitative Analysis

Feasibility Evaluation

CHAPTER IV: RESULTS

Scale Construction and Reliability

Study Sample

Partners' Covariance on Key Study Constructs

Multivariate Regressions 
Survivor Depressive Symptomatology

Spouse Depressive Symptomatology

Biographical Disruption as a Moderator

Narrative Content Analysis

Additional Aspects of Biographical Disruption

Stroke Across the Lifespan

CHAPTER V: DISCUSSION AND CONCLUSION

Primary Findings

Strengths and Limitation of the Study

Implications and Future Directions

Implications for Social Work and other Rehabilitation Practice Implications for Research

Conclusion

REFERENCE LIST 


\section{LIST OF TABLES}

Table 1: Studies Examining Dyad-level Variables with Effect Sizes 35

Table 2: Individual-level Constructs and Instruments 39

Table 3: Dyad-level Constructs and Instruments $\quad 42$

Table 4: Reliability of Scales and Subscales 47

Table 5: Survivor-specific and Spouse-specific Characteristics 55

Table 6: Pearson correlations between key study constructs 59

Table 7: Hierarchical Regression of Survivor Depressive Symptoms on
Survivor-reported Relationship Quality and Covariates

Table 8: Hierarchical Regression of Survivor Depressive Symptoms on

Survivor-reported Illness Ambiguity and Covariates 62

Table 9: Hierarchical Regression of Spouse Depressive Symptoms on Spousereported Relationship Quality and Covariates

Table 10: Hierarchical Regression of Spouse Depressive Symptoms on

65

Spouse-reported Active Engagement, Protective Buffering, and Covariates

65 


\section{LIST OF FIGURES}

Figure 1: Developmental-Contextual Model of Coping

Figure 2: Levels of Depressive Symptoms among Survivors and Spouses

Figure 3: Simple Slopes Test of Interaction between Survivor Gender and Illness Ambiguity

Figure 4: Bivariate Skatterplots between Spouse Depression, Active Engagement, and Protective Buffering 


\section{CHAPTER I: INTRODUCTION}

Disability is the great leveler. While certain demographic groups undeniably experience specific disabilities in greater numbers (e.g., traumatic brain injury among young males, neurodegenerative disorders among older adults), disability in general does not discriminate by race, gender, socioeconomic status, or age. Whether through accident, lifestyle choice, genetic predisposition, chronic illness, or traumatic health event, disability can impact one’s life, either directly or by association, when one is least expecting it. A test of our society and our modern social service and health care system is how we respond to the onset of disability, not only in acute care but in the long term supports we offer individuals, caregivers, and families as they struggle to rehabilitate from or adjust to the consequences of disability. One reflection of the quality and quantity of this support is the prevalence of secondary health conditions experienced by many people with disabilities. This scenario is well illustrated by the most common secondary mental health condition associated with stroke, post-stroke depression (PSD).

PSD is a growing concern to the field of social work, affecting approximately 33\% of stroke survivors (Hackett, Yapa, Parag, \& Anderson, 2005), with corresponding impacts on their spouses and other informal caregivers (Han \& Haley, 1999; Low, Payne, \& Roderick, 1999). In the remainder of this proposal, the term "PSD” will be used to describe depression resulting from the stroke experience in survivors and/or their spouses. The term "spouse(s)" will be used broadly to refer to committed partners who are married and/or living together. Although stroke can be devastating, it does not have to mean the end of happiness, fulfillment, and social and psychological health for survivors

and their loved ones. Unfortunately, an alarming number of stroke survivors and spouses 
experience a range of residual social and psychological problems following stroke, including PSD. Moreover, there is evidence that PSD may be even more of an issue for younger survivors. Why this is the case and, more importantly, how social workers can effectively intervene, are issues worthy of study.

In spite of abundant knowledge about the severity of this problem, effective interventions for post-stroke depression among survivors and their spouses remain elusive (Brereton, Carroll, \& Barnston, 2007; Knapp, Young, House, \& Foster, 2000; Paranthaman, \& Baldwin, 2006) for at least two possible reasons. First, existing poststroke depression research has failed to adopt a dyadic perspective but, instead, has focused almost entirely on the experiences of either the survivor or his or her spouse outside of the relationship context. PSD in many couples is an interactive experience (Klinedinsk, Clark, Blanton, \& Wolf, 2007; Visser-Meily et al., 2006) so it is essential that both members of the survivor-spouse dyad be included in our inquiries. Second, most studies of post-stroke depression have focused on older populations in which stroke incidence is higher, despite evidence that younger people may be at greater risk for depression following stroke (Barker-Collo, 2007; Hughes, Giobbie-Hurder, Weaver, Kubal, \& Henderson, 1999). As will be discussed in greater detail later in this dissertation, one of the factors that could explain increased risk of post-stroke depression is “biographical disruption” (Bury, 1982), which happens when couples experience chronic illnesses that are developmentally off schedule or unexpected (Faircloth, Boylstein, Rittman, Young, \& Gubrium, 2004; Pound, Gompertz, \& Ebrahim, 1998; Roding, Lindstrom, Malms, \& Ohman, 2003). While existing research has led to valuable 
insights, additional knowledge is needed related to dyad-level factors that influence poststroke depression across the lifespan and the role of biographical disruption.

\section{Significance of the Problem - Stroke and Depression}

Every 40 seconds someone in the United States (U.S.) experiences a stroke (American Heart Association [AHA], 2008). It is the third leading cause of death in the U.S. where, in 2005, an estimated 253,000 deaths were directly or indirectly attributable to stroke (AHA, 2008). For the approximately 400,000 individuals per year for whom stroke is not immediately fatal (i.e., "stroke survivors”), stroke is the leading cause of long-term emotional, physical, and mental disabilities including PSD (CDC, 2007). In 2008, the estimated direct and indirect costs of stroke in all age groups was $\$ 65.5$ billion, up from \$57.9 billion in 2006 and \$53.6 billion in 2004 (AHA, 2004, 2006, 2008). Projections based on current incidence and prevalence rates place the total cost of stroke from 2005 to 2050 (in 2005 dollars) at \$2.2 trillion (AHA, 2008).

Although stroke is more common in persons over the age of 65, persons of all ages are at risk (CDC, 2007). The AHA (2006) reports that an estimated $12 \%$ of U.S. stroke patients between 1999 and 2002 were ages 20 to 64. The economic burden of stroke in younger adults is likely even more substantial due to costs associated with the increased number of years of lost productivity and the increased length of time they may live with stroke-related physical and mental health conditions like depression (Jacobs, Boden-Albala, Lin, \& Sacco, 2002).

Independent of stroke, depression is also a major social problem in the U.S. and the world. Depression is described as "one of the most important causes of disability... among adults aged 15 and over” (World Health Organization [WHO], 2003, p. 20). It 
imposes a staggering burden on the U.S. economy with costs estimated to be roughly \$53 billion annually (Greenberg, Kessler, Nelss, Finkelstein, \& Berndt, 1996).

\section{The Confluence of Stroke and Depression: Post-stroke Depression.}

Like stroke and depression in and of themselves, depression resulting from stroke is a major social problem as well. PSD is the most common psychological problem for stroke survivors, affecting between $29 \%$ and 55\% of the survivor population (Kappelle et al., 1994; Naess, Nyland, Thomassen, Aareth, \& Myhr, 2005). PSD can be differentiated from other neuropsychological symptoms common after stroke such as emotionality, irritability, agitation, apathy, anxiety, mania, and psychosis (Dafer, Rao, Shareef, \& Sharma, 2008; Paranthaman \& Baldwin, 2006). The symptoms of PSD and functional depression (i.e., without a known medical cause) are similar and include loss of interest, sadness or hopelessness, sleep difficulties, fatigue, changes in appetite, feelings of selfblame or failure, concentration difficulties, slowed movement or restlessness, and thoughts of death or suicide (Aben \& Verhey, 2006; Beblo \& Driessen, 2002; Gilbody, Richards, Brealey, \& Hewitt, 2007). While there continues to be debate about the most valid way to distinguish PSD symptoms from other symptoms common among survivors, especially somatic symptoms, there is general agreement that PSD often goes unrecognized and untreated (Salter, Bhogal, Foley, Jutia, \& Teasell, 2007) and that survivors may be at the greatest risk for developing PSD within the first few months after stroke (Paolucci, et al., 2005).

In addition to the immediate pain and distress caused by PSD, the condition has been linked to a variety of poor psychosocial and physical health outcomes including lack of engagement in rehabilitation activities, longer hospital stays, inability to return to 
work, and impaired social functioning (Turner-Stokes \& Hassan, 2002). For example, Cardo-Artal and colleagues (Carod-Artal, Trizotto, Coral, \& Moreira, 2009) found that survivors experiencing PSD scored significantly lower than their counterparts without PSD in the health-related quality of life domain of social participation (mean $=38.5+/-$ 19.2 and mean $=53.6+/-23.1$, respectively; $\mathrm{p}<.0001)$ and Santus, Ranzenigo, Caregnato, and Inzoli (1990) found a high association between depression and poor social and family functioning $(\mathrm{r}=.47, \mathrm{p}<.001)$ at 1year post-stroke.

PSD has also been linked with increased risk of mortality in a number of studies. Morris, Robinson, Andrzejewski, Samuels, and Price (1994) found that, controlling for demographic (e.g., age sex, SES) and stroke-specific factors (e.g., stroke type, lesion location), survivors $(\mathrm{N}=103)$ diagnosed with either major or minor PSD were 3.4 times more likely to have died during a 10-year follow-up period. In a large study utilizing U.S. Department of Veterans Affairs databases $(\mathrm{N}=51,119)$, Williams and colleagues (Williams, Ghose, \& Swindle, 2004) found that survivors diagnosed with PSD were at significantly higher risk for mortality within a 3-year follow-up period (hazard ratio = 1.13, 95\% CI = 1.07-1.22). Stenager, Madsen, Stenager, \& Boldsen $(1998 ; \mathrm{N}=37,869)$ concluded that individuals with PSD, especially women and persons in younger age groups, had a significantly increased risk of suicide (persons $</=49$ years, Standardized Mortality Ratio = 656, 95\%CI: 324-1352; persons 50-59 years, Standardized Mortality Ratio $=580$, 95\%CI: 338-823). In other chronic illness populations including asthma, arthritis, diabetes, obesity, cystic fibrosis, and cancer, depression has also been associated with severity of symptoms, functional status, and mortality (Chapman, Perry, \& Strine, 2005; Quittner et al., 2008). 
It is critical to recognize that, sadly, PSD is not strictly an experience of survivors (Han and Haley, 1999; Low, Payne, \& Roderick, 1999). Falconer, Naughton, Strasser and Sinacore (1994) report that up to $46 \%$ of stroke survivors indicate, “unpaid helpers”, including spouses, are their primary caregivers at the time of hospital discharge. For these caregivers, depression following stroke is also a significant problem, affecting between 36\% and 53\% of the population (Grant, Bartolucci, Elliot, \& Giger, 2000; Wade, LeighSmith, \& Hewer, 1986). Fortunately for survivors and spouses, PSD and its consequences may be preventable if we can identify the most salient correlates and then modify them through proactive interventions.

\section{Aims for Dissertation Research}

The goal of this dissertation study is to examine modifiable factors associated with depression in this population in order to identify variables to include in a future large-scale study that will inform intervention efforts. Though individual-level factors associated with post-stroke depression in survivors and spouses have been identified (e.g., post-stroke physical and cognitive functioning of the survivor), dyad-level factors associated with depression such as relationship quality, collective illness appraisal (e.g., predictable vs. uncertain prognosis), dyadic coping strategies (e.g., active engagement vs. protective buffering), and perceived ability to fulfill mutually-expected roles have been investigated almost exclusively in populations experiencing other illnesses (e.g., myocardial infarction, multiple sclerosis). This study has the following three aims:

Aim 1: To investigate the extent to which dyad-level factors are associated with current depression in stroke survivor/spouse dyads, above and beyond the influence of individual-level factors. 
Aim 2: To investigate the extent to which biographical disruption associated with stroke, as measured by Likert-scaled items, moderates the strength of association between individual and dyad-level factors and depression.

Aim 3: To explore additional individual- and couples-level features of disruption from stroke not included in the structured portion of the interview, and to explore how the experience of stroke may be different for couples in different developmental stages of life.

\section{Importance to the Field of Social Work}

The long-term goal of this dissertation study is to contribute to the evolution of social work clinical practice. Effective interventions for preventing or treating PSD do exist but currently, these interventions are predominantly targeted at individual patients (Anderson, Hacket, \& House, 2004; Knapp, Young, House, \& Forster, 2000). Although few in number, those that have targeted couples (e.g., Clark, Rubenach, \& Winsor, 2003; Mant, Carter, Wade, \& Winner, 2000; Smith, Forster, \& Young, 2004) tend to be based around case management or education and counseling for helping couples to increase knowledge about stroke or learn practical problem solving skills, rather than facets of the relationship between the survivor and spouse than may facilitate good mental health. With the exception of two studies (i.e., Clark, Rubenach, \& Winsor, 2003; Smith, Forster, \& Young, 2004), the literature reviewed on this topic also focused on individual patient mental health outcomes rather than mental health outcomes for both survivors and their spouses. 
Based on the age range of the samples in which existing couples-based PSD interventions have been tested, couple-based interventions are typically structured around the needs of people who experience stroke in later life. For example, the mean ages for survivors and spouses in the study conducted by Clark and colleagues (Clark, Rubenach, \& Winsor, 2003) were approximately 72 and 70 years, respectively. Similarly, the median ages of survivors and spouses in the study conducted by Smith and colleagues (Smith, Forster, \& Young, 2004) were approximately 74 and 66 years, respectively. Results from this study will inform the development of interventions that are couplesbased (i.e., aimed at preventing or treating PSD in survivors and their spouses) and appropriate to individuals’ and couples’ developmental stage.

This study will also contribute to the development of knowledge in the field of social work research, specifically around methods for examining dyads as the unit of analysis. A dyadic approach is both ecological- and strengths-based because it recognizes and embraces individual survivors in the context of their natural supports, and it will likely result in improved outcomes for the broader family system. Unlike the vast majority of research in this area, this study also focuses on the survivor-spouse dyad in a developmental context. In addition to identifying modifiable factors associated with depression in this population, it contributes to existing theory related to couples' experiences of developmentally asynchronous chronic illnesses.

From a policy standpoint, this research will continue to draw attention to an often underrecognized group of vulnerable persons, stroke survivor-spouse dyads of all ages. Too often, younger stroke survivors are placed in programs designed for older people or in programs for younger people with different types of brain injury (e.g., TBI). Social 
workers must advocate for age-appropriate services, not one-size-fits all approaches, and they must advocate for vulnerable populations, regardless of any privilege they may have enjoyed before chronic illness.

This document began by describing the significance of the problem of PSD and continues with a discussion of theories that allow us to better understand the interconnection of partners' responses to PSD and the differential impacts of PSD on couples across the lifespan. A review of available literature on PSD, as well as postillness depression among couples in comparable chronic illness contexts, is provided. Hypotheses, with associated rationale, are proposed and a detailed description of the study methods is given. Results specific to each study aim are presented and the dissertation concludes with a discussion of findings, strengths and limitations of the study, and implications for social work and other rehabilitation research and practice. 


\section{CHAPTER II: REVIEW OF THE LITERATURE}

The dyadic formulation of this study is grounded in the recognition that, although depression following stroke may be a qualitatively different experience for individual partners, it nevertheless affects both members of the spousal dyad equally and profoundly. Several theoretical frameworks have been put forth in an effort to explain the shared emotional states experienced by committed partners. Two of these frameworks, emotional contagion (Hatfield, Cacioppo, \& Rapson, 1993) and positive assortative matching (Wilson, 2002), are described below with particular emphasis on why they may be germane in the context of stroke. Two additional theories about why stroke and other chronic illnesses may be experienced differently according to one’s age or developmental stage are also synthesized as a basis for this study's secondary focus on the impact of stroke across the lifespan.

\section{Theoretical Frameworks}

Interconnectedness of Spousal Depression. The fact that depression and, specifically, PSD is an experience that goes beyond individual survivors is hardly disputable (Marshall \& Harper-Jaques, 2008; Palmer \& Glass, 2003; Tower \& Kasl, 1996; Visser-Meiley et. al, 2006). One potential mechanism underlying the interconnectedness of spousal depression is emotional contagion. Hatfield and colleagues (Hatfield, Cacioppo, \& Rapson, 1993) were among the earliest contemporary researchers to develop theory related to the concept of emotional contagion in humans. Alternatively known as affect similarity (Goodman \& Shippy, 2002), mood convergence (Bookwala \& Schultz, 1996), affect concordance (Epstude \& Mussweiler, 2009), transference or

countertransference (Hatfield, Cacioppo, \& Rapson, 1993), or emotional transmission 
(Thompson \& Bolger, 1999), emotional contagion has been defined as "the tendency to automatically mimic and synchronize expressions, vocalizations, postures, and movements with another person's and, consequently, to converge emotionally (Hatfield, Cacioppo, \& Rapson, 1993, p. 96).

The central propositions of emotional contagion theory, mimicry, feedback, and contagion, are intuitive and may be particularly applicable to couples dealing with the aftermath of stroke. For example, many survivors exhibit an acutely anxious, depressive, or emotionally labile affect in the early months of the recovery process (Paranthaman \& Baldwin, 2006). Despite his or her best efforts to be supportive and encouraging, a spouse may unconsciously mimic these behaviors, setting in motion the afferent feedback process by which one's real emotional state is influenced by one's facial expressions and unconscious behaviors. The result of this process is that the spouse may begin to take on the emotions of the survivor. The process may be cyclical, with the survivor then unconsciously reacting to or mimicking his or her spouse's expressions and, consequently, being influenced emotionally by his or her own unconscious behaviors or facial expressions.

On the other hand, it has been documented that many survivors, especially those experiencing PSD or with lesions to specific regions of the brain, lose the ability to recognize and appropriately respond to the emotional facial expressions of others (Montagne, et al., 2007; Shamay-Tsoory, Tomer, Goldsher, Berger, \& Aharon-Peretz, 2004; Spillmann, et al., 2000). If affected in this way, a survivor may be less susceptible to emotional contagion stemming from his or her spouse's affect. However, impairments to the survivor's ability to respond to and express emotions may be perceived by the 
spouse as lack of concern or appreciation. The spouse may unconsciously or consciously react to this perception (e.g., become resentful) or, may unconsciously mimic the survivor's disengaged affect. The spouse's affect may, in turn, contribute to actual disengagement from the relationship via afferent feedback which may, in turn, exacerbate the social and psychological problems of each member of the dyad.

Another explanation for the interconnectedness of depression in survivors and spouses is the concept of positive assortative matching (Wilson, 2002) in which individuals tend to affiliate with those who share similar or complementary traits or behaviors as themselves, including risk factors for depression in response to life events. Like emotional contagion theory, assortative matching offers a rational explanation for why individual members of the dyad may react similarly (i.e., become depressed) to stressors brought about by stroke and, as such, it lends further support to the need for framing the issue of PSD as one experienced by two people in a committed relationship, as opposed to an experience of separate individuals.

While the notions of emotional contagion (Hatfield, Cacioppo, \& Rapson, 1993) and positive assortative matching (Wilson, 2002) are fascinating and may help to explain some of the processes underlying committed partners' shared moods, the introduction of a traumatic health event like stroke into a couple's life complicates matters immensely. In this context, other factors like mutual compassion, empathy, and even sympathy for one's partner's suffering may be just as relevant. Thus, additional theories are needed to explain the impact of chronic illness on couples relationship dynamics and moods and, especially, how these impacts differ by couples' life stage. 
The Developmental-Contextual Model of Coping. The DevelopmentalContextual Model of Coping (Berg \& Upchurch, 2007; Figure 1) is a useful theoretical framework for examining the relative influence of dyad-level factors on depression and it guides this research study. The Model describes dyadic coping as an interactive process that unfolds in three sequential stages (appraisal, coping, and adjustment) across the temporal illness experience (anticipatory coping, to initial symptom identification, to coping with treatment, to daily management).

Figure 1

Developmental-Contextual Model of Coping (Berg \& Upchurch, 2007)

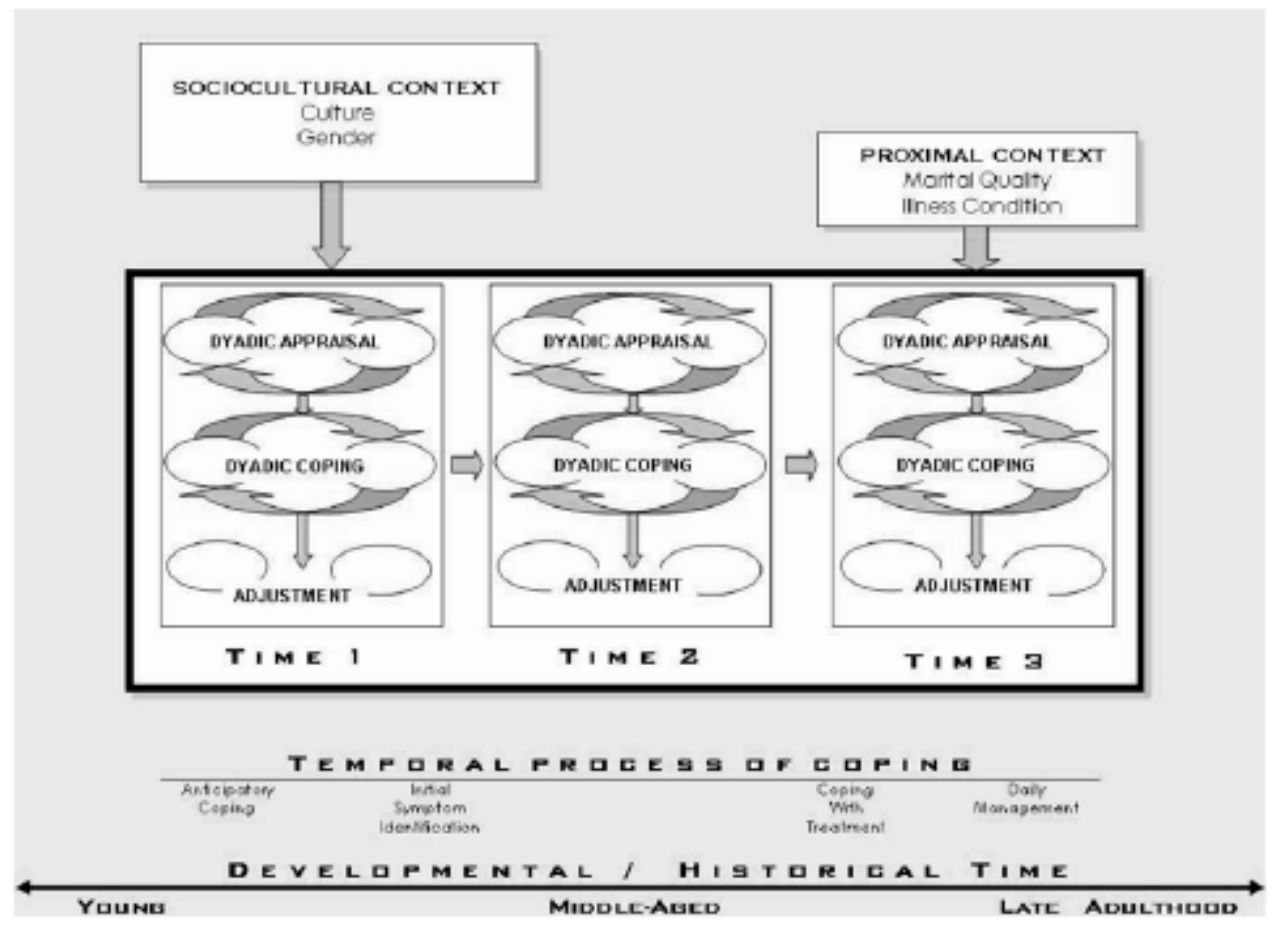

Wang and colleagues (Wang, Badley, \& Gignac, 2006) describe contextual factors within the WHO-ICF framework. Definitions of contextual factors include "the 
physical environment, social situation, and resources available to individuals” (Badley,1995, as cited in Wang, Badley, \& Gignac, 2006); “extra-individual, intraindividual, and risk factors” (Verbrugge \& Jette, 1994, as cited in Wang, Badley, \& Gignac, 2006); and "biological, social and physical environmental, and behavioral factors” (Institute of Medicine, 1991, as cited in Wang, Badley, \& Gignac, 2006). In the Berg and Upchurch Model (2007), contextual influences include sociocultural (e.g., culture, gender) and proximal (e.g., marital quality, illness condition) factors. The Model embraces the concept of emotional contagion in its dyadic formulation, incorporates many elements of Bury’s (1982) concept of biographical disruption (e.g., recognition, uncertainty, and mobilization), and is developmental in its framing of the illness experience as different for couples across the lifespan (e.g., young, middle-aged, late adulthood).

Since it was articulated in 2007, the Developmental Contextual Model has informed research with chronic illness populations such as cancer (Berg et al., 2008; Gagliese, et al., 2009; Scott \& Kayser, 2009), renal disease (Pruchno, Wilson-Genderson, \& Cartwright, 2009), Parkinson’s (Lyons, Stewart, Archbold, \& Carter, 2009), and diabetes (Berg et al., 2009; Berg, Schindler, \& Maharajh, 2008), as well as with couples coping with infertility (Benyamini, Gozlan, \& Kokia, 2009; Moreno-Rosset, Jurado, \& Rio, 2009; Peterson, et al., 2009). In this proposed study, the Model is used to conceptually organize variables that may be associated with depression in stroke survivors and spouses at the "coping with treatment" stage of the illness.

Developmental Response to Stroke. The theory of "biographical disruption" (Bury, 1982) has been employed by sociology scholars as a conceptual framework in 
their investigations of the impact of chronic illness on patients and families. The theory rests on three main assumptions: 1) that identity is socially constructed; 2) that there are expected stages in the development of individuals and families across the lifespan; and 3) that chronic illness, while a critical event that is fundamentally disruptive to the anticipated trajectory of one's health and by extension, the anticipated course of one's life and family, can be adjusted to and eventually transcended.

This last assumption can be viewed in contrast to other major theories in this field. Parsons (1951), for example, articulated a sick role theory in which survivors of chronic illness internalized often dependency-based social definitions of themselves which then served as a guide for future behavior including the active seeking out of professional assistance. In a similar vein, labeling theory (Scheff, 1984) has been applied to the notion of disability, especially potentially stigmatizing disabilities, by a variety of social theorists and researchers. In contrast to biographical disruption, labeling theory might assert that once a person experiences stroke, society may label him or her as disabled and, as a consequence, he or she may adopt stereotypical characteristics of how he or she perceives a “disabled person” to behave. For example, couples who have experienced stroke may cease to strive for goals they had when they perceived themselves as fully able-bodied or may become unnecessarily over-dependent on others. According to biographical disruption theory, chronic illness leads to a disruption with three main aspects or stages: disruptions to taken-for-granted assumptions and behaviors, disruptions to explanatory frameworks, and mobilization of resources (Bury, 1982, p. 169-170). Bury (1982) describes how “chronic illness involves a recognition of the worlds of pain and suffering, possibly even death, which are normally only seen as 
distant possibilities or the plight of others” (p. 169). In the case of stroke, couples may be forced to recognize the true nature of their relationship, in light of the possibility of diminished physical, cognitive, and sexual functioning and growing dependency. For couples in earlier developmental stages and/or with the associated life demands (e.g., dependent children), this aspect of disruption may be especially distressing as the intimate relationship is forced into a state of transformation before it may be fully actualized. This stage of disruption could be said to align with the Developmental Contextual Model’s (Berg \& Upchurch, 2007) appraisal stage.

Couples’ explanatory frameworks may also be disrupted by stroke as they are forced to acknowledge their own mortality and cope with the uncertainty around their expectations and plans for their future together. For this reason, it has been asserted that biographical disruption may not be a universal experience within the stroke population. For example, Faircloth and colleagues (Faircloth et al., 2004) concluded that age, comorbid conditions, and past knowledge of the illness experience protected older stroke survivors from biographical disruption and that, in fact, the concept should be abandoned in favor of the notion of biographical flow. Pound and colleagues (Pound, Gompertz, \& Ebrahim, 1998) similarly argued for the limitations of biographical disruption theory among older populations, citing evidence from interviews with stroke survivors (mean age 71 years) about the experience being “not that bad” (Pound, Gompertz, \& Ebrahim, 1998, p. 489). Rather than diminish the theory's credibility, however, these efforts reinforce its value for highlighting the role of age or developmental stage in distress following stroke. Similar to disruptions to taken-for-granted assumptions and behaviors, 
facing the implications of stroke for the future of one's family parallels the coping stage presented in Berg \& Upchurch’s (2007) Developmental Contextual Model.

Finally, Williams (2000) describes how, within the mobilization stage, individuals and couples strive to regain a sense of coherence or potency by bracketing off or normalizing the illness (Williams, 2000). Berg and Upchurch (2007) label this the adjustment stage. In the case of survivor/spouse dyads in earlier developmental stages, this adjustment may be impeded by practical life demands such as the need to care for young children or the necessity of earning an income through paid work.

Each of these theories is informative and valuable for justifying and guiding inquiry about the impacts of stroke among committed partners. However, more investigation and theory building may be necessary given the biological, psychological, and social aspects of stroke, as well as the complexities involved with partners coping together. This study will generate additional knowledge for moving thought in this area forward.

\section{Individual-Level Factors associated with PSD in Stroke Survivors and Spouses}

Bidirectional models accounting for the comorbidity between depression and stroke have been proposed (Mosovich et al., 2007), and there is some evidence that depression may predispose one to vascular disease (Thomas, Kalaria, \& O’Brien, 2004). However, there is persistent evidence that rates of depression are substantially higher among survivors and spouses dealing with stroke than in the general population (Hackett et al., 2005; Riolo, Nguyen, Greden, \& King, 2005) and that the incidence and severity of depression is associated with individual survivor characteristics such as lesion location and volume and, especially, physical and cognitive functioning. 
In their review of structural neuroimaging studies, Soares and Mann (1997) conclude that there is some evidence that lesions in the frontal and temporal lobes, thalamus, and cerebellum, as well as "global atrophy” of the brain are associated with mood disorders including PSD. Based on this frame of reference, the majority of treatments for PSD involve the administration of antidepressant medications including selective serotonin reuptake inhibitors, tricyclic antidepressants, noradrenaline reuptake inhibitors, serotonin noradrenaline reuptake inhibitors, and psychostimulants (Anderson, Hackett, \& House, 2004; Paranthaman \& Baldwin, 2006). Hackett and colleagues (Hackett, Yapa, Parag, \& Anderson, 2005) estimate that up to 31\% of survivors receive antidepressant medication within 2 years of experiencing stroke.

Other authors point out that biological variables alone do not explain the presence of depression following stroke (Abin \& Verhey, 2006). In this spirit of inquiry, Hosking, Marsh and Friedman (2000) found that Activities of Daily Living (ADL) dependence, in combination with demographic and other medical variables, accounted for approximately $38 \%$ of the variance in survivors' depression 3 months after stroke and that, in the context of these other factors, cognitive functioning uniquely accounted for $16 \%$ additional variance. Saxena, Ng, Yong, Fong and Koh (2008) found that survivors' cognitive functioning on admission was significantly associated with depressive symptoms 6 months after stroke (OR = 4.78; 95\%; CI = 1.85; 12.29). Barker-Collo (2007) found that survivors' cognitive functioning uniquely accounted for $51.3 \%$ of the variance in survivor depression 3 months after stroke.

Physical and cognitive functioning of the stroke survivor may also be associated with depression in spouses. In a two-year longitudinal study, Wade and colleagues (1986) 
found that spousal depression was significantly predicted by the survivor's degree of disability during the first year of stroke $\left(\mathrm{X}^{2}=16.8, \mathrm{~F}(2,223)=10.27, \mathrm{p}<.01\right)$ but not up to two years later. Wright, Hiskey, Buckwalter, Kelechi, and Hendrix (1998) found that, at 3 month post-stroke, survivor cognitive functioning and ADL dependency accounted for approximately 39\% and 73\% of the variance, respectively, in spousal depression ( $\mathrm{p}<$ .05). A sample of 29 predominantly female spouses also identified survivor ADL dependence as their primary source of psychological burden (Williams, 1993).

\section{Dyad-Level Factors associated with PSD - An Emerging Area of Study}

Although both survivors and spouses individually experience depression as a result of stroke, for many couples, depression appears to be an interconnected phenomenon (Klinedinsk, Clark, Blanton, \& Wolf, 2007). A review of the literature uncovered few studies that examined depression among stroke survivors and spouses in the context of their relationship. Four of these studies investigated the extent to which the quality of the dyadic relationship, variously termed spousal interactions (Wright, Hickey, Buckwalter, Kelechi, \& Hendrix, 1998), family functioning (King, et al., 2001; EpsteinLubow, Beevers, Bishop, \& Miller, 2009), and marital satisfaction (Blonder, Langer, Pettigrew, \& Garrity, 2007) impacted PSD in survivors and spouses.

Wright, Hickey, Buckwalter, Kelechi, and Hendrix (1998; N = 14 dyads) found no direct association between dyadic cohesion, tension, and affection (Spanier, 1976) and survivor depression. However, dyadic attachment in the form of less cohesion $(r=-.71$, $\mathrm{p}$ $<.05)$ and more frequent $(\mathrm{r}=.837, \mathrm{p}<.01)$, less frustrating $(\mathrm{r}=-.863, \mathrm{p}<.01)$ affectional interactions at baseline did have a significant impact on stroke survivors’ physical functioning at follow up which, as described earlier, has been consistently 
associated with PSD . The association between poor dyadic relationship quality and survivor depression was further evidenced in cross-sectional studies conducted by Epstein-Lubow, Beevers, Bishop, and Miller (2009; $\mathrm{N}=191$ dyads; $\mathrm{r}=.18, \mathrm{p}<.05$ ) and by Blonder and colleagues (2007; $\mathrm{N}=20$ dyads) who, in spite of a relatively small sample size, found a large negative association between family functioning and survivor depression $(r=-.59, \mathrm{p}<.01)$.

In terms of PSD among caregiving spouses, Epstein-Lubow and colleagues (2009) found a moderate association between poor relationship quality and spouse depression $(r=.27, \mathrm{p}<.01)$. In a short longitudinal study, King and colleagues (2001; $\mathrm{N}$ $=136$ dyads $)$ found that poor relationship quality $(\beta=.22, p<.01)$ and avoidant coping $(\beta=.28, \mathrm{p}<.001)$, in the context of demographic factors and baseline depression, accounted for approximately 50\% of the variance in spousal PSD (significance level not provided).

In another study about the role of dyadic coping in PSD among survivors and spouses, Visser-Meily and colleagues (2009; N = 211 dyads) examined the impact of different coping strategies (i.e., passive, active confronting, palliative, seeking social support, avoiding, expressing emotions, and reassuring) on spousal PSD over the course of three years and found that two specific coping strategies, passive coping and expressive coping, were strongly associated with spouse depression $(\beta=.49, \mathrm{p}<.01 ; \beta=$ $-.19, \mathrm{p}<.05$, respectively). Taken together, dyadic coping strategies accounted for approximately $24 \%$ of the variance in spouse depression (significance level not provided). Also noteworthy among this study’s results were the fact that, while patient ADL functioning improved significantly between Time One and Time Three, spouse 
depression decreased significantly between Time One and Time Two but not between Times Two and Three or between Times Three and Four. This would seem to point to a non-linear association between survivor functioning and spouse depression.

In a similar but shorter longitudinal study (baseline, 3, and 6-months post stroke), Rochette, Bravo, Desrosiers, St. Cyr-Tribble and Bourget (2007) investigated the dyadlevel variables illness appraisal (i.e., whether couples perceived the illness as a threat versus a challenge) and coping strategies (e.g., rationalize, hope) as potential factors associated with depression 6 months after stroke ( $\mathrm{N}=135$ couples). In addition to documenting the trajectories of certain coping strategies over the first few months following stroke, Rochette and colleagues (2007) found that, in the context of both demographic and clinical characteristics of individual participants (e.g., lesion location and volume), illness appraisal accounted for approximately $27 \%$ of the variance in survivor depression $(\mathrm{p}<.001)$ and $22 \%$ of the variance in spouse depression $(\mathrm{p}=.001)$ as measured by the 21-item Beck Depression Inventory (Beck, Ward, Mendelson, Mock, \& Erbraugh, 1961).

In a cross-sectional study, Franzen-Dahlin and colleagues (Franzen-Dahlin, et al., 2006) interviewed 71 dyads in which the stroke survivor had been diagnosed with minor or major PSD according to established cutoff points of the Montgomery-Asberg Depression rating Scale (MADRS; Montgomery \& Ashberg, 1979). These authors observed differences in experiences of distress following stroke based on the gender configuration of the dyad, with spouses of male survivors reporting more negative outcomes than spouses of female survivors. They also concluded that survivor functioning was significantly associated with both survivor and spouse depression. 
Interestingly, survivors who had less impaired functioning were more likely to experience major depression $(\mathrm{p}=.0007)$. Although this finding is in the context of a sample in which all participants were experiencing some level of PSD and an effect size was not reported, it does run somewhat counter to the preponderance of studies in this area. Survivor functioning was not significantly associated with diminished life situation among spouses $(\mathrm{r}=-.156, \mathrm{~ns})$, although need of assistance and survivor depression were $(\mathrm{r}=.557, \mathrm{P}<$ $.01 ; \mathrm{r}=.325, \mathrm{p}<.05)$

As with many studies that include data related to both survivors and their spouses, Franzen-Dahlin and colleagues’ study (Franzen-Dahlin, et al., 2006) is substantially limited by its use of proxy assessments of survivor mood made by spouses, including depressive symptoms, to examine associations between survivor and spouse factors. Associations between self-reported survivor depression and spouse factors were either not examined or not reported.

Finally, Clark and Stephens (1996) interviewed 55 survivor-spouse dyads crosssectionally to investigate the extent to which survivors' and spouses’ perceptions about caregiving (e.g., helpful versus unhelpful actions) were associated with survivor depression. Survivors and spouses both reported a far greater proportion of helpful versus unhelpful actions (147 helpful versus 64 unhelpful), with more men than women reporting unhelpful actions related to emotional insensitivity (54.5\% versus $27.3 \%$ ). Controlling for demographic characteristics and survivor ADL functioning, survivor’s perceptions of unhelpful actions accounted for a significant amount of variance in survivor depression $\left(\mathrm{R}^{2}\right.$ change $\left.=.29, \mathrm{p}<.001\right)$. 
These findings, especially those of Visser-Meiley and Rochettes’ research groups, make a valuable contribution to our understanding of dyad-level factors related to depression but the studies have limitations including failure to control for couples’ premorbid psychosocial functioning (Visser-Meily, et al., 2009) and exclusion of survivors with communication deficit who, conservatively, constitute approximately $20 \%$ of the survivor population (Kyrozis, et al., 2009). As will be described later, this dissertation study addresses these limitations. The studies reviewed here also do not take into account other dyad-level factors associated with depression (in addition to relationship quality) with documented large effects in populations of people experiencing comparable illnesses: uncertainty in illness, active engagement and protective buffering coping, and role expectations. Examining these variables in the stroke population may lead to new insights and more effective interventions.

\section{Dyad-level Factors associated with Depression in Other Illness Contexts}

Relationship Quality. Relationship quality has been found to be significantly associated with depression in the stroke population as well as in other chronic illness contexts. In a short longitudinal study, Suls, Green, Rose, Lounsbury and Gordon (1997) found that, for spouses of individuals with myocardial infarction, higher marital satisfaction accounted for approximately $15 \%$ of the variance in depression scores (p < .01). In a sample of persons experiencing various physical disabilities (including poststroke) and their spouses, Martire, Schulz, Wrosch, and Newsom (2003) found that marital quality accounted for approximately $8 \%$ of the variance in depression scores among patients $(\mathrm{p}<.05)$ at one year post-stroke. In a larger longitudinal study, Strating, Van Duijn, Van Schuur and Suurmeijer (2007) found that marital quality accounted for 
approximately $39 \%$ of the variance in dyadic scores of depression among couples contending with rheumatoid arthritis $(\mathrm{p}<.01)$.

Uncertainty in Illness. Uncertainty in illness has also has been found to be significantly associated with depression in persons with Multiple Sclerosis. For example, Gold-Spink, Sher, and Theodos (2000) documented strong associations between uncertainty about the course of the illness and depression at one year. Both patient and spouse uncertainty accounted for approximately $38 \%$ and $31 \%$ of the variance, respectively, in patient depression $(\mathrm{p}<.05)$.

Coping Strategies. Two specific coping strategies, protective buffering (i.e., the extent to which one partner "buffers" the other from his or her personal experiences and emotions) and active engagement (i.e., the extent to which one partner "engages" the other about his or her personal experience and emotions), have been identified as significant risk/protective factors, respectively, for depression in groups with chronic illness. For couples experiencing the aftermath of myocardial infarction, Suls et al., (1997) found that protective buffering, on the part of the patient to his or her spouse or vice versa, accounted for a substantial amount of the variance in both patient and spouse depression $\left(\mathrm{R}^{2}=.32, \mathrm{p}<.001\right.$ for patient buffering to patient depression; $\mathrm{R}^{2}=.32, \mathrm{p}<$ .001 for spouse buffering to spouse depression; $\mathrm{R}^{2}=.27, \mathrm{p}<.001$ for spouse buffering to patient depression). In a cross-sectional study with this population, Coyne and Smith (1991) found that both patient and spouse protective buffering accounted for approximately $15 \%$ and $38 \%$ of the variance $(\mathrm{p}<.001)$, respectively, in spousal depression, and that active engagement among spouses accounted for approximately $9 \%$ of the variance in this group $(\mathrm{p}<.01)$. In a cross-sectional sample of couples coping with 
cancer, Hagedoorn, Kuijer, Buunk, Wobbes, and Sanderman (2000) found that protective buffering accounted for $34 \%$ of the variance $(\mathrm{p}<.01)$ in reported poor marital quality which, as described, has been linked to depression in both survivors and spouses.

Role Expectations. Finally, role expectations appear to have a notable effect on depression. Bediako and Friend (2004) cross-sectionally examined ability to fulfill mutual role expectations as factors associated with depressive symptoms in mid-aged Rheumatoid Arthritis patients and their spouses. Patient expectations accounted for $44 \%$ of the variance in patient depressive symptoms when controlling for disease severity and social relations (Sig. $\mathrm{F}=.001$ ), 38\% of the variance when controlling for disease severity and relationship quality (Sig. $\mathrm{F}=.005$ ), and $39 \%$ of the variance when controlling for disease severity and perceived criticism (Sig. F = .001). In related research with Alzheimer's patients and their spouses, Boss (1977) and others found strong associations between family role ambiguity (i.e. boundary ambiguity) and spousal depression $\left(\mathrm{R}^{2}=\right.$ .49, p <.01; Kaplan \& Boss, 1999).

\section{The Role of Biographical Disruption}

This dissertation study integrates the concept of biographical disruption, which may have particular utility for understanding the extent to which stroke is disruptive to couples’ lives and developmental trajectories. Almost three decades ago, Michael Bury (1982) conceived of the notion of Biographical Disruption based on semi-structured interviews with persons affected by rheumatoid arthritis in younger age. Subsequent researchers have built upon Bury’s work, attempting to document and explain the differential impacts of chronic illnesses with effects reminiscent of "premature aging” (Singer 1974, as cited in Pound et al., 1998) that manifest in younger versus older 
persons, including HIV/AIDS (le Carricaburu \& Pierret, 1995; Wilson, 2007), cancers with reproductive health implications (Kenen, Ardern-Jones, \& Eeles, 2003; Navon \& Morag, 2004; Rajaram \& Hill, 1997), chronic fatigue syndrome and fibromyalgia (Asbring, 2001); spinal cord injury (Dickson, Allan, \& O’Carroll, 2008), multiple sclerosis (Green, Todd, \& Pevalin, 2007), Parkinson’s Disease (Gisquet, 2008), and stroke (Becker, 1993; Faircloth et al., 2004; Pound et al., 1998; Roding et al., 2003; Stone, 2007). Work in this area has been strictly qualitative and primarily individuallyoriented, and has provided rich descriptive information about how chronic illnesses that are asynchronous with one’s personal or familial “social clock” (Bury, 1991, p. 94) are excessively disruptive due to both instrumental and psychological challenges.

Qualitative studies examining aspects of biographical disruption in the context of stroke have identified three key factors associated with more pronounced instrumental and psychological disruption: 1) family income being primarily derived from paid work done by the survivor (Pound et al., 1998; Stone, 2007), 2) dependent children being cared for in the home (Roding et al., 2003), and 3) stroke being the couple’s first encounter with chronic illness (Faircloth et al., 2004). These factors are not meant to represent a comprehensive list of the circumstances in which stroke can be disruptive to couples’ lives. It is recognized that the disruptiveness of stroke may be amplified by a variety of other factors (e.g., inability to access the same forms of social support as before the stroke, impaired sexual relationships). However, these factors are most solidly grounded in previous qualitative studies and they provide a starting point for operationalizing and empirically examining the moderating influence of biographical disruption on couples’ experiences of depression following stroke. 
Adults of all ages may experience biographical disruption and its effects for the reasons described above, although younger couples may be more likely to experience biographical disruption in their developmental trajectory (Faircloth et al., 2004; Pound et al., 1998). It should be noted that, although there is some debate about the relationship between age and depression in the stroke population, several studies have found that depression is significantly associated with younger chronological age (e.g., Barker-Collo, 2007; Hughes et al., 1999; Ko, Aycosk, \& Clark, 2007). While these findings suggest a relationship between stroke at a younger age and depression, other researchers contend that chronological age may be an inadequate proxy for examining the degree to which stroke affects couples differently across the lifespan (Monteparte, 1996). Age and biographical disruption may be highly correlated with one another but they are not synonymous. Based on the substantial body of qualitative literature related to the impacts of stroke across the lifespan, biographical disruption could be a factor underlying the association between age at time of stroke and depression and, thus, it is an important potential moderator to investigate.

\section{Study Aims and Hypotheses}

This study has three primary aims. The first aim is to investigate the extent to which dyad-level factors are associated with current depression in stroke survivor/spouse dyads, above and beyond the influence of individual-level factors. This study specifically hypothesizes that relationship quality, illness appraisal, coping strategy, and perceived ability to fulfill expected roles will be significant factors associated with current depression. The second aim is to investigate the extent to which biographical disruption associated with stroke, as measured by Likert-scaled items based on previous qualitative 
studies, moderates the strength of association between individual and dyad-level factors and depression. The hypothesis is that, in couples for whom stroke is biographically disruptive, associations between all predictor variables and depression will be exacerbated (i.e., greater impairments in post-stroke functioning, lower relationship quality, greater illness uncertainty, more protective buffering and less active engagement coping, and less ability to fulfill mutually expected roles will be more predictive of depression in couples for whom stroke is biographically disruptive, compared to couples for whom it is not biographically disruptive). This study's final aim is to explore additional individual- and dyad-level features of disruption from stroke not included in the structured portion of the interview, and to explore how the experience of stroke may be different for couples in different developmental stages of life. No existing studies have specifically investigated dyad-level disruptions from stroke, nor have they purposefully targeted participants from a wide range of ages in order to investigate qualitative, agerelated differences in couples' experiences. Thus, this study has the potential to make a substantial contribution to knowledge in this area.

The preceding aims and hypotheses are driven by a thorough review of existing literature on post-illness depression and the unique experiences of younger couples contending with illnesses that are commonly associated with later life viewed through the lens of Berg and Upchurch’s Developmental-Contextual Model (Berg \& Upchurch, 2007) and Bury’s (1982) biographical disruption theory. They are also the result of conversations with experts in the field, preliminary interviews with stroke survivors and their spouses, and the investigator's personal experience as an immediate family member of a couple dealing with the aftermath of stroke. Prior to drafting the proposal for this 
dissertation, the investigator conducted six individual interviews to identify issues relevant for examining depression in this population and, through these, became aware of the lack of developmentally-adapted services and the importance of dyad-level factors in these investigations. These conclusions were reinforced through a discussion with a stroke support group for couples. In reflecting on this discussion, the potential role of biographical disruption also became clear, as some couples described greater adaptation to stroke while other (generally younger) couples described greater adversity due to practical and psychological challenges. The remainder of this dissertation is devoted to discussing the study methods, results, and implications of this research for social work and other rehabilitation research and practice. 


\section{CHAPTER III: METHODS}

\section{Research Design}

This cross-sectional survey study examined the relationship between dyad-level factors and depression in survivors and spouses and the potentially moderating role of biographical disruption. The aims of this study were to: 1 ) investigate the extent to which dyad-level factors are associated with current depression in stroke survivor/spouse dyads, above and beyond the influence of individual-level factors; 2) investigate the extent to which biographical disruption associated with stroke, as measured by Likert-scaled items, moderates the strength of association between individual and dyad-level factors and depression; and 3) explore additional individual- and couples-level features of disruption from stroke not included in the structured portion of the interview, and to explore how the experience of stroke may be different for couples in different developmental stages of life. Study hypotheses were evaluated by collecting data from stroke survivors and their spouses on key variables between 1 and 24 months post stroke (mean $=11.8$ months, SD $=12.07)$.

\section{Setting and Sample}

The setting for this proposed study was the Portland, OR metropolitan area and surrounding cities including Salem, Tillamook, and Prineville, OR. Participants in the study were 32 stroke survivors and their spouses between the ages of 21 and 90 (survivor mean age $=62.06$ years, $S D=13.38$; spouse mean age $=60.69$ years, $\mathrm{SD}=14.02$ ) Participants from a broad age range were recruited in order to maximize the variability in developmental stage of the sample. Survivor participants who experienced their first symptomatic stroke between 1 and 24 months prior to the interviews and who were 
currently involved in a committed relationship (i.e., married and/or living together) were sought for this study. This time frame was selected based on existing studies and input from stroke survivors and project mentors regarding the most logical timeframe to obtain data on dyad response to stroke following the first few months of acute reaction. To be included in the study, participants had to be capable of providing informed consent and have some reliable method to respond to the study questions (e.g. speaking, pointing, closing eyes). Information was gathered to document the characteristics of participants and accommodations provided.

\section{Procedure}

Pilot-test. The data collection protocol, cover letter and informed consent, and questionnaire were pilot tested with six survivor-spouse dyads. This pilot study was very informative and several recommendations from participants were incorporated into the study procedures. For example, the pilot study confirmed that the written questionnaire was difficult for some participants to independently complete and that some survivors and spouses were reluctant to complete the questionnaire without one another's input. Consequently, it was decided that structured interviews would be used to increase questionnaire accessibility and the independence of data collected from individual members of the dyad. Details about participant recruitment, data collection, instrumentation, and analysis are described below.

Recruitment. The sample of 32 couples was obtained through intensive, multipronged recruitment efforts conducted over a 10 month period. Participants were recruited through clinics in the Portland metropolitan area; through community-based organizations such as Meals on Wheels, Elders in Action, and the American Stroke 
Association; through community living facilities such as Cedar Sinai and Providence ElderCare; through print- and web-based sources such as Craigslist; and through networking with local stroke support groups. Specific clinic recruitment sites included Oregon Health \& Science University’s Oregon Stroke Center and outpatient rehabilitation facility, the Providence Health System’s Stroke Center, neurology clinic, and acute inpatient rehabilitation unit, and the Legacy Health System’s Rehabilitation Institute of Oregon (RIO). These sites are recognized as national leaders in acute stroke treatment and they provide comprehensive stroke services to patients and families throughout the Pacific Northwest.

Clinic recruitment sites, Meals on Wheels meal sites, assisted living facilities, and the American Stroke Association posted recruitment flyers in visible locations and distributed recruitment flyers in person to couples they thought may qualify for the study. Flyers contained the study inclusion criteria (e.g., first symptomatic stroke between 1 and 24 months prior, committed relationship). Announcements about the study were placed in several local newspapers’ Classifieds or Community Bulletin Board sections as well as posted on-line. The Investigator also met with several local stroke support groups to describe the study, distribute recruitment materials, answer questions, and invite couples to participate.

Couples were asked to contact the Investigator by telephone for an initial screening prior to arranging the interviews. On the initial telephone call, the Investigator reviewed the study purpose with potential participants, confirmed eligibility and each member's interest in participating, inquired about needed interview accommodations (for 
both survivors and spouses), reviewed major elements of the consent, answered any outstanding questions, and scheduled the interview appointment.

Several challenges arose during recruitment of participants for this study such as medical_providers not seeing couples that fit the study criteria as often as had been anticipated and/or not referring eligible couples as frequently as had been anticipated. An original recruitment strategy for this study was also for the Oregon Stroke Center (OSC) to mail study materials to patients prior to their first appointment. Unfortunately, in practice, responsibility for including materials in patient mailings fell to another unit and that unit was not as supportive of the mail-outs as the OSC had anticipated. Further, separate healthcare systems, with the exception of OHSU, required independent IRB review and approval of the study protocol and materials prior to recruitment, as opposed to ceding oversight to the IRB of Portland State University. This led to several months of delays in bringing additional participants into the study.

Challenges to recruitment through community organizations and groups also arose including stroke support groups being populated primarily by individuals or couples for whom the stroke occurred longer than 24 months ago (i.e., "long-timers”). Similarly, residents of assisted living facilities were primarily widows and widowers and, therefore, did not qualify to participate in a study of couples.

Fortunately, the Investigator was able to develop a number of strategies that eventually resulted in an adequate number of participants for this study. These strategies may be useful for future recruitment efforts with this population. First, the process of meeting with key clinic staff, not necessarily those individuals in official organizational leadership positions, to stress the practical clinical value of the study was critical to 
recruitment. In this way, “champions” for the study were identified and, through these persons' efforts, including reviewing recent patient charts and contacting potentially eligible couples personally by phone, the majority of participants were enrolled in this study. Further, it was important to cultivate relationships with providers who, themselves, had ongoing relationships with patients (as opposed to, for example, neurologists who may only see a patient one time immediately following the stroke). Providers with ongoing patient relationships had, in most cases, earned their patients' trust and, as such, were more effective referral sources.

Ongoing reminders to medical providers, feedback on the process (e.g., that couples were having positive experiences with being interviewed), and frequent expressions of appreciation were also valuable for study recruitment. Finally, advertising in smaller local newspapers, especially with circulation areas that included a large number of retired persons, and reaching out to colleagues and friends who may have been aware of a couple affected by stroke proved to be effective recruitment strategies.

Given the demographics of the stroke patient population, it was anticipated that the final sample would consist of a roughly equivalent number of male versus female survivors from a range of ages. Data entry occurred in tandem with data collection and the Investigator monitored recruitment closely to ensure that the final sample was adequately varied in terms of gender and age.

Power Analysis. An initial power analysis was performed to estimate the number of participants that would be needed to examine the bivariate associations of depression and the predictor variables. Based on previous research findings (Table 1), with significance level set at $\alpha=p<.05$ per Cohen, Cohen, West, and Aikens' (1992) 
recommendations for testing a priori hypotheses, a sample size of 60 couples was deemed sufficient to give the study adequate power for detecting significant bivariate relationships between depression and the predictor variables of interest: relationship quality (power $P \approx .89$ ); illness uncertainty $(P \approx .99)$; protective buffering $(P \approx .98)$; active engagement $(P \approx .82)$; and role expectations $(P \approx .99)$.

A review of the literature, as well as consultation with experts in the field, failed to uncover any previous studies that tested the specific multivariate model proposed here in stroke or any other populations with comparable illnesses. As such, it was not possible to conclusively project the overall multivariate power of this proposed study due to a lack of information on the intercorrelation of predictor variables. However, other studies have used multivariate models with comparable samples (e.g., Clark \& Stephens, 1996, 55 survvior/spouse dyads; Rochette, Bravo, Desrosiers, St. Cyr-Tribble, \& Bourget, 2007, 88 survivors and 47 spouses), included dyad-level variables to predict depression in the stroke survivor/spouse population, and found significant results.

Table 1

Studies Examining Dyad-level Factors Associated with Depression in Similar Chronic Illness Groups

\begin{tabular}{|c|c|c|c|c|}
\hline Author, date & N couples & Factor & Criterion & $r$ \\
\hline Suls et al., 1997 & 43 & Relationship Quality & Spouse depression & $.38^{* *}$ \\
\hline Martire et al., 2003 & 91 & Relationship Quality & Survivor depression & $.28^{*}$ \\
\hline Strating et al., 2007 & 61 & Relationship Quality & $\begin{array}{l}\text { Dyad depression } \\
\text { score }\end{array}$ & $.62^{* *}$ \\
\hline Gold-Spink et al., 2000 & 18 & Uncertainty & $\begin{array}{l}\text { Survivor depression } \\
\text { Spouse depression }\end{array}$ & $\begin{array}{l}.61^{*} \\
.55^{*}\end{array}$ \\
\hline Suls et al., 1997 & 43 & Protective buffering & $\begin{array}{l}\text { Survivor depression } \\
\text { Spouse depression }\end{array}$ & $\begin{array}{l}.56^{* * *} \\
.51^{* * *}\end{array}$ \\
\hline Coyne \& Smith, 1997 & 56 & $\begin{array}{l}\text { Protective buffering } \\
\text { Active engagement }\end{array}$ & $\begin{array}{l}\text { Spouse depression } \\
\text { Spouse depression }\end{array}$ & $\begin{array}{l}.61^{* *} \\
.38^{* *}\end{array}$ \\
\hline Bediako \& Friend, 2004 & 39 & Role expectations & Survivor depression & $.66 * * *$ \\
\hline
\end{tabular}


Literature describing the association between biographical disruption and depression is exclusively qualitative and descriptive. As such, it was difficult to accurately anticipate the potential statistical effect of biographical disruption. However, the current study provides data to inform more accurate power analyses for future studies in this area, both for the main variables of interest as well as for the biographical disruption moderator.

The aforementioned challenges in participant recruitment conducted within the time and resource limitations of a dissertation study resulted in a smaller sample size than originally anticipated. Post hoc power analyses were performed to evaluate the feasibility of examining the associations of interest with a smaller sample. Based on effect sizes from previous research, with significance level set at $\alpha=p<.05$, the following sample sizes were anticipated to be sufficient to give the study adequate power (.80) to examine the bivariate and predictive associations between the variables of interest and depression: relationship quality $(\mathrm{N}=47)$; illness uncertainty $(\mathrm{N}=26)$; protective buffering $(\mathrm{N}=27)$; active engagement $(\mathrm{N}=57)$; and role expectations $(\mathrm{N}=20)$. Although the final sample of 32 dyads may have been less than optimal for minimizing the risk of Type II errors for certain variables (i.e., relationship quality, active engagement; Cohen, Cohen, West, \& Aikin, 2003), this study provided valuable information to inform future, larger-scale studies.

Data Collection. Eligible survivors and their spouses completed questionnaires via face-to-face interviews. Interviews with survivors and spouses took place separately, at the same time, and were conducted by the Investigator and a Research Assistant. Interviews were conducted in a location that was most convenient for participants and 
geographically feasible: in the participant's home, at the offices of the School of Social Work or Regional Research Institute, or in a private community location (i.e. meeting room at a nearby library). Before beginning the interview, interviewers reviewed the informed consent with the participant, asking comprehension questions to verify his or her understanding.

Interviews consisted of the interviewer reading verbatim questions from the measures described later in this dissertation and then marking participants' responses on a paper form and an open-ended, audio-recorded portion in which the interviewer asked participants to describe ways in which the stroke had been disruptive to his or her individual life, to his or her partner's life, and to their life as a couple. Interviewers utilized skills for interviewing persons with impairments and various administration accommodations were offered based on those utilized during the informed consent process and in response to specific participant requests and periodic "checking" for understanding and consistency of responses during the interview. For example, providing substitute straightforward language to clarify meaning of words, repeating an earlier question to evaluate clarity of understanding and consistency of response, and providing response options on a large card that an aphasic participant could point to or that a participant with limited movement could gaze at or make a sound when the interviewer pointed to the chosen option. Each survivor/spouse paper questionnaire contained matching numeric identifiers to provide for matching and comparison of individual members of the survivor/spouse dyad during data analysis.

After each individual participant had completed his or her interview, couples were given $\$ 50$ in appreciation for their time. This compensation was not thought to be 
coercive to participants but rather, as was learned from piloting the questionnaire and protocol for this proposed study with couples experiencing stroke, it was thought to be appropriate to the time required for participation in the study and justified in light of the financial strain many couples face as a result of stroke. The questionnaire also contained an item to assess the extent to which this compensation influenced participant's willingness to take part in the interview. Completed questionnaires were converted to Portable Document File format and, with Teleform technology, data were immediately uploaded to two SPSS databases, one for survivor data and one for spouse data. Prior to analysis, these separate databases were matched on dyad ID\# and merged, per the dyad data structure described by Kenny, Kashy, and Cook (2006). After the completion of this study, the Investigator met with a group of survivors and spouses to discuss the meaning and implication of the findings for practice and research.

Measures. Several considerations were made in the selection of measures for this proposed study including: parsimony, face validity of the instrument (i.e., whether the items addressed the topical areas of interest), whether the instruments had established reliability and validity within the stroke (or comparable illness) population, whether the instrument had been developed for self-report or administration by an interviewer, and availability (i.e., publicly available or only available for purchase). 
Table 2

Individual-level Constructs and Instruments

\begin{tabular}{llcc}
\hline Construct & Instrument(s) & Population & \#Items \\
\hline Personal characteristics & $\begin{array}{l}\text { BRFFS w/population-specific questions } \\
\text { (Rochette et al., 2007) }\end{array}$ & Stroke & 14 \\
Pre-morbid depression & $\begin{array}{l}\text { Depression subscales of the MNI } \\
\text { (Lecrubier et al., 1997) }\end{array}$ & $\begin{array}{l}\text { Multiple } \\
\text { Sclerosis }\end{array}$ & 5 \\
Pre-morbid relationship quality & $\begin{array}{l}\text { Stability subscale (Busby, et al., 1995) } \\
\text { of DAS }\end{array}$ & $\begin{array}{l}\text { Coronary } \\
\text { disease }\end{array}$ & 2 \\
Survivor phys./cog. functioning & $\begin{array}{l}\text { SIS: Version 3 (Lai et al., 2003) } \\
\text { Severity of disability }\end{array}$ & $\begin{array}{l}\text { Modified Rankin Scale (van Swieten et } \\
\text { al., 1988) }\end{array}$ & Stroke \\
\hline
\end{tabular}

Table 2 and Table 3 depict the primary individual- and dyad-level constructs and associated measures that were used. All measures were administered to both survivors and spouses. Survivors and spouses completed measures in reference to themselves, except for survivor functioning measures which spouses completed in reference to the survivor (e.g., “In the past 2 weeks, how difficult was it for him/her to...”).

Outcome measure. Depression is a key variable in this study and so two measures of the construct were included: the Patient Health Questionnaire-9 [PHQ-9] (Kroenke, Spitzer, \& Williams, 2001) and the Major Depressive (current) and Dysthymia subscales of the Mini International Neuropsychiatric Interview [MINI] (Lecrubier et al., 1997). Both the presence of clinical depression as well as the severity of depressive symptoms were examined as outcomes. The PHQ-9 contains 9, 4-point Likert-scaled items and has demonstrated good sensitivity (78\%) and specificity (96\%) in the stroke population (Williams et al., 2005). Cut points for identifying major and minor depressive syndrome using the PHQ-9 have been recommended (Kroenke, Spitzer, \& Williams, 2001) and the PHQ-9 generates a numerical score reflecting depression severity (e..g, normal to mild, moderate, moderately severe, and severe; Rabkin, McElhiney, Moran, Acree, \& 
Folkman, 2009). MINI subscales contain 18 dichotomous items in total $(9,9)$ and have been used in a variety of populations, including multiple sclerosis (Patten, Newman, Becker, Riddell, \& Metz, 2007). The MINI was used to identify categorical clinical depression and the total number of items from the Major Depressive Episode subscale (9 items which closely match DSM-IV criteria and PHQ-9 items) survivors and/or spouses endorsed as “yes” were examined as an indicator of depression severity. Both the MINI and the PHQ-9 are driven by DSM-IV clinical criteria and, as such, allow for conclusions about the presence or absence of clinical depression, as well as severity. Both measures are brief and required minimal training to administer (Lecrubier et al., 1997; Gilbody, Richards, Brealey, \& Hewitt, 2007).

Demographics. Information including respondent age, gender, race/ethnicity, affected side (left, right, both), dominant hand, time since most recent stroke, relationship status and duration, number and ages of current dependents, and living environment and occupational status prior to stroke was collected using the Demographic Questions Set based on the Behavioral Risk Factor Surveillance System Demographics Core as well as the work of Rochette and colleagues (2007) in their study of stroke survivors and spouses. Participants were also asked whether or not they were currently taking prescription medication for depression.

Pre-morbid factors. Three questions were used to measure and control for premorbid depression: “Before the stroke, were you ever hospitalized for depression?”, “Before the stroke, were you ever prescribed medication for depression?", and "Before the stroke, were you ever in counseling for depression?”. Pre-morbid relationship quality was assessed with 2 Likert-scaled items (0: “All the time” to 5: "Never”) from the Dyadic 
Adjustment Scale [DAS] (Spanier, 1976) representing the Stability Subscale (Busby, Christensen, Crane, \& Larson, 1995): “Before the stroke, how often did you and your partner discuss or consider divorce, separation, or terminating the relationship?” and “Before the stroke, how often did you ever regret that you married (or lived together)?”

Individual-level factors. The Stroke Impact Scale: Version 3 [SIS] (Lai, Perera, Duncan, \& Bode, 2003) was used to measure perception of survivors’ post-stroke functioning. The SIS 3.0 contains 59 items across 8 subscales. The 10 items from subscale five were used to measure impairments in activities of daily living. The nine items from subscale six were used to measure impairments in mobility. The seven items in subscale two were used to measure impairments in cognition. In addition to survivors completing the SIS in reference to themselves, spouses completed the companion SIS Proxy Version in reference to the survivor. Although an evaluation of the reliability and validity of the SIS version 3.0 has not been published, internal consistencies for subscales of the nearly-identical version 2.0 range from .83 to .90 and that instrument has been deemed valid in comparison with long-standing measures such as the Barthel Index (Duncan et al., 1999; Mahoney \& Barthel, 1965). The Modified Rankin Scale (van Swieten, Koudstaal, Visser, Schouten, \& van Gijn, 1988) is another widely used instrument for assessing global outcome following stroke (Wilson et al., 2005) and, as such, it was also used as an “objective” measure of the severity of survivors' strokerelated disability.

Dyad-level factors. The Dyadic Adjustment Scale [DAS] (Spanier, 1976) was used to assess post-illness relationship quality. The DAS has been widely used with a variety of chronic illness populations. It contains 32 items that measure four factors: 
dyadic satisfaction, dyadic cohesion, dyadic consensus, and affectional expression. When summed, higher total scores reflect a better dyadic relationship. Corcoran and Fischer (1987) report strong concurrent validity and excellent internal consistency $(\alpha=.96)$.

The 31-item Mishel Uncertainty in Illness Scale [MUIS] (Mishel, 1981) was used to assess survivors' and partners' illness perceptions. The 31 MUIS items are formatted on a 5-point Likert scale and reflect four factors: ambiguity, complexity, inconsistency, and unpredictability. Mishel (1996) reports acceptable reliability for these subscales across multiple chronic illness populations ( $\alpha$ range $=.66$ to.81). Gold-Spink et al., (2000) created a parallel version of the MUIS for use with partners of persons with Multiple Sclerosis. Both scales were used in this study.

Table 3

\begin{tabular}{|c|c|c|c|}
\hline Construct & Instrument(s) & Population & \# Items \\
\hline \multirow[t]{2}{*}{ Depression } & $\begin{array}{l}\text { Patient Health Questionnaire-9 (Kroenke, } \\
\text { et al., 2001) }\end{array}$ & Stroke & 9 \\
\hline & $\begin{array}{l}\text { Depression subscales of the MINI } \\
\text { (Lecrubier et al., 1997) }\end{array}$ & $\begin{array}{l}\text { Multiple } \\
\text { Sclerosis }\end{array}$ & 18 \\
\hline Relationship quality & DAS (Spanier, 1976) & $\begin{array}{l}\text { Multiple } \\
\text { Sclerosis }\end{array}$ & 32 \\
\hline Illness appraisal & MUIS (Mishel, 1981) & $\begin{array}{l}\text { Multiple } \\
\text { Sclerosis }\end{array}$ & 31 \\
\hline Coping strategies & Buunk et al. (1991) & $\begin{array}{l}\text { Myocardial } \\
\text { Infarction }\end{array}$ & 28 \\
\hline Role fulfillment & PES (Bediako \& Friend, 2004) & Chronic Pain & 16 \\
\hline $\begin{array}{l}\text { Biographical } \\
\text { Disruption }\end{array}$ & $\begin{array}{l}\text { Indicators derived from qualitative } \\
\text { studies (Becker, 1993; Boylstein et al., } \\
2007 \text {; etc.) }\end{array}$ & Stroke & 3 \\
\hline
\end{tabular}

Coping strategies (i.e., active engagement, protective buffering) were assessed based on measures constructed by Buunk, Berkhuysen, Sanderman, Nieuwland, and Ranchor (1996) which were based on an original measure developed by Coyne and Smith 
(1991) for use with couples dealing with recovery from myocardial infarction. Active engagement was measured by five Likert-scaled items including “My partner tries to discuss [the stroke] openly with me”. Protective buffering was measured with 8 Likertscaled items including “My partner tries to hide his or her worries about me”. In a sample of persons with myocardial infarction, coefficient alphas for Coyne and Smiths’ original scales are reported as .90 and .89 .

The 16-item Patient Expectations Scale [PES] (Bediako \& Friend, 2004) was used to measure the degree to which survivors and spouses perceived themselves and one another as fulfilling premorbid interpersonal roles. Items including "I sometimes feel my spouse expects that I can do much more around the house than I really can." and "I sometimes feel my spouse expects me to cope with many more social activities than I actually can.” are rated on a 5-point Likert scale. Items are totaled and higher scores reflect a greater mismatch between expectations by significant others and individuals' perceived capabilities or, in other words, the extent to which dyad members are not fulfilling expected roles. Bediako and Friend (2004) report coefficient alpha for the PES as .93 among a patient sample.

Biographical Disruption Moderator. To the Investigator's knowledge, this study represents the first concerted effort to operationalize, measure, and statistically examine the potential role of biographical disruption from chronic illness. As such, and in keeping with the developmental aims of this dissertation research, a measure was developed to assess biographical disruption. Whether or not, and the extent to which, the stroke was biographically disruptive to survivors and spouses was assessed in several ways. First, biographical disruption was assessed with 3 questions derived from factors directly 
identified in past qualitative studies on biographical disruption in the stroke population. "At the time of stroke... did your family's primary income come from paid work done by the survivor?";"... did you and your spouse have dependent children that were cared for in the home?”; and “... as a couple, did you and your spouse lack direct personal experience with chronic illness?” Participants who answer “yes” to at least one of these items were considered to have experienced biographical disruption from stroke. The extent to which participants perceived each event as biographically disruptive was then assessed on a 5-point Likert scale from "not disruptive at all (1)” to "very disruptive (5)”. All participants, regardless of the presence of specific indicators, were also asked to rate on a similar 5-point Likert scale the degree to which the stroke was globally biographically disruptive to 1) him or herself as an individual, 2) his or her spouse, and 3) the couple. Finally, an open-ended question was included: "Please describe for me the ways in which [your/your partner's] stroke disrupted your life as an individual, your partner's life, and your lives as a couple.”

Feasibility. At the conclusion of the interview, 3 brief social validity questions were asked to learn about the participant’s perceptions of the accessibility and satisfaction with the interview, as well as barriers to participation and recommendations for improvement: "On a scale of 0 (not very much) to 3 (a lot)... how comfortable were you in answering the questions you were just asked?;" "How much did the incentive influence your willingness to be interviewed?"; and "Given that you experienced a stroke a short time ago, do you have any suggestions for how this interview could have been done differently or better?” These questions were drawn from six items administered to assess social validity of a survey study conducted by the Dissertation Chair with a 
population of individuals $(N=305)$ experiencing physical, mobility, cognitive, and speech impairments $(\alpha=.70)$ (Oschwald et al., 2009).

\section{Overview of Data Analysis Approach}

A mixed-methods approach, informed by what Neal, Hammer, and Morgan (2006) term a connected contributions motivation, was taken in the analysis of study data. Connected contributions describes an approach in which one method of inquiry, in this case quantitative, serves as the primary data collection tool and another method of inquiry, in this case qualitative, serves as an adjunct to the primary method. As outlined above, the primary aim of this study was to investigate the influence of individual- and dyad-level factors on survivors' and spouses' depression following stroke. A secondary aim was to examine the potential moderating role of biographical disruption, as assessed through Likert-scaled items. A final aim of the study was to explore additional features of disruption from stroke, as well as how disruption may be experienced for couples in different developmental stages, through couples' narrative accounts of their experience. The following section details the treatment of both the quantitative and qualitative aspects of data analysis for this study.

Quantitative analysis. Quantitative analysis for this study unfolded in several stages. The first stage involved a close examination and cleaning of study data. This process was facilitated by the Investigator's use of Teleform technology in the data collection and entry process which allows missing or incorrect values to be immediately assessed and corrected as needed.

Stage two involved merging the separate survivor and spouse datasets, imputing missing data as needed, and computing and assessing the reliability of scales and 
subscales. Although it may lead to biases toward Type I errors, mean imputation at the individual item level was selected as most appropriate for this study due to the modest sample size and small amount of missing data being dealt with. For the primary study constructs (i.e., survivor- and spouse-reported survivor physical and cognitive functioning, relationship quality, illness appraisal, coping, role expectations), fewer than $1 \%$ of potential data points were missing and an examination of mean summary scores before (i.e., with available cases using listwise deletion) and after (i.e., with all cases including imputed values) missing data imputation suggested that imputation made very little difference. It is believed that few data were missing because of the simultaneous data collection and entry used in this study and the Investigator's ability to immediately follow up with participants to remedy missing or ambiguous data. More importantly, the face-to-face data collection procedure in which interviewers had the opportunity to prompt participants for responses as needed, contributed to the completeness of study data.

Scales and subscales were computed based on factor structures identified in previous research. Table 4 provides details about the content and reliability of scales used in the present study. In most cases, study scales were identical to the original measures. However, adaption of the scales for participants who experienced stroke within the 24month inclusion period of this study was necessary in certain instances. Three items referring to current care received in inpatient settings were removed: "I do not know when to expect things will be done to me.”; "It is vague to me how I will manage my care after I leave the hospital."; and "I can depend on the nurses to be there when I need them.”. The majority of participants reported not experiencing pain as a result of stroke 
and, as such, two related items were removed: "It is unclear how bad my pain will be.”; and “When I have pain, I know what this means about my condition.”.

Table 4

Reliability of Scales and Subscales

\begin{tabular}{|c|c|c|c|c|c|c|}
\hline & \multicolumn{3}{|c|}{ Strvivor } & \multicolumn{3}{|c|}{ Spouse } \\
\hline & $\begin{array}{c}\text { original } \\
\text { items }\end{array}$ & $\begin{array}{l}\text { study } \\
\text { items }\end{array}$ & $a$ & $\begin{array}{c}\text { original } \\
\text { items }\end{array}$ & $\begin{array}{l}\text { study } \\
\text { items }\end{array}$ & $\alpha$ \\
\hline Scale and subscale & & & & & & \\
\hline Depression symptomatology & 9 & 9 & .830 & 9 & 9 & .918 \\
\hline \multicolumn{7}{|l|}{ Functioning: } \\
\hline Physical & 10 & 10 & .889 & 10 & 10 & .913 \\
\hline Cognitive & 7 & 7 & .933 & 7 & 7 & .914 \\
\hline Mobility & 9 & 9 & .920 & 9 & 9 & .945 \\
\hline \multicolumn{7}{|l|}{ Relationship quality } \\
\hline Summary score & 32 & 32 & .922 & 32 & 32 & .933 \\
\hline Dyadic satisfaction & 10 & 10 & .806 & 10 & 10 & .800 \\
\hline Dyadic cohesion & 5 & 5 & .683 & 5 & 5 & .638 \\
\hline Dyadic consensus & 13 & 13 & .887 & 13 & 13 & .902 \\
\hline Affectional expression & 4 & 4 & .683 & 4 & 4 & 562 \\
\hline \multicolumn{7}{|l|}{ Illness appraisal } \\
\hline Ambiguity & 13 & 10 & .809 & 13 & 10 & .848 \\
\hline Complexity & 7 & 5 & .494 & 7 & 5 & .565 \\
\hline Inconsistency & 7 & 7 & .734 & 7 & 7 & .715 \\
\hline Unpredictability & 5 & 5 & .705 & 5 & 5 & .607 \\
\hline $\begin{array}{l}16 \text {-item ambiguity factor } \\
\text { score }\end{array}$ & 16 & 16 & .829 & 16 & 16 & .873 \\
\hline $\begin{array}{l}12 \text {-item complexity factor } \\
\text { score }\end{array}$ & 12 & 12 & .749 & 12 & 12 & .767 \\
\hline \multicolumn{7}{|l|}{ Coping strategies } \\
\hline Active engagement & 5 & 5 & .627 & 5 & 5 & .823 \\
\hline Protective buffering & 8 & 8 & .529 & 8 & 6 & .701 \\
\hline \multicolumn{7}{|l|}{ Role fulfillment } \\
\hline Misunderstandings & 6 & 6 & .906 & 6 & 3 & .848 \\
\hline Unrealistic expectations & 10 & 10 & .924 & 10 & 9 & .846 \\
\hline Biographical Disruption (3-item & & & & & & \\
\hline summary score) & & 3 & .808 & & 3 & .886 \\
\hline
\end{tabular}

Much previous research has been concerned with the effects of coping communication (e.g., active engagement, protective buffering) on patient outcomes and spousal reports have been used to assess the accuracy of patient perceptions. However, this study aimed to examine the effects of being the recipient of active engagement or protective buffering communication for both partners and so scale items were worded to assess engagement or buffering toward the respondent (i.e., survivors and spouses) from 
his or her partner. For this reason, two items related to experiencing an illness or impairment oneself were removed from the spouse version of the protective buffering subscale ("With an excuse, my spouse tried to persuade me to follow the doctor's instructions." and "My spouse takes over as much of my work as possible.") and four items were removed from the spouse versions of the role fulfillment subscales ("I get disturbed when my spouse expects me to take medicine that makes me feel unpleasant or sick"; "I feel upset at times when my spouse doesn't recognize how ill I really am."; "I sometimes feel angry when my spouse doesn't notice the symptoms I experience."; "I feel upset sometimes when my spouse doesn't understand that I can' always attend planned events when I suddenly don't feel well.”).

Stage three consisted of running descriptive statistics for all survivor and spousereported variables. Paired sample t-tests were used to investigate whether there were significant differences in continuous-level partners' reports and, where found, the degree of magnitude of the difference was noted for future investigations into factors related to partner incongruence.

Stage four involved calculating Pearson product-moment correlations in order to examine the covariance between partners on key study constructs including survivor and spouse perceptions of the survivor's mobility, physical, and cognitive functioning and the couple's relationship quality, illness appraisal, coping strategies, perceived ability to fulfill mutually expected roles, perceived disruption from stroke, and depression. Given the developmental aims of this study (i.e., generating hypotheses for future studies), corrections to account for multiple pairwise tests were thought to be excessively conservative. However, 15 pairwise correlations between partners were tested in total 
(i.e., all variables of interest and their constituent subscales) so, with significance level set at $\mathrm{p}<.05$, it was anticipated that less than one association would be the result of a Type I error.

The original goal of this dissertation study was to examine depression following stroke at the dyad level through pooled regression analyses based on the Actor-Partner Interdependence Model (APIM; Kenny, Kashy, \& Cook, 2006). Unfortunately, this study's final sample size and consequent low statistical power prohibited the use of such a complex model. Thus, the final stages of analysis were based on the sequential (a.k.a., hierarchical) regression approach described by Tabachnick \& Fidel (2007). Dyad-level constructs that were observed to significantly covary (or sub-constructs thereof) were entered singularly into hierarchical linear regressions to assess the extent to which each construct accounted for variance in individual survivor and spouse depression, after partialling out the effects of demographic and individual-level factors (e.g., survivor functioning). In this way, portions of the Developmental-Contextual Model (Berg \& Upchurch, 2007) that guided this study could be evaluated within the confines of the study's scope and modest sample size $(N=32)$. Additional analyses were also conducted to examine potential cross-partner effects, regardless of whether the predictors of interest covaried significantly between partners.

Qualitative analysis. Participant responses to the open-ended question about biographical disruption were content analyzed and used to provide context to statistical analyses and highlight other important issues related to couples experiences with stroke. A constant-comparative method (Glaser \& Strauss, 1967, as cited in Strauss \& Corbin, 1994) was used for this analysis. A constant-comparative method is an iterative form of 
internal validation in qualitative research that involves fragmenting data (e.g., research participant narratives) into discreet segments for comparison and analysis (Ritchie \& Lewis, 2003). A subset of data fragments (e.g., participant statements contained within a portion of the total interview transcripts) is closely examined in order to develop preliminary ideas about themes which may be present throughout the entire data set. Themes are then given codes and the suitability of these codes is then tested by a comparison with the rest of the data. Codes are revised based on this expanded analysis and the process is repeated until comprehensive data treatment is achieved (Silverman, 2005). This approach has been widely used in research with the stroke population (e.g., Kessler, Dubouloz, Urbanowski, \& Egan, 2009; Winkens et al., 2006; White et al., 2008), as well as a variety of other chronic illness and other groups. Specific analyses, by study aim, are described below.

Aim 1: To investigate the extent to which dyad-level factors are associated with current depression in stroke survivor/spouse dyads, above and beyond the influence of individual-level factors.

Analysis for Aim 1: Sequential analysis proceeded according to the theoretical model developed by Berg and Upchurch (2007). Controlling for demographic factors with significant bivariate associations with the dependent variable, pre-morbid factors, and survivor functioning, separate models for survivor and spouse depression were estimated by stepping in dyad-level variables separately into the final block: (1) relationship quality; (2) illness appraisal; (3) coping; and (4) perceived ability to fulfill expected roles. Various cross-partner effects (e.g., the extent to which the spouse's perception of the couple's relationship quality impacts the survivor's depressive 
symptoms) were also explored in this manner, as well as the influence of couple's incongruence about certain aspects of the illness (e.g., outlook on the future) on individual member’s depression.

Aim 2: To investigate the extent to which biographical disruption associated with stroke moderates the strength of association between individual and dyad-level factors and depression.

Analysis for Aim 2: As described, the potential role of biographical disruption was first explored by examining the extent to which survivors and spouses agreed or disagreed about the disruptive nature of the stroke. Due to the objective nature of the indicators of biographical disruption used in this study and their basis in previous studies (e.g., primary income from survivor, yes/no; presence of dependent children in the household, yes/no; past experience with chronic illness, yes/no), it was anticipated that there would be little disagreement within couples about whether or not the stroke was biographically disruptive according to the criteria used for this study. Nevertheless, crosstabulations with McNemar's Tests were used to confirm this assumption. Couples for whom stroke was biographically disruptive, as determined by endorsement of any one of the three indicators by either partner, were analyzed according to the approach used for Aim 1 and compared with couples for whom the stroke was not biographically disruptive, to evaluate the strength of associations between predictor variables and depression. The influence of each individual indicator of biographical disruption was also examined through additional segmentation and analysis (e.g., Is there a different association between predictor variables and depression specifically for couples with dependent children in the household?). 
Biographical disruption was further examined based on survivors’ and spouses’ scores about the extent to which the stroke was "globally" biographically disruptive to themselves individually (range $=1-5$ ), their spouse individually (range $=1-5$ ), and to their life as a couple (range $=1-5$ ), and based on the summary score of these items (range $=3$-15). In this analysis, for example, individual's global disruption scores were used to create interaction terms with individual- and dyad-level predictors and these interaction terms, with their corresponding main effects, were entered into the regression equation in the final step as described in Aim One.

Where significant interactions were found, simple slopes tests (Cohen, Cohen, West, \& Aiken, 2003) were used to more closely examine the nature of these interactions and answer question such as, "Is there a stronger association between relationship quality and depression in couples whose global and/or summary score reflects their perception of the stroke as being highly biographically disruptive (i.e., 1 standard deviation above the mean)?”.

Aim 3: To explore additional individual- and couples-level features of disruption from stroke not included in the structured portion of the interview, and to explore how the experience of stroke may be different for couples in different developmental stages of life.

Analysis for Aim 3: Conversations with individual survivors and spouses were audio recorded and lasted between 2 and 25 minutes. Audio recordings were professionally transcribed for analysis and review. The investigator and a graduate research assistant independently reviewed a subset of 20 interview transcripts (10 survivor, 10 spouse) and independently generated a list of the most 
frequently occurring themes and topic areas. After this independent generation of themes and topics, they met to identify areas of consensus and disagreement. The most commonly occurring, consensually identified topics were given codes. The original subset of transcripts was then reviewed again and these consensually identified codes were applied. The investigator and research assistant met again to discuss this process, whether the coding system was adequate, and whether some codes should be combined, discarded, or whether additional codes should be added. This process was conducted until the Investigator and Research Assistant reached agreement across the codes assigned.

The investigator used AtlasTI qualitative analysis software to apply codes to the entirety of the interview transcripts. In total, approximately 90 pages of raw interview transcripts resulted in 359 coded participant responses. In addition to organizing data generally by theme and topic area, AtlasTI allows for a comparison of coded responses by code "family". This feature was used to examine qualitative differences in the experiences of individual survivors, spouses, and couples at different life stages. Following analysis and interpretation of the coded data, preliminary findings were presented to a group of survivor-spouse to garner feedback. This feedback was valuable for further interpretation and refinement of theory based on these data.

Feasibility evaluation. Data related to implementation were collected to facilitate improvement of the proposed study and design of future studies. Fidelity checklists were developed for the recruitment, consent, and survey administration protocols, and data were taken throughout the study to document adherence to protocol and variations incorporated. The Investigator maintained research logs including: (1) implementation 
barriers observed, as well as strategies attempted to address each barrier and their respective effectiveness; (2) comments and suggestions offered by participants related to the study design and procedures; and (3) comments and suggestions offered by staff of the recruitment sites and other professionals. Answers to the social validation questions were analyzed to identify common issues, barriers, and alternative strategies for study implementation. 


\section{CHAPTER IV: RESULTS}

\section{Study Sample Characteristics}

Descriptive statistics for the study sample are presented in Table 5. Unless

otherwise noted (e.g., spouses’ report of survivor functioning), all statistics are reported by the respondent to whom they refer. In total, 32 opposite-sex couples participated in the study. There were slightly fewer female survivors than males (13 female, 19 male) and, conversely, slightly more female spouses than male (19 female, 13 male). Most survivors

Table 5

Survivor-specific and Spouse-specific Characteristics

\begin{tabular}{|c|c|c|}
\hline & Survivor $(n=32)$ & Spouse $(n=32)$ \\
\hline Sex ( 96 female) & 41 & 60 \\
\hline Race ( $\%$ white or Caucasian) & 81 & 94 \\
\hline Occupational status (\% working for pay) & 16 & 31 \\
\hline Mean age & $62.06(13.38)$ & $60.69(14.20)$ \\
\hline Mean years of education & $14.34(2.59)$ & $14.50(2.42)$ \\
\hline Mean rating of PHQ-9 depression symptomatology (possible nange $=$ Sur. $0-27 /$ Sps. 0-27) & $7.34(5.36)$ & $5.78(6.26)$ \\
\hline \multicolumn{3}{|l|}{ Mean rating of survivor fumctioning: } \\
\hline $\begin{array}{l}\text { physical (possible range: Sunvivor }=0-100 \text {, Spouse }=0-100 \text { ) } \\
\text { cognitive (possible range }=\text { Sur. } 0-100 / \text { Sps. 0-100) }\end{array}$ & $\begin{array}{l}16.00(15.68) \\
14.55(15.57)\end{array}$ & $\begin{array}{l}17.25(18.66) \\
19.28(16.75)^{6}\end{array}$ \\
\hline mobility (possible nange $=S i r .0-100 / S p s .0-100)$ & $17.15(16.91)$ & $21.59(21.77)^{4}$ \\
\hline \multicolumn{3}{|l|}{ Mean rating of Relationship Quality: } \\
\hline summary score (possible range $=S w, 0-151 / S p s .0-151$ ) & $117.89(15.12)$ & $122.09(15.45)$ \\
\hline dyadic satisfaction (possible range $=S \mathrm{su} \cdot 0.50 / \mathrm{Spc} .0-50$ ) & $39.17(5.38)$ & $41.02(4.62)^{\circ}$ \\
\hline dyadic cohesion (porsible nange $=S w r .0-24 / S p s .0-24$ ) & $17.84(2.79)$ & $18.12(2.56)$ \\
\hline dyadic consensus (possible ravge $=S u r .0-65 /$ Sps. 0.65 ) & $52.11(7.47)$ & $53.24(8.16)$ \\
\hline affectional expression (possible range $=S i a r .0-12 /$ Spc. $0-12$ ) & $8.75(2.44)$ & $9.70(2.08)^{* *}$ \\
\hline \multicolumn{3}{|l|}{ Mean rating of illiness appraisal: } \\
\hline ambiguity (possible range $=$ Sur. $10-50 /$ Sps. $10-50$ ) & $25.36(6.75)$ & $25.75(7.58)$ \\
\hline complexity (possible range $=\mathrm{Sur} \cdot 5-25 /$ Sps.5-25) & $11.12(2.20)$ & $10.98(2.46)$ \\
\hline inconsistency (possible nange $=S u r .7-35 / S p s .7-35$ ) & $16.03(4.39)$ & $15.71(4.83)$ \\
\hline unpredictability (possible range = Sur. 5-25/ Sps. 5-25) & $15.96(3.50)$ & $17.62(3.34)^{6 * t}$ \\
\hline \multicolumn{3}{|l|}{ Mean rating of coping strategies: } \\
\hline active engagement (porsible range $=$ Siv. 5-25/ Sps.5-25) & $18.57(3.36)$ & $17.34(4.41)$ \\
\hline protective buffering (possible range $=$ Sur. $8-40 /$ Sps.6-30) & $18.90(4.29)$ & $15.18(4.49)^{* *}$ \\
\hline \multicolumn{3}{|l|}{ Mean rating of role fulfillment: } \\
\hline Misumderstandings (possible range $=$ Sur. $6-30 /$ Sps.3-15) & $14.12(5.93)$ & $7.65(3.67)^{* \star *}$ \\
\hline umrealistic expectations (possible range $=$ Sur. 10-50/ Sps.9-45) & $22.40(8.70)$ & $20.09(6.85)$ \\
\hline \multicolumn{3}{|l|}{ Mean rating of biographical disnuption to: } \\
\hline Self (possible nange $=$ Sur.1-5/Sps.1-5) & 3.53 (1.16) & $3.75(1.32)$ \\
\hline Spouse (possible range $=$ Sur. $1-5 /$ Sps. $1-5$ ) & $3.58(1.00)$ & $4.25(1.13)^{* \infty}$ \\
\hline Couple (possible range = Sur.1-5/Sps.1-5) & $3.13(1.12)$ & $3.56(1.21)^{\star}$ \\
\hline 3-item summary score (possible range = Sur. 3-15/ Sps.3-15) & $10.23(2.81)$ & $11.56(3.32)^{* t}$ \\
\hline
\end{tabular}

Note: Paired-samples $\mathrm{t}$-tests were used to compare survivor and spouse mean scores. ${ }^{*} \mathrm{p}<.10 ;{ }^{* *} \mathrm{p}<.05$.

and spouses were not currently employed and the majority of survivors and spouses indicated "white" as the group that best represented their race. However, five mixed-race 
couples (i.e., Black/White, Asian/White, American Indian/White) participated. Survivors and spouses were roughly equivalent in terms of age (survivor mean age $=62.06$ years; spouse mean age $=60.69$ years) and were relatively well educated (survivor mean education $=14.34$ years; spouse mean education $=14.50$ years $)$.

Figure 2

Levels of Depressive Symptoms among Survivors and Spouses

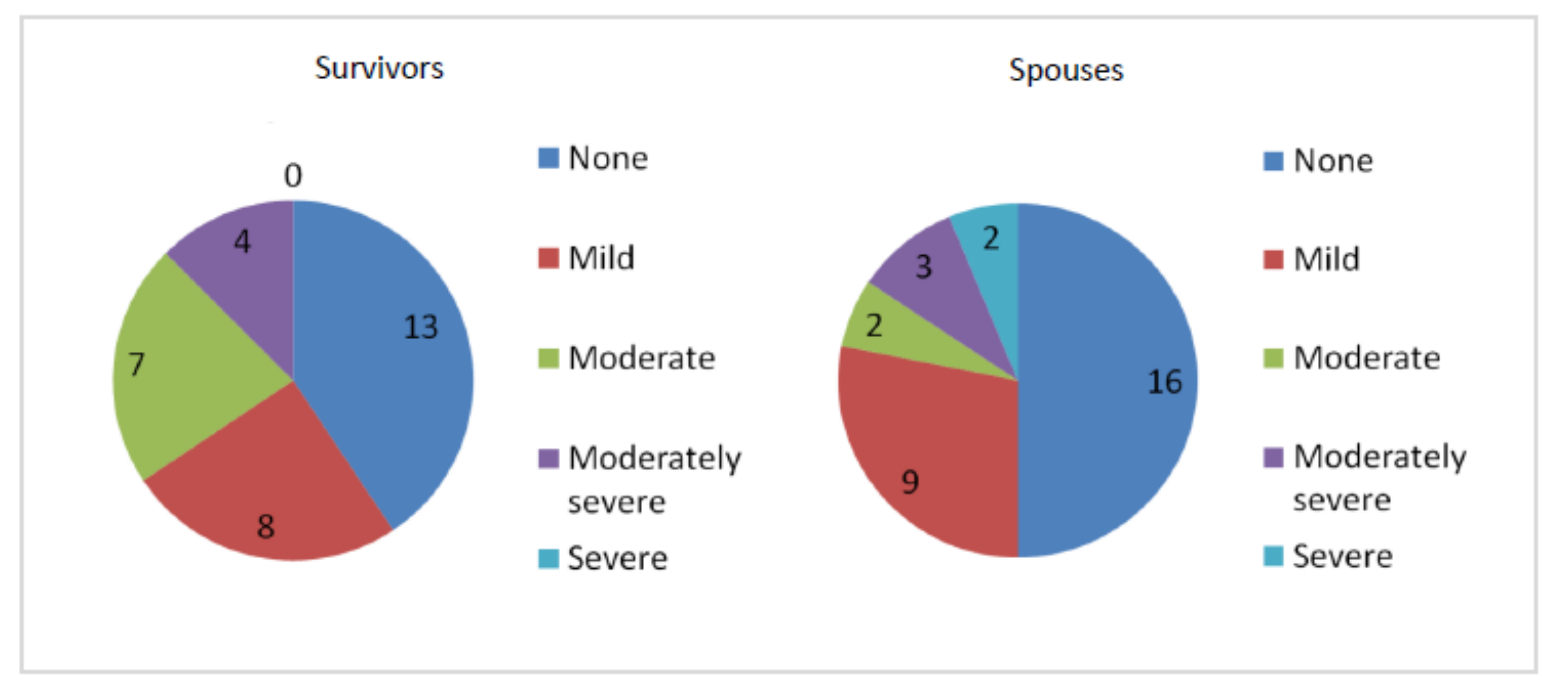

Seventeen survivors indicated that their left side had been most affected by the stroke, eight indicated that their right side had been most affected, and four indicated bilateral effects. By comparison, 28 survivors indicated their right as their dominant hand. No statistically significant differences were found between survivor and spouse reports of length of the relationship or time since stroke. Couples (i.e., averaged survivor/spouse report) reported the mean length of their relationship as approximately 26.5 years $($ median $=25.8$ years $)$ and the mean time since stroke as approximately 11.8 months (median $=5.3$ months). 
Survivors and spouses were similar with respect to many of the study constructs. In terms of depression, survivors exhibited slightly greater symptomatology, as measured by the PHQ-9, with a mean depression severity score of 7.35 (range $=0-19$ ). According to the cut points described by Kroenke, Spitzer, \& Williams (2001; 5 to $9=$ mild depression, 10-14 = moderate depression, 15-19 = moderately severe depression, 20+ = severe depression), 13 survivors were not experiencing measurable depression, eight survivors met criteria for mild depression, seven for moderate, and four for moderately severe. By comparison, spouses’ mean depression severity score was 5.78 (range $=0$ to 22), and 16 had no measurable depression, nine met criteria for mild depression, two for moderate, three for moderately severe, and two for severe depression (see Figure 2). Survivors and spouses were similar in their perceptions of survivor physical, cognitive, and mobility functioning, reporting an average difficulty score of approximately 17 on a scale from 0 to 100, although spouses consistently rated survivor cognitive $(\mathrm{t}=-1.98, \mathrm{df}=31, \mathrm{p}=.05)$ and mobility functioning $(\mathrm{t}=-1.72, \mathrm{df}=31, \mathrm{p}=.09)$ as significantly worse than survivors did themselves. Spouses generally rated the quality of the couples' relationship as better than did survivors, with statistically significant differences in partners' ratings of dyadic satisfaction $(t=-1.80, \mathrm{df}=31, \mathrm{p}=.08)$ and affectional expression $(\mathrm{t}=-2.47 \mathrm{df}=31, \mathrm{p}=.01)$. Partners had similar ratings on measures of illness appraisal such as ambiguity, complexity, and inconsistency, although a statistically significant difference was observed between partners on perceptions of illness unpredictability $(\mathrm{t}=-2.06, \mathrm{df}=31, \mathrm{p}=.04)$, with spouses rating the course of illness and rehab as more unpredictable than did survivors. 
Partners had comparable perspectives in terms of active engagement coping, although significant differences were observed between partner's ratings of the extent to which one partner practiced protective buffering toward the other $(\mathrm{t}=3.72, \mathrm{df}=31, \mathrm{p}=$ .001), as well as the extent to which one partner had "perceived misunderstandings" about the other's post-stroke capacities $(\mathrm{t}=5.94, \mathrm{df}=31, \mathrm{p}<.001)$. There was also a significant difference in partners' ratings of the extent to which the stroke was biographically disruptive to their partner $(\mathrm{t}=-2.87, \mathrm{df}=31, \mathrm{p}=.007)$ and to the couple $(\mathrm{t}$ $=-1.84, \mathrm{df}=31, \mathrm{p}=.075)$, with spouses consistently rating each higher.

While the majority of scales and subscales demonstrated acceptable reliability in this relatively small sample ( $\mathrm{N}=32$ ), it should be noted that a number of survivor-rated scales and spouse-rated scales demonstrated poor reliability (i.e., $\alpha<.65$ ). For survivors these scales were: Illness Complexity and Active Engagement and Protective Buffering Coping. In the case of the Coping scales, reliability may have been poor due to the complexity of the items (i.e., asking a survivor respondent to reflect on his or her spouse's actions with respect to the survivor's feelings - “My spouse can’t endure me being concerned and acts as if s/he doesn't notice my worries.”) and the potential for cognitive impairment among survivors. For spouses, the poorly performing scales were Dyadic Cohesion and Affectional Expression and Illness Complexity and Inconsistency. Caution should therefore be exercised in the interpretation of findings based on these scales.

\section{Partners’ Covariance on Key Study Constructs}

Table 6 presents Pearson product-moment correlation coefficients $(r)$ between survivors and spouses on the 15 dyad-level constructs examined in this study. Rows 
represent survivor reports and columns represent spouse reports. Thus, the diagonal depicts covariation in partners' ratings with r-values equal to.29 but less than .35 being significant at $\mathrm{p}<.10, \mathrm{r}$-values equal to .35 but less than .43 being significant at $\mathrm{p}<.05$, and r-values equal to .43 and higher being significant at $\mathrm{p}<.01$. Intercorrelations between scales and subscales, as well as between partners' reports on different scales and subscales, are in the off-diagonal and, where relevant, will be reported later in the context of other covariates.

The strongest correlations between partners were on depressive symptomatology $(\mathrm{r}=.43, \mathrm{p}<.01)$, ratings of relationship quality including overall relationship quality $(\mathrm{r}=$ $.43, \mathrm{p}<.01)$, dyadic consensus $(\mathrm{r}=.43, \mathrm{p}<.01)$, and affectional expression $(\mathrm{r}=.55, \mathrm{p}<$ $.01)$, illness ambiguity $(\mathrm{r}=.51, \mathrm{p}<.01)$ and inconsistency $(\mathrm{r}=.47, \mathrm{p}<.01)$, and biographical disruption $(\mathrm{r}=.35, \mathrm{p}<.05)$. Partners' ratings of dyadic satisfaction were correlated at the non-significant trend-level $(\mathrm{r}=.33, \mathrm{p}<.10)$, although ratings of dyadic cohesion were not significantly correlated $(r=.20$, ns).

Table 6

Pearson Correlations between Key Study Constructs

\begin{tabular}{|c|c|c|c|c|c|c|c|c|c|c|c|c|c|c|c|}
\hline Self-reported spouse $(n=32)$ & 1 & 2 & 3 & 4 & 5 & 6 & 7 & 8 & 9 & 10 & 11 & 12 & 13 & 14 & 15 \\
\hline \multicolumn{16}{|l|}{ Self- reported sunvivor $(n=32)$} \\
\hline 1. Depression & .43 & & & & & & & & & & & & & & \\
\hline 2. RQ: summary score & -.33 & .43 & & & & & & & & & & & & & \\
\hline 3. RQ: dyadic satisfaction & -.22 & .26 & .33 & & & & & & & & & & & & \\
\hline 4. RQ: dyadic cohesion & -.17 & .23 & .18 & .20 & & & & & & & & & & & \\
\hline 5. RQ: dyadic consensus & -.33 & .45 & .41 & .25 & .43 & & & & & & & & & & \\
\hline 6. RQ: affectional expression & -.35 & .46 & .36 & .37 & .40 & .55 & & & & & & & & & \\
\hline 7. IA: ambiguity & .25 & -.21 & -.26 & -.12 & -.16 & -.19 & .51 & & & & & & & & \\
\hline 8. IA: complexity & .23 & .08 & .02 & .04 & .08 & .17 & .19 & -.08 & & & & & & & \\
\hline 9. IA: inconsistency & .39 & -.36 & -.29 & -.22 & -.35 & -.44 & .46 & .17 & .47 & & & & & & \\
\hline 10. IA: unpredictability & -.01 & -.03 & -.03 & .17 & -.08 & -.05 & .35 & .41 & .34 & .12 & & & & & \\
\hline 11. CS: active engagement & .07 & -.21 & -.22 & -.27 & -.13 & -.21 & .06 & .02 & .08 & .06 & -.09 & & & & \\
\hline 12. CS: protective buffering & .24 & -.06 & -.06 & -.02 & .06 & -.05 & .50 & .32 & .38 & .05 & -.11 & .18 & & & \\
\hline 13. RF: misunderstandings & .29 & -.25 & -.29 & -.09 & -.27 & -.13 & .46 & .43 & .35 & -.01 & -.39 & .23 & .25 & & \\
\hline 14. RF: unreal expectations & .20 & -.22 & -.20 & -.02 & -.24 & -.21 & .47 & .50 & .36 & .12 & -.24 & .23 & .22 & .28 & \\
\hline 15. Bio. Dis. (to couple) & 40 & -.30 & -.19 & -34 & -30 & -.23 & .31 & .20 & .26 & 21 & -.24 & .11 & .23 & .23 & .35 \\
\hline
\end{tabular}


Although significant associations were found on the aspects of illness appraisal just reported, partners ratings of illness complexity $(r=-.08$, ns) and unpredictability $(r=$ .12, ns) were not significant. No significant associations were found between partners’ reports about coping strategies and, as will be discussed later, this may suggest that survivors and spouses approach coping in somewhat different ways. Likewise, no significant associations were found between partners’ reports of post-stroke role fulfillment, suggesting lack of agreement about the extent to which each partner may be understanding the other partner's illness experience or meeting the other partner's expectations. Partners’ perceptions about the extent to which the stroke was biographically disruptive to themselves as a couple were moderately correlated $(r=.35$, p $<.05)$.

\section{Multivariate Regressions}

Survivor depressive symptomatology. Hierarchical OLS regression was used to identify which dyad-level factors, observed to covary between survivors and spouses, were significantly associated with depression in individual survivors and spouses after partialling out the effects of demographic and individual-level predictors. Table 7 presents the results of survivor depressive symptomatology regressed on progressive blocks of control and explanatory variables ending with survivor-reported relationship quality. P-values of less than .10 are noted due to the study’s small sample size. In step one, survivor age, gender, and income (i.e., demographic variables that had significant association with depression at the bivariate level) were entered into the regression 
Table 7

Hierarchical Regression of Survivor Depressive Symptoms on Survivor-reported Relationship Quality and Covariates $(\mathrm{N}=32)$

\begin{tabular}{|c|c|c|c|c|c|c|c|c|}
\hline \multirow{2}{*}{ Block and variables } & \multicolumn{2}{|c|}{1} & \multicolumn{2}{|l|}{2} & \multicolumn{2}{|c|}{3} & \multicolumn{2}{|c|}{4} \\
\hline & $\beta$ & Sig & $\beta$ & Sig & $\beta$ & Sig & $\beta$ & Sig \\
\hline \multicolumn{9}{|l|}{ Block 1: Control } \\
\hline Age & -.470 & .004 & -.400 & .022 & -.385 & .019 & -.251 & ns \\
\hline Gender & -.083 & ns & -.031 & ns & -.055 & ns & -.118 & ns \\
\hline Income & -.556 & .001 & -.573 & .002 & -.368 & .042 & -.300 & .084 \\
\hline \multicolumn{9}{|l|}{ Block 2: Pre-morbid factors } \\
\hline Pre-stroke depression & & & .178 & ns & .077 & ns & .126 & ns \\
\hline Pre-stroke relationship quality & & & .086 & ns & .017 & ns & -.090 & ns \\
\hline \multicolumn{9}{|l|}{ Block 3: Individual-level factors } \\
\hline Survivor physical functioning & & & & & .236 & ns & .196 & ns \\
\hline Survivor cognitive functioning & & & & & .277 & ns & .268 & ns \\
\hline \multicolumn{9}{|l|}{ Block 4: Dyad-level factors } \\
\hline Relationship quality (summary score) & & & & & & & -.323 & .077 \\
\hline F/F Sig. & $6.75 / .00$ & & $4.40 / .006$ & & $4.62 / .00$ & & $4.93 / .00$ & \\
\hline$\Delta R^{2}$ & .438 & & .040 & & .117 & & .057 & \\
\hline Adjusted $R^{2}$ & .373 & & .370 & & .467 & & .520 & \\
\hline
\end{tabular}

equation. Together, these demographic variables accounted for approximately $37 \%$ of the variance in survivors' depressive symptomatology (adjusted $\mathrm{R}^{2}=.37$; F Sig = .002), with younger survivors $(\beta=-.47, p=.004)$ and those with lower household income $(\beta=$ $.556, \mathrm{p}=.001$ ) being significantly more depressed. Premorbid factors (i.e., survivors' pre-stroke depression, survivor-reported pre-stroke relationship quality) were entered in step two, although neither was significant. In step three, survivor-reported physical and cognitive functioning were entered and, together, accounted for an additional $12 \%$ of variance explained $\left(\Delta \mathrm{R}^{2}=.117\right.$; adjusted $\mathrm{R}^{2}=.467 ; \mathrm{F}$ Sig = .003), although, individually, neither factor reached statistical significance (physical functioning $\beta=.236$, ns; cognitive functioning $\beta=.277$, ns).

In the final step, survivor-reported relationship quality was entered into the equation. This variable accounted for an additional $6 \%$ of variance explained $\left(\Delta \mathrm{R}^{2}=\right.$ 
.057 ; adjusted $\mathrm{R}^{2}=.520$; F Sig $\left.=.002\right)$, with higher relationship quality being associated with lower depressive symptomatology $(\beta=-.323, \mathrm{p}=.077)$ at the trend level. Of the other variables remaining in this final model, only survivor-reported income remained marginally significant $(\beta=-.300, \mathrm{p}=.084)$, with lower income being associated with greater depression.

Table 8

Hierarchical Regression of Survivor Depressive Symptoms on Survivor-reported Illness Ambiguity and Covariates $(\mathrm{N}=32)$

\begin{tabular}{|c|c|c|c|c|c|c|c|c|}
\hline \multirow{2}{*}{ Block and variables } & Step & 1 & \multicolumn{2}{|c|}{2} & \multicolumn{2}{|c|}{3} & \multicolumn{2}{|c|}{4} \\
\hline & $\beta$ & Sig & $\beta$ & Sig & $\beta$ & Sig & $\beta$ & Sig \\
\hline \multicolumn{9}{|l|}{ Block 1: Control } \\
\hline Age & -.465 & .004 & -.422 & .009 & -.383 & .010 & -.312 & .013 \\
\hline Income & -.576 & .001 & -.600 & .000 & -.387 & .021 & -.277 & ns \\
\hline \multicolumn{9}{|l|}{ Block 2: Pre-morbid factors } \\
\hline Pre-stroke depression & & & .206 & ns & .096 & ns & .030 & ns \\
\hline \multicolumn{9}{|l|}{ Block 3: Individual-level factors } \\
\hline Survivor physical functioning & & & & & .243 & ns & .008 & ns \\
\hline Survivor cognitive functioning & & & & & .269 & .084 & .178 & ns \\
\hline \multicolumn{9}{|l|}{ Block 4: Dyad-level factors } \\
\hline Gender & & & & & & & -.094 & ns \\
\hline Illness ambiguity & & & & & & & .971 & .000 \\
\hline Gender $\mathrm{X}$ illness ambiguity & & & & & & & -.642 & .005 \\
\hline F/F Sig. & \multicolumn{2}{|c|}{$10.25 / .000$} & \multicolumn{2}{|c|}{$7.73 / .001$} & \multicolumn{2}{|c|}{$6.98 / .000$} & \multicolumn{2}{|c|}{$9.26 / .000$} \\
\hline$\Delta R^{2}$ & \multicolumn{2}{|c|}{.432} & \multicolumn{2}{|c|}{.040} & \multicolumn{2}{|l|}{.121} & \multicolumn{2}{|c|}{.187} \\
\hline Adjusted $R^{2}$ & \multicolumn{2}{|l|}{.390} & \multicolumn{2}{|l|}{.518} & \multicolumn{2}{|l|}{.508} & \multicolumn{2}{|l|}{.695} \\
\hline
\end{tabular}

Table 8 presents the results of survivor depressive symptomatology regressed on progressive blocks of control and explanatory variables ending with survivor gender, survivor-reported illness ambiguity, and a product term of the two. Results from steps one through three are similar to those described above, although pre-morbid relationship quality was not included as a control in this model. The final block of variables accounted for an additional $19 \%$ of variance explained $\left(\Delta \mathrm{R}^{2}=.187\right.$; adjusted $\mathrm{R}^{2}=.695$; $\mathrm{F}$ Sig $=$ .000), with greater ambiguity about the future with respect to the stroke being strongly 
associated with greater depression $(\beta=.971, \mathrm{p}<.001)$. Although the main effect of survivor gender was not significant, the interaction of survivor gender by illness ambiguity was significantly associated with depression $(\beta=-.642, \mathrm{p}=.005)$, suggesting a different pattern to the relationship between illness ambiguity and depression for men versus women. A simple slopes test was used to examine this interaction and results showed that the association between illness ambiguity and depression was more pronounced for male survivors than for female survivors (see Figure 3). Survivor age also remained significant in this final model $(\beta=-.312, \mathrm{p}=.013)$, with younger survivors experiencing more depression.

\section{Figure 3}

Simple Slopes Test of Interaction between Survivor Gender and Illness Ambiguity

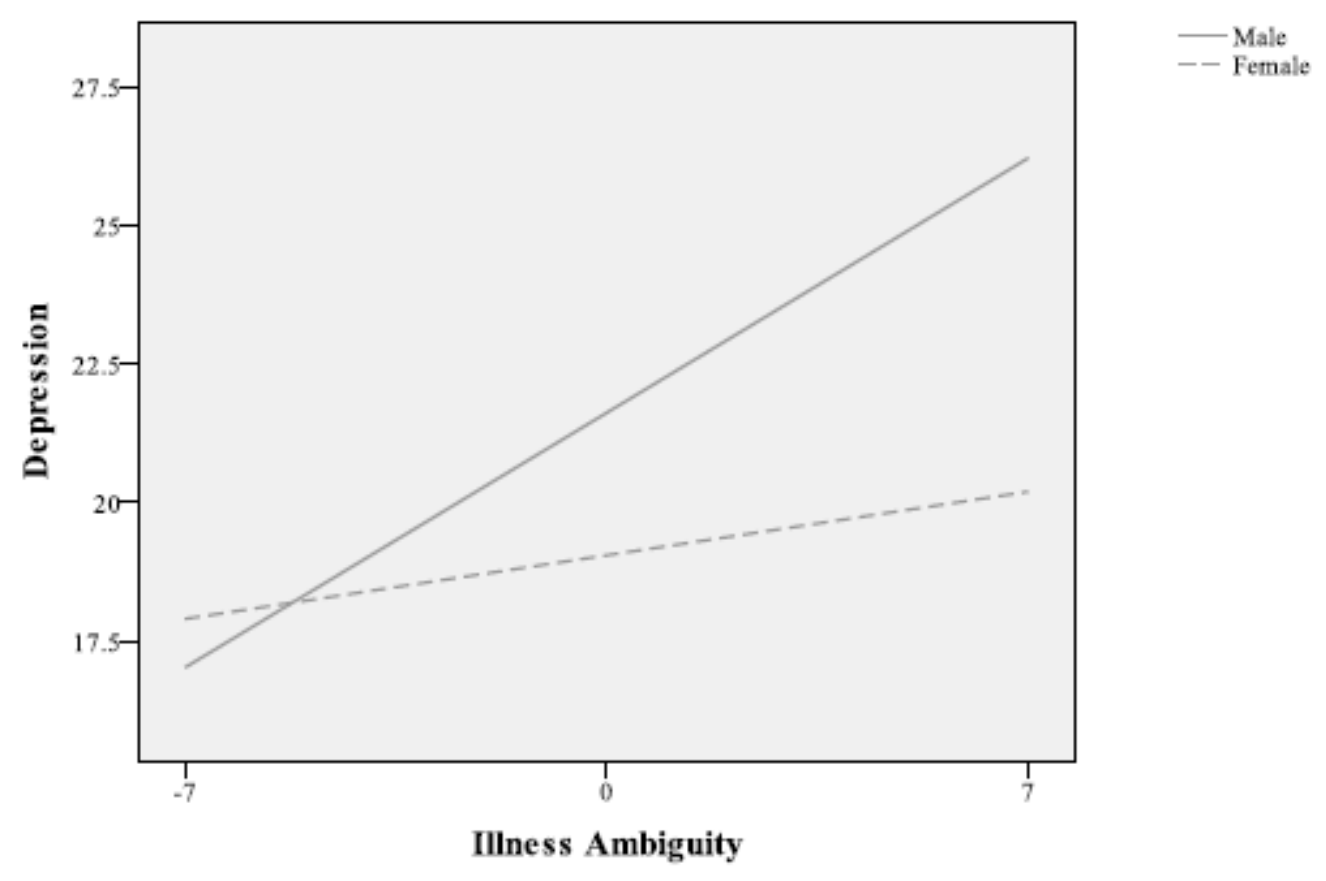


Although not depicted in table format, a marginally significant effect from survivor-reported perceived misunderstandings (i.e., the extent to which survivors feel that spouses misunderstand them with respect to their post-stroke physical and emotional capacity) to survivor depression $(\beta=.339, \mathrm{p}=.079)$ was also observed.

Spouse depressive symptomatology. An examination of the influence of dyadlevel explanatory variables such as relationship quality on spouse depression proceeded in the same way as the analysis of survivor depression (see Table 9). Spouse demographic characteristics that had a significant association with depression at the bivariate level (i.e., age, gender, years of education) were entered in step one. Of these, gender $(\beta=.395, \mathrm{p}=.019)$ and education $(\beta=-.310, \mathrm{p}=.059)$ were significant, with females and those with fewer years of education being more depressed (adjusted $\mathrm{R}^{2}=.23$; F Sig = .016). Pre-morbid factors (i.e., spouses’ pre-stroke depression, spouse-reported pre-stroke relationship quality) were entered in step two and, like the survivor model, these variables did not have a significant impact on depression. Spouse-reported survivor physical and cognitive functioning, entered in step three, also had no significant impact of spouse depression although, controlling for these factors, pre-stroke relationship quality became marginally significant $(\beta=-.378, \mathrm{p}=.063)$. In step four, spouse-reported relationship quality was entered and accounted for an additional $15 \%$ variance ( $\beta=-.465$, $\mathrm{p}=.009 ; \Delta \mathrm{R}^{2}=.152$, adjusted $\mathrm{R}^{2}=.422, \mathrm{~F}$ Sig $=.005$ ), with higher relationship quality predictive of lower depression. Pre-stroke relationship quality $(\beta=-.317, \mathrm{p}=.077)$ and survivor physical functioning $(\beta=.278, \mathrm{p}=.090)$ also remained marginally significant in this final model, with lower pre-stroke relationship quality and higher physical impairment being associated with greater depression. In a model with identical 
covariates not depicted here in table format, greater spouse illness ambiguity also had a

significant association with greater spouse depression $(\beta=.422, \mathrm{p}=.041)$.

Table 9

Hierarchical Regression of Spouse Depressive Symptoms on Spouse-reported Relationship Quality and Covariates $(\mathrm{N}=32)$

\begin{tabular}{|c|c|c|c|c|c|c|c|c|}
\hline \multirow{2}{*}{ Block and variables } & \multicolumn{2}{|c|}{1} & \multicolumn{2}{|c|}{2} & \multicolumn{2}{|c|}{3} & \multicolumn{2}{|c|}{4} \\
\hline & $\beta$ & Sig & $\beta$ & Sig & $\beta$ & Sig & $\beta$ & Sig \\
\hline \multicolumn{9}{|l|}{ Block 1: Control } \\
\hline Gender & .395 & .019 & .346 & .040 & .276 & ns & .209 & ns \\
\hline Education & -.310 & .059 & -.274 & ns & -.215 & ns & -.128 & ns \\
\hline \multicolumn{9}{|l|}{ Block 2: Pre-morbid factors } \\
\hline Pre-stroke relationship quality & & & -.286 & ns & -.378 & .063 & -.317 & .077 \\
\hline \multicolumn{9}{|l|}{ Block 3: Individual-level factors } \\
\hline Survivor physical functioning & & & & & .186 & ns & .278 & .090 \\
\hline Survivor cognitive functioning & & & & & .122 & ns & .066 & ns \\
\hline \multicolumn{9}{|l|}{ Block 4: Dyad-level factors } \\
\hline$\Delta R^{2}$ & .305 & & .066 & & .048 & & .152 & \\
\hline Adjusted $R^{2}$ & .230 & & .250 & & .250 & & .422 & \\
\hline
\end{tabular}

spouse depression at the bivariate level and, thus, were removed from the model for parsimony.

Table 10

Hierarchical Regression of Spouse Depressive Symptoms on Spouse-reported Active Engagement, Protective Buffering, and Covariates (N $=32$ )

\begin{tabular}{|c|c|c|c|c|c|c|c|c|}
\hline \multirow{2}{*}{ Block and variables } & \multicolumn{2}{|c|}{1} & \multicolumn{2}{|c|}{2} & \multicolumn{2}{|c|}{3} & \multicolumn{2}{|c|}{4} \\
\hline & $\beta$ & Sig & $\beta$ & Sig & $\beta$ & Sig & $\beta$ & Sig \\
\hline \multicolumn{9}{|l|}{ Block 1: Control } \\
\hline Age & -.189 & ns & -.188 & ns & -.172 & ns & .020 & ns \\
\hline Gender & .395 & .019 & .383 & .026 & .356 & .049 & -.051 & ns \\
\hline Education & -.310 & .059 & -.280 & ns & -.240 & ns & .026 & ns \\
\hline \multicolumn{9}{|l|}{ Block 2: Pre-morbid factors } \\
\hline Pre-stroke depression & & & .083 & ns & .102 & ns & .158 & ns \\
\hline \multicolumn{9}{|l|}{ Block 3: Individual-level factors } \\
\hline Survivor physical functioning & & & & & .124 & ns & .310 & .058 \\
\hline Survivor cognitive functioning & & & & & .033 & ns & -.224 & ns \\
\hline \multicolumn{9}{|l|}{ Block 4: Dyad-level factors } \\
\hline Active engagement & & & & & & & -.400 & .017 \\
\hline Protective buffering & & & & & & & .556 & .011 \\
\hline$F^{\prime} / F_{\text {Sig. }}$ & \multicolumn{2}{|c|}{$4.09 / .016$} & \multicolumn{2}{|c|}{$3.04 / .034$} & \multicolumn{2}{|c|}{$2.02 / .100$} & \multicolumn{2}{|c|}{$4.18 / .003$} \\
\hline$\Delta R^{2}$ & \multicolumn{2}{|l|}{.305} & \multicolumn{2}{|l|}{.006} & \multicolumn{2}{|l|}{.016} & \multicolumn{2}{|l|}{.266} \\
\hline Adjusted $R^{2}$ & \multicolumn{2}{|l|}{.230} & \multicolumn{2}{|l|}{.208} & \multicolumn{2}{|l|}{.165} & \multicolumn{2}{|l|}{.451} \\
\hline
\end{tabular}

Note: Spouse employment status and income and spouse-reported relationship duration and time since stroke were not significantly correlated with spouse depression at the bivariate level and, thus, were removed from the model for parsimony. 
The role of the dyadic coping variables active engagement and protective buffering were also examined with respect to survivor and spouse depression, although significant effects were only observed among spouses. Table 10 presents results of spouse depression regressed on controls and spouse-reported active engagement (i.e., the extent to which spouses report that survivors engage them) and protective buffering (i.e., the extent to which spouses report that survivors buffer them). The first three blocks are similar to what has been described above. In the final block, which accounts for approximately $27 \%$ additional variance $\left(\Delta \mathrm{R}^{2}=.266\right.$, adjusted $\mathrm{R}^{2}=.451$, F Sig $\left.=.003\right)$, lower levels of active engagement $(\beta=-.400, p=.017)$ and higher levels of protective buffering ( $\beta=.556, \mathrm{p}=.011$ ) are associated with greater depression. For illustration purposes, the bivariate relationships between these three variables are depicted in Figure 4.

Figure 4

Bivariate Skatterplots between Spouse Depression, Active Engagement, and Protective Buffering
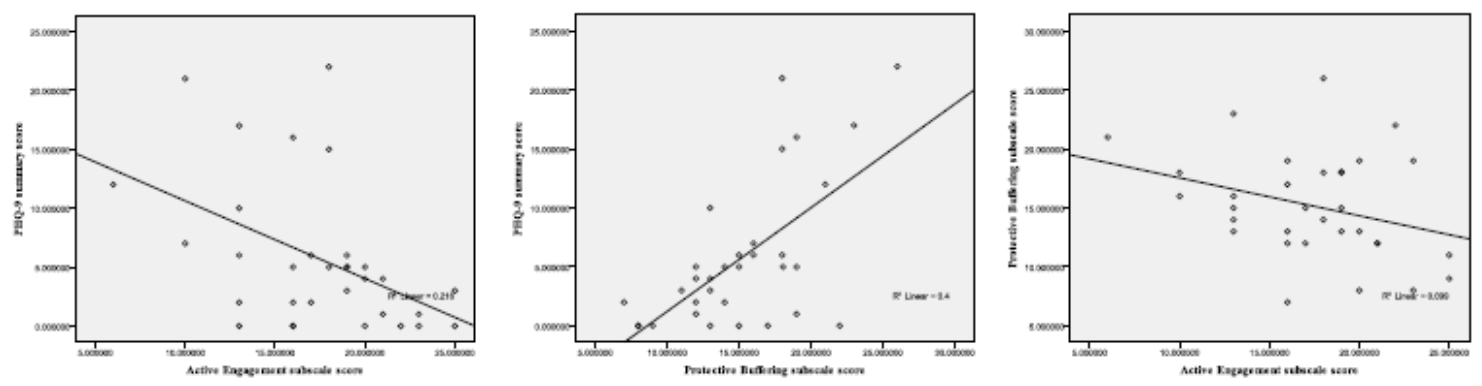

Because of the association between partners' depression established in this and other studies, survivor depression was included as an additional covariate in each of the spouse outcome models just described. Controlling for survivor depression ( $\beta=.156$, ns), 
spouse-reported relationship quality $(\beta=-.429, \mathrm{p}=.018)$ remained a significant predictor of spouse depression. Similarly, controlling for survivor depression $(\beta=.154, \mathrm{p}=\mathrm{ns})$, spouse-reported active engagement $(\beta=-.366, \mathrm{p}=.033)$ and protective buffering $(\beta=$ $.565, \mathrm{p}=.010$ ) remained significant predictors of spouse depression.

\section{Biographical Disruption as a Moderator}

Analyses were conducted to examine the potential moderating effects of biographical disruption on survivors', spouses', and couples' experiences with stroke. Unfortunately, the small sample and consequent low statistical power precluded examination of disruption as measured by the binary indicators included in this study (e.g., At time of stroke...primary household income derived from paid work done by stroke survivor; dependent children cared for in the home; previous experience with serious health problems). An analysis of product terms computed from continuous measures of biographical disruption to oneself, one's spouse, and the couple with dyadlevel predictor variables also yielded null findings. However, there were noteworthy main effects in both survivor and spouse models related to the differential impacts of perceived disruptions to each partner or the couple on individual respondents' depression. For example, controlling for survivor demographic factors, premorbid depression, and functioning, survivors' perception of the extent to which the stroke was disruptive to the couple was not significant. However, controlling for these same factors and the extent to which survivors perceived the stroke as disruptive to themselves and their spouse individually, only perceived disruption to oneself was significantly associated with survivor depression $(F=6.16 ; \mathrm{F}$ Sig $=.000 ; \beta=.407, \mathrm{p}=.028)$. 
The pattern of findings when examining spouse depression was somewhat different. Neither spouse-reported perception of disruption to themselves, their partner, nor the couple were significant predictors of spouse depression. However, survivorreported disruption to the couple was significantly associated with spouse depression $(\mathrm{F}=$ 2.64; F Sig $=.036 ; \beta=.420 ; p=.042$ ), suggesting that, on some level, survivors may be in tune with the effects of the stroke on their relationships and the consequences of these effects.

\section{Narrative Content Analysis}

Additional aspects of biographical disruption. In total, 54 interview transcripts were examined. Content analysis revealed four key themes related to features of biographical disruption from stroke - instrumental challenges, psychological challenges, relationship challenges, and unexpected changes in couple’s anticipated life course - and numerous features of disruption from stroke not included in previous research or the structured interview. Additionally, two other themes emerged related to individuals and couples mobilizing resources in the face of adversity and, for a variety of reasons, not experiencing the stroke as substantially disruptive at all.

Instrumental challenges. Participants commented about post-stroke instrumental challenges stemming from lack of accessible environments, lack of resources to take care of children and other dependent family members, being overburdened with medical appointments, inability to work for pay and consequent financial strain, inability to drive a car, cumbersome insurance and benefits plans, cancelled travel plans, inability to pursue former hobbies (e.g., gardening, mechanical projects), and impaired functioning or fatigue. Of these, disruption to survivors', as well as caregiving spouses', ability to 
work for pay following stroke was, by far, the most frequently cited challenge with one couple commenting about having to sell their home as a result of strained finances and several others describing how the stroke had "been a huge hit financially.”

Psychological challenges. In addition to the strain brought about by instrumental challenges, a number of psychological challenges experienced by survivors and spouses surfaced in the interviews. For survivors, these included disturbances in one's ability to deal with stress and emotions, embarrassment about impaired functioning, loss of work and/or social status, and feelings of guilt for the impact the stroke may have had on children and other family members. For both survivors and spouses, psychological challenges stemmed primarily from uncertainty and fear about the future with respect to the survivor's health, feelings of being "lost" or isolated from the broader world and from one another, bodily changes (e.g., weight gain, feeling “deformed”), inability to think or plan long-term, and perceived loss of control and/or dependency. Sentiments including "pretty much everyday not knowing what is going to happen" and "not knowing which way is up” were common and several survivors and spouses commented about their mutual loss of independence following stroke due to physical or cognitive impairments or caregiving responsibilities, respectively. In a particularly moving account of how the stroke had adversely affected her ability to deal with stress and emotion, one survivor related how "since [she] had the stroke [she] cries almost every day."

Relationship challenges. Disruptions to couples’ relationships following stroke stemmed from the instrumental and individual psychological challenges described above, as well as from dyadic factors such as shifting pre- to post-stroke roles (e.g., survivors and spouses adopting “patient” and “caregiver” roles, survivors who were household 
decision-makers prior to stroke now having to defer to their spouse's decisions), each partners' feelings of lack of independence from one another, compromised intimacy and feelings of loneliness due to physical or emotional absence of the survivor, partners’ inability to participate in shared recreation activities, conflicts over household division of labor (e.g., spouses feeling overwhelmed by household and extra-household responsibilities), amplified existing relationship problems, spousal resentment that the survivor had not cared for him or herself better prior to stroke, and in newer relationships, pressure from family and friends to separate due to the survivor's new care needs. Several spouses, in longer-term relationships, also commented about feeling the need to protect the survivor's ego following stroke by minimizing the survivor's deficits or downplaying their own abilities.

Happily, an additional theme that emerged related to the impact of stroke on couples’ relationships involved the positive aspects of the experience. Many couples commented about how the experience had “brought [them] closer together”. One participant, whose wife survived a severe stroke, described how he and his wife "sit there on the couch and hold hands and think how lucky [they] are.” Another reflected that, "for all the tragedy, we are better for it."

Changes in anticipated life course. Many of the changes in anticipated life course mentioned by participants involved forced transitions into early retirement or alternative living situations. For example one survivor had worked his entire adult life with the intention of retiring from the U.S. Postal Service with 100\% retirement benefits. Unfortunately, his stroke and its physical and cognitive after-effects forced him to retire early with a much smaller portion of his pension. Another survivor had built his career 
and personal identity on being a commercial airline pilot. His professional career was abruptly ended as a result of the stroke and, complicating matters further, he was reluctant to seek treatment for his subsequent depression based on a justifiable fear that the Federal Aviation Administration would suspend his pilot's license if they became aware that he was "mentally impaired". Several participants also commented on having to relocate to smaller, more manageable dwellings following stroke, or into facilities that offered some level of professional care for the survivor. Conversely, one couple commented on having to delay a planned transition into retirement as a result of the stroke: "We had just retired and the day we planned to start that future is when he had the stroke so everything kind of got put on hold... we hadn't even unpacked our house or anything yet.”

Many participants also made reference to profound global changes brought about by stroke such as how "everyday family life has been unbelievably changed” or how the stroke had "turned the world upside down," or "totally disrupted... life in every way imaginable”. One survivor remarked, “It destroyed who I am.” Finally, many of the changes in life course mentioned by participants had to do with the unexpectedness of the illness given the survivor's age or past health. One survivor commented about how she felt "very alone... being so young having a stroke.” Another reflected on how he had “never had medical issues, never had any problems... and now [he had] major ones.”

Mobilizing resources. Regardless of the severity of stroke of disruptive nature of the experience, most couples commented on the mobilization of tangible resources to aid in recovery (e.g., physical and speech therapy), personal emotional resources (e.g., optimism, reflecting on gains made since stroke, thankfulness that he stroke was not 
“worse”), and social support resources (e.g., supportive church networks, employers, friends and family). A recurrent theme was that of the stroke as a "blessing in disguise" that served as an “eye opener” about couples’ lifestyles with respect to their health. Other participants remarked about how the stroke prompted them to "reevaluate their values" or appreciate how "good life [could] be.”

Lack of disruption. Although fewer in number, a number of participants, both survivors and spouses, commented about how the stroke had been relatively undisruptive to their lives. Some participants attributed this to age (i.e., past experiences with illness, co-occurring conditions that, because of their own symptoms, reduced the impact of stroke-specific symptoms) or experiences with other loved ones with chronic illnesses that were equally or more severe than the stroke. Some participants, attributed this lack of disruption to having minimal residual effects from the stroke. Other couples seemed to weather the impact of the stroke more easily due to not having to renegotiate dyadic roles following stroke. For example, in couples for whom the spouse was the primary driver, the survivor's inability to drive a car post-stroke had less impact.

Stroke across the lifespan. AtlasTI's family manager function was used to filter and analyze coded responses in order to examine how the experience of stroke may have been different for couples in different developmental stages of life. Individual's and couple’s developmental stage was operationalized by age of the participant (i.e., early adulthood 17-44, middle adulthood 45-64, late adulthood 64-85, late late adulthood 85+; Levinson, 1977) and duration of the couple’s committed relationship (<5 years, $6-15$ years, 16 - 24 years, 25+ years; Anderson, Russell, \& Shume, 1983). In total, four participants for whom interview transcripts were available were between the ages of 17 
and 44, 29 were between the ages of 45 and 64, 19 were between the ages of 65 and 84, and three were over the age of 85 . Five couples had been in a committed relationship for 5 or fewer years, seven for 6 to 15 years, three for 16 to 24 years, and 14 for more than 25 years (see Figure 5).

\section{Figure 5}

\section{Duration of Couples' Relationships}

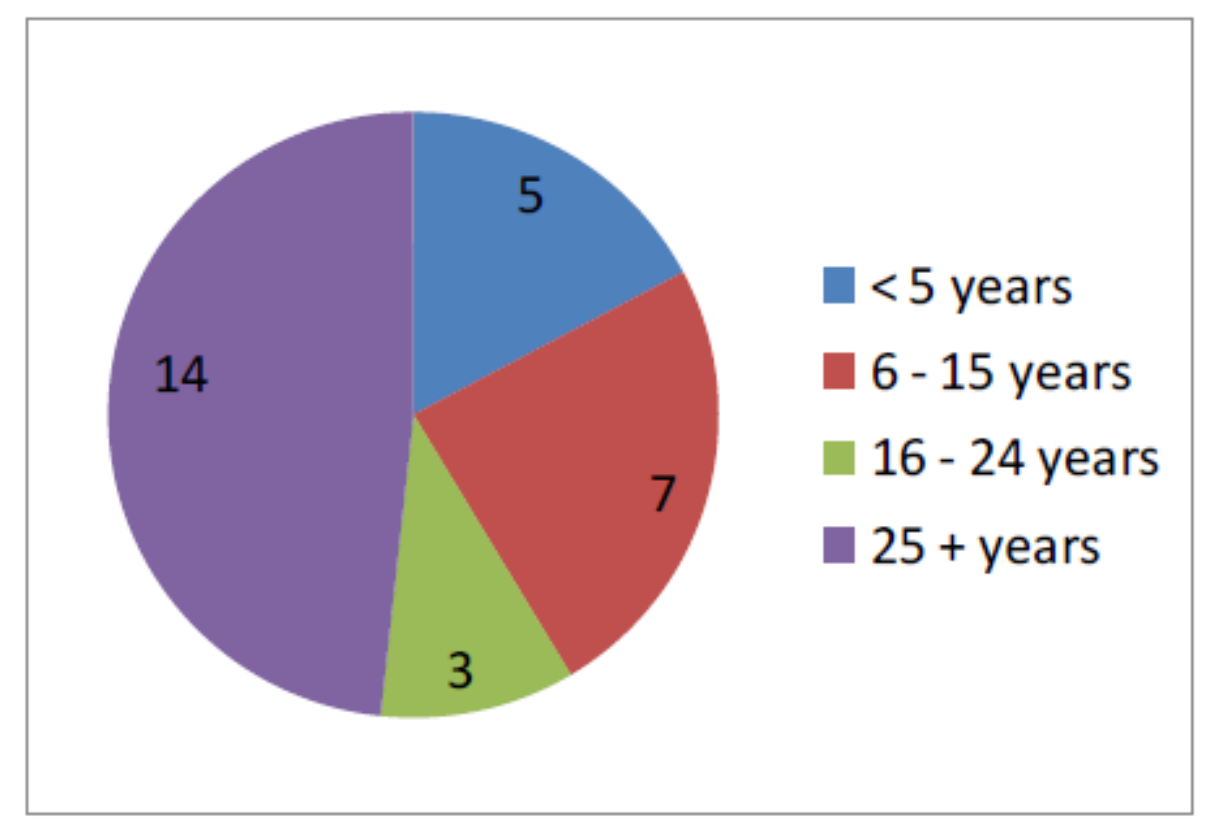

Although there were distinct differences in the narratives of participants across all age groups, contrary to the assumptions expressed earlier in this dissertation about the relationship of chronological age and biographical disruption, no age group stood out above the others as experiencing greater disruption from stroke. However, the role of chronological age became quite pronounced when observing participants at opposite ends of the age spectrum. For example, the youngest couple in this study (survivor aged 33, spouse aged 37) related a story in which the survivor had experienced her stroke one month before giving birth to their first child. Her spouse described how he "took care of 
everything at the house plus had to make sure [his] wife was doing good in rehab” and how the experience "changed [his] whole life having to do all of that at home and [being] worried about [his] wife's optimism and emotionally and physically and raising a baby all by [him]self, and helping [his] wife out who is disabled now and still going to work.” By contrast, the oldest couple in this study (survivor aged 93, spouse aged 85) recounted how the primary impact of the stroke had been an increase in the already burdensome number of doctor's appointments they had each week and how they “put [their] difficulties on age more than the stroke”.

Although comments related to instrumental and psychological disruptions and changes in couples’ anticipated life course were evenly distributed across age groups, older couples appeared generally more reflective about the meaning of the experience for their lives. For example, one spouse (aged 67) mused about how having a stroke “reminds you that plans for the future have to include the possibility that there won't be a future”. Another spouse (aged 84) reflected about how, given their ages and the health issues that he and his wife had previously experienced: "Death is not a specter anymore it is just a friend who is waiting. So when she had her stroke, we weren't frightened. Not at all.”

An examination of the relational impacts of stroke among couples at different stages of their committed relationship also showed more distinct differences between couples at each end of the spectrum. In newer relationships, existing problems appeared more exacerbated by stroke than in longer-term relationships and the commitment to dealing with the problem within the couple appeared less certain. For example, one survivor described how his spouse had "problems” before stroke: “The last time my wife 
and I had a fight... I finally said enough is enough and I walked and walked... three hours... and my mom came and I never came back.” By comparison, in longer-term relationships spouses tended to except the amplification of their partner's personality traits (e.g, being “a scatterbrain”) as pieces of their personality that they had come to appreciate and love.

In longer term relationships, the "absence" of the survivor, both physically and emotionally, also appeared to have a greater impact on spouses than in newer relationships: "I am used to having him around the house everyday...just counting on him for little things to do...just being able to talk to him and get feedback...just having someone to talk to has been really difficult because even though he is back living with me, it is not the same.” Roles also appeared to be more concretely defined between more long-term partners and, thus, less flexible following stroke. For example, in reference to his role as "decision-maker" in the family, one survivor commented, "I guess I am the one that holds everything together....you know between us and the kids and the company that I still run. She doesn't do much of any of that, I mean company wise and making money and things of that sort, she never has done that.”

An examination was also undertaken of how the experience of stroke differed in couples for whom the stroke was or was not biographically disruptive according to the presence of the individual indicators derived from past studies (i.e., working for pay versus retired, presence of dependent children versus no children or grown children, previous health issues versus first experience with chronic illness), as endorsed by either partner. Perhaps not surprisingly, couples for whom the stroke was biographically disruptive by these indicators described greater disruption to household finances, to 
children and the broader family system, and to the anticipated course of their lives, respectively. Results from the preceding quantitative and qualitative analyses are incorporated and expanded upon in the following discussion. 


\title{
CHAPTER V: DISCUSSION AND CONCLUSION
}

\section{Primary Findings}

\author{
Aim 1. This study has been among the first to demonstrate that \\ modifiable, dyad-level factors are relevant to survivors’ and spouses’ experiences \\ of depression following stroke, even after controlling for individual demographic \\ factors and physical and cognitive functioning of the survivor. Descriptively, \\ approximately 59\% of survivors and 50\% of spouses in this sample were \\ experiencing measurable depression (i.e., equal to or greater than the level of mild \\ depression) per the cut points described by Kroenke, Spitzer, \& Williams (2001). \\ This is at the upper range reported by meta-analyses on this subject (e.g., Hackett, \\ Yapa, Parag, \& Anderson, 2005; Han \& Haley, 1999), although these and other \\ authors acknowledge that sample-specific prevalence is highly subject to \\ influence from factors such as case selection, method of assessment, and \\ instrumentation.
}

In this study, depressive symptomatology among survivors still experiencing direct physical and cognitive effects from stroke could have been inflated by somatic items contained in the PHQ-9 (e.g., Feeling tired or having little energy.; Trouble concentrating on things such as watching TV or reading a newspaper.). For spouses not contending with direct effects from stroke, however, these items would likely not have had as great an influence, suggesting that depression in this group may have been an even bigger problem. This inconsistency in measurement across dyad members points to a methodological tension between administering identical measures for the purpose of comparison 
versus selecting different measures that may be more appropriate for individual partners' circumstances.

There was also no significant difference between survivor and spouse reports on total depressive symptomatology (i.e., 7.34 and 5.78, respectively) and depression was observed to covary at a significant level. These findings are consistent with past research and support the notion that both partners in a committed relationship may be equally affected by stroke in terms of mood.

This study supports the role of perceived relationship quality as a protective factor against depression for both partners. This finding is consistent with the majority of past studies (e.g., Blonder et al., 2007; Epstein-Lubow, Beevers, Bishop, \& Miller, 2009; King, et al., 2009) and is particularly meaningful in light of this study's small sample size and inclusion of other covariates. It is also noteworthy given the significant covariation in partners' reports of relationship quality, as well as spouses' consistent reports of being more satisfied with the relationship than survivors, despite their rating of survivor functioning as being more impaired. It seems that, although spouses perceived survivors’ post-stroke functioning as more compromised than survivors did themselves, they were actually more satisfied with the quality of the couple's relationship and this satisfaction, for both partners, had a bearing on mood. This may be important in terms of post-stroke rehabilitation services that, in addition to focusing on helping survivors regain pre-stroke functioning or adjust to residual disability, could benefit from fostering better post-stroke relationship quality in order to promote better psychological outcomes for both partners. 
This study strongly supports the role of illness ambiguity in both partners’ experiences of depression and, thus, adds to the existing literature in this field. This is logical given the strong bivariate association between partners’ perceptions of illness ambiguity. This study also suggests that ambiguity may have a greater impact on male survivors' depression than female survivors’ depression. Although we may only conjecture about possible reasons for this, this finding may relate to the differential approaches to chronic illness and other life stressors by gender. For example, Berg and Upchurch (2007) describe how males exhibit greater independent self-representations (Cross \& Malden, 1977, as cited in Berg \& Upchurch, 2007) and, thus, factors that compromise this independence (e.g., uncertainty about the present and future with respect to one's health and functioning) may have a greater impact.

Findings in this study related to the roles of active engagement and protective buffering coping were compelling, consistent with past research in comparable illness populations, and particularly relevant for informing interventions targeted at couples. The extent to which spouses perceive survivors as engaging versus buffering them from their personal, emotional experience with stroke has tangible impacts on these spouse's mood. However, this was not the case with survivors, suggesting that survivor depression may be less impacted by survivors' perceptions of how their spouse is behaving toward them and more impacted by other factors (e.g., age, gender, perceived relationship quality, illness ambiguity), although it is possible that this null finding is a function of poor reliabilities of these coping scales in the survivor group. Regardless, effective 
dyad-level interventions must include content related to healthy, interpersonal illness communication.

Because this study failed to find more than a trend-level association between survivor cognitive and physical functioning and depression in either partner, it’s findings do not support a large number of studies in this area. This could be due to this study's small sample size and consequent lack of power to detect weaker effects or it could also be due to it's dyadic and inclusion of relational factors that may be more relevant to couples’ post-stroke adjustment and mood. Although a larger sample would have allowed for simultaneous examination of dyad-level factors so that the effects of each could be more precisely estimated, the current findings, as well as the covariation in survivorspouse reports and the narrative accounts from couples at different life stages presented earlier, provide overall support for the utility of the Developmental Contextual Model of Coping (Berg \& Upchurch, 2007) for understanding the experience of depression in survivor-spouse dyads.

It should also be mentioned that a large number of statistically significant bivariate associations (i.e., in the off-diagonal of Table 6) were observed between survivor and spouse reports of different, and theoretically complementary constructs. For example, spouse perceptions of illness ambiguity was strongly associated with survivor perceptions of protective buffering $(r=.50, \mathrm{p}=.004)$, but not active engagement, misunderstandings $(\mathrm{r}=.50, \mathrm{p}=.008)$, and unreal expectations $(r=.50, \mathrm{p}=.007)$. Similarly, a strong negative association was observed between survivor-reported perceived misunderstandings and spouse- 
reported active engagement $(r=-.39, p=.029)$, raising the possibility that survivors who perceive greater understanding from spouses reciprocate by actively engaging with their spouse around their personal experience with the illness.

Although this study's statistical findings do little to explain the mechanisms behind this covariation - that is, whether it is the result of emotional contagion between partners (Hatfield, Cacioppo, \& Rapson, 1993), the process of positive assortative matching (Wilson, 2002), or some entirely different interpersonal process - the in-depth and, frequently emotional, conversations with survivors and spouses conducted for the qualitative aspect of this study leads this investigator to conclude that even the most psychologically-stable individual may be adversely affected by his or her spouse's reactions to distress (e.g., depressive or emotionally labile affect). Certain individuals are likely at greater risk for depression following a traumatic health event like stroke and partners may share similar risk factors for poor adjustment. Contending daily with the depressed affect of one's spouse is a more proximal determinant, however, and, thus, may exert a greater influence on one's mood. Additional longitudinal studies are needed to shed more light on this matter.

Aim 2. Although quantitative analyses of the role of biographical disruption yielded null findings, the role of age in the present study bears mentioning. For survivors, younger age was consistently and strongly related to higher depressive symptomatology even after controlling for a variety of other factors. While this finding does not resolve the current debate in the literature 
about the role of age in couples' experience of depression, it provides some support for the notion that the experience of stroke should be looked at from a developmental perspective, especially in the context of the qualitative information about biographical disruption from stroke collected for this study. Based on these complementary findings, we can conclude that stroke does not affect all people the same, regardless of age or life stage.

Partners' different ratings of the extent to which the stroke was biographically disruptive to themselves, their spouses, and to the couple, as well as in the summary score of all three items, also bear mentioning. It must be noted that, with the exception of the summary score, these ratings are based on single items. However, by all four standards, spouses consistently rated the stroke as being more disruptive (i.e., to themselves, to their spouse, to the couple, summary score) than did survivors and this difference reached statistical significance on all measures except disruptions to self. Although this difference in partners' perceptions about disruption from stroke was somewhat substantiated by the multivariate models where only disruption to oneself was relevant to survivor depression and only disruption to the couple, as reported by survivors, was relevant for spouse depression, this apparent cross-partner effect remains perplexing and, unfortunately, is further obscured by the narrative portion of the study. For example, an examination of code frequencies between survivors and spouses suggested that spouses commented about twice as often about disruptions to the relationship than did survivors (60 coded comments about relationship disruption by spouses, 36 by survivors). Given the comparable demographics of 
the two groups, it is unlikely that this difference is due to other factors such as participant age or sex, although this should be examined in future work. Additional work investigating how and why each partner feels the stroke had differential impacts on one another would be valuable.

Aim 3. The qualitative portion of this study yielded extremely rich findings with respect to aspects of biographical disruption from stroke not addressed in previous studies or in the structured portion of these interviews. Readers will recall that biographical disruption was assessed in this study with three Likert-scaled items: “At the time of stroke... did your family’s primary income come from paid work done by the survivor?";”... did you and your spouse have dependent children that were cared for in the home?”; and “... as a couple, did you and your spouse lack direct personal experience with chronic illness?”.

These interviews have suggested numerous other items that could be used in the development of a quantitative measure of this construct for couples dealing with chronic illness of all ages. Such a measure might consist of three primary domains of items: instrumental disruptions, psychological disruptions, and relationship disruptions.

In terms of instrumental disruptions, this measure could include items about: the perceived accessibility of the couple's environment; burden from medical and therapy appointments stemming from stroke, including driving and transportation issues; financial and time disruptions stemming from dealing with cumbersome insurance providers; ADL difficulties; overwhelming fatigue in the earlier stages of recovery; compromised ability to pursue recreation and leisure- 
time activities; and altered travel plans. Among survivors, psychological disruption from stroke could be assessed with items related to: disruptions in one's ability to cope with stress; embarrassment at impaired functioning or recent “deformity"; loss of social status; guilt at being a "burden” to one’s spouse or other family members. For both partners, psychological disruption might be illuminated through questions about: feelings of isolation and loss (i.e., control, from one another, from the broader world); fears and uncertainties around future financial security, health, and functioning; forced transitions (i.e., into retirement, into assisted living facilities) or delayed transitions; and the extent to which the stroke was experienced as a profound, global disruption. Similarly, relationship disruptions could be assessed with items about: shifting interpersonal and interfamily roles resulting from stroke, including household division of labor issues; perceived lack of mutual independence; disruption to shared leisure time activities; disruptions to physical and emotional intimacy; exacerbation of existing interpersonal issues; disruptions to healthy communication patterns; and disruptions to relationship complacency (i.e., the extent to which the stroke caused couples to reevaluate their relationship, their goals, and the things they believe to be important in life).

In terms of the items included in the structured portion of this study, existing binary indicators could be eliminated altogether in favor of reworded continuous items. For example, Item One might better read "at the time of stroke did a significant portion of your families' income come from paid work done by the survivor?” or even “To what extent was your family’s income disrupted by 
this stroke?”, in order to capture the fact that working spouses are often forced to leave paid employment (or prevented from seeking paid employment) in order to care for survivors.

\section{Strengths and Limitations of the Study}

Strengths of this study include its basis in previous research, its multi-informant, multi-method approach, its inclusion of survivors experiencing communications impairments, and the wide range of ages and durations of committed relationships represented by the sample. Piloting regarding important questions to ask survivors and spouses was critical and resulted in this study's ability to detect significant effects, even in multivariate contexts, despite its modest sample size. The multi-informant approach adopted here (i.e., data collected from both survivors and spouses, rather than collecting survivor data by proxy) is somewhat innovative in the field of stroke research and led to a clearer picture of the nuanced relationship between individual and interpersonal factors and mood following stroke. Similarly, this study’s mixed methods approach provided truly “connected contributions,” with statistical findings informing interpretation of qualitative data and qualitative data bolstering conclusions derived from statistical analyses, and the multiple sources through which recruitment occurred likely resulted in a more representative sample than would have clinic- or registry-based recruitment alone. Finally, the wide range of ages (i.e., survivors aged 33 to 93 years; spouses aged 31 to 86 years) and relationship durations (i.e., 1 year and 9 months to over 60 years) provided great variability in terms of examining the impact of stroke on couples at different developmental stages. 
Despite the strengths of this study, a number of limitations must be mentioned. First, the cross-sectional design, imperfect controls for premorbid factors, and lack of comparison group did not allow for firm conclusions about the direction of relationships between individual- and dyad-level factors and depression or the direct influence of stroke. Second, the modest sample size precluded examination of more complex statistical models that would have undoubtedly captured the experiences of participants more completely and accurately and, especially, it prevented the investigator from using more sophisticated modeling techniques (e.g., Actor-partner Interdependence Model; Kenny, Kashy, \& Cook, 2006) for examining depression at the level of the dyad. Related to this, significant bivariate relationships between certain predictor variables were observed (e.g., participant age and rating of relationship quality), raising the possibility of confounding relationships. Third, the sample consisted of couples who, on average, had been in very long-term relationships (mean years = 26.5 years). These were longer-term, more stable relationships and, thus, may have been less subject to change due to chronic illness. The pattern of statistical findings in this study, with respect to post-stroke relationship quality and its effects on depression, may have been more pronounced among a sample of more recent couples and this possibility must be considered in terms of generalizability of the current findings to the broader population of survivor-spouse dyads. Finally, this study's racially homogenous (i.e., White) sample made it difficult to examine race, or dyadic racial configuration, as a potential factor influencing participants’ experiences of depression. A more racially diverse sample would allow for, at a minimum, adequate control for participant race. This will be critical for future work given the disproportionately high number of African American and other ethnic minority 
groups that experience stroke (AHA, 2008), and the suggestion that members of these minority groups may be under-diagnosed and undertreated for depression due to cultural factors (Shen, Lin, \& Jackson, 2010).

\section{Implications and Future Directions}

Implications for social work and other rehabilitation practice. In the present sample, survivor functioning was much less statistically relevant to the psychosocial adjustment of survivors and spouses than relational factors. Although it is recognized that prevention of depression is not the sole, or possibly even primary, goal of many poststroke rehabilitation programs, practitioners that embrace a holistic approach to healing from stroke should begin to acknowledge the role of spouses and address relational factors in their work with couples. This study also reinforces the value of a strengthbased approach to working with stroke survivors that embraces spouses not only as effective natural supports, but as individual who may also be in need of support following stroke.

In addition to relational factors, the qualitative portion of this study uncovered a number of contextual stressors experienced by survivors and spouses that social workers may be uniquely suited to address because of their biopsychosocial orientation, their commitment to viewing people within their social contexts (i.e., their committed relationships and families), their frequent involvement with discharge and treatment planning subsequent to acute inpatient rehabilitation, and the opportunities they often have to interact with spouses and other family members during the rehabilitation process and, thus, bring natural support systems to bear. For example, social workers could 
advocate or intervene directly to address couples’ perceived lack of accessible home environments and caregiving resources. Social workers could address reductions in family income due to caregiving demands placed on working caregivers by advocating for more flexible work/family arrangements. Lack of adequate transportation and burden from attending medical provider appointments could be addressed through more coordinated provider appointments. Couples' uncertainty about the future could be mitigated by social workers providing more information to patients or facilitating conversations between patients and medical providers. By placing greater attention on the needs of both survivors and spouses following stroke and by becoming aware of both the contextual stressors and relational factors that affect each partners' outcomes, social workers can significantly reduce the burden of stroke among survivors and their loved ones and maximize families’ chances of successfully rebuilding their lives after stroke.

Moreover, viewing survivors and their spouses in the context of their relationship is not only justified by this study, but also in line with the values embraced by the profession (e.g., the central importance of human relationships). By viewing PSD as an experience of couples embedded within a larger context of systems and services, and, consequently, focusing on the relational aspects of the condition and their implications for treatment, social workers can mitigate the burden from stroke, reduce the incidence of secondary problems, and maximize recovery among survivors and their loved ones.

Implications for research. This preliminary, cross-sectional study provided further evidence for the salience of dyad-level factors in survivors' and spouses' depression following stroke. Future, larger-scale, longitudinal studies should build upon the current findings and, with predictors selected based on the effect sizes established 
here (e.g., active engagement and protective buffering coping), continue to disentangle the complexities associated with chronic illness in the context of committed relationships. A larger sample would allow for more sophisticated modeling techniques, including multilevel modeling, to more accurately estimate within- and between-dyads variance. Greater diversity in terms of race and ethnicity would allow for a more complete picture, especially considering that African Americans have more than twice the risk of stroke than their White counterparts (AHA, 2008).

Continued examination of factors that may account for partners' incongruence on certain constructs (e.g., ratings of survivor functioning and relationship quality) would also be interesting and valuable. Relationship quality is a key determinant of both physical and mental health so uncovering factors that promote better relationship quality in couples is critical.

The current findings also warrant future work - both quantitative and qualitative that continues the development of measures for biographical disruption as both a moderator of, and independent predictor of, depression following stroke. Findings from this study are very encouraging with respect to operationalizing and measuring this concept. A validated measure for biographical disruption would be an excellent addition to the field of chronic illness research as work in this area has, thus far, been mostly theoretical.

\section{Conclusion}

For many years, post-stroke depression was either overlooked in survivors and spouses or viewed as an unfortunate but unsurprising consequence of the illness. However, social workers and other rehabilitation professionals are increasingly 
acknowledging the problem of PSD and that it may not be a "normal” or inevitable outcome of stroke. The immediate distress caused by PSD, as well as the associated problems such as increased mortality and risk of suicide, necessitate that this condition be taken seriously. Research into modifiable factors that contribute to the presence or absence of PSD in survivors and their loved ones, especially research that goes beyond conventional examinations of individual-level factors like survivor functioning, is critically needed if we hope to address this problem. Moreover, studies that examine these issues in relation to couples' developmental stage and expected health trajectories are integral for improving our understanding and ability to effectively intervene.

To date, the study of post-stroke depression has largely focused on separate areas of research about survivor depression and spouse depression following stroke. This dissertation study is among the first to examine the role of relational, dyad-level factors in couples' experiences of depression following stroke. It has demonstrated that relational factors are, in fact, very relevant for both partners’ mental health outcomes. It has also illuminated a variety of factors related to how couples at different stages in their lives and relationship experience chronic illnesses like stroke and, because of this, it will increase our understanding of, and sensitivity to, the unique needs of couples of all ages. While this line of research may still be in it's infancy, early findings about the role of dyad-level factors in couples' experiences of PSD across the lifespan are encouraging and bode well for effective social work interventions in the near future. 


\section{REFERENCE LIST}

Abin, I. \& Verhey, F. (2006). Depression after a cerebrovascular accident: The importance of the integration of neurobiological and psychological pathogenic models. Panminerva Medicine, 48, 49-57.

American Heart Association. (2004). Heart disease and stroke statistics - 2004 update. Dallas, TX: Author.

American Heart Association. (2006). Heart disease and stroke statistics - 2006 update. Dallas, TX: Author.

American Heart Association. (2008). Heart disease and stroke statistics - 2008 update. Dallas, TX: Author.

Anderson, C. S., Hackett, M.L., \& House, A. O. (2004). Interventions for preventing depression after stroke (review). Cochran Database of Systematic Reviews,2(CD003689).

Asbring, P. (2001). Chronic illness - a disruption in life: Identity-transformation among women with chronic fatigue syndrome and fibromyalgia. Journal of Advanced Nursing, 34 (3), 312-319.

Barker-Collo, S. L. (2007). Depression and anxiety 3 months post stroke: Prevalence and correlates. Archives of Clinical Neuropsychology, 22, 519-531.

Beck A.T., Ward, C.H., Mendelson, M., Mock, J., \& Erbaugh, J. (1961). An inventory for measuring depression. Archives of General Psychiatry, 4, 561-571.

Becker, G. (1993). Continuity after a stroke: Implications of life-course disruption in old age. The Gerontologist, 33 (2), 148-158. 
Bediako, S. M., \& Friend, R. (2004). Illness-specific and general perceptions of social relationships in adjustment to rheumatoid arthritis: The role of interpersonal expectations. The Society of Behavioral Medicine, 28 (3), 203-210.

Benyamini, Y., Gozlan, M., \& Kokia, E. (2009). Women's and men's perceptions of infertility and their associations with psychological adjustment: A dyadic approach. British Journal of Health Psychology, 14, 1-16.

Berg, C. A., \& Upchurch, R. (2007). A developmental-contextual model of couples coping with chronic illness across the adult lifespan. Psychological Bulletin, 133(6), 920-954.

Berg, C. A., Wiebe, D. J., Butner, J., Bloor, L., Bradstreet, C., Upchurch, R., Hayes, J., Stephenson, R., Nail, L., \& Patton, G. (2008). Collaborative coping and daily mood in couples dealing with prostate cancer. Psychology and Aging, 23(3), 505516.

Berg, C. A., Schindler, I., \& Maharajh, S. (2008). Adolescents' and mothers' perceptions of the cognitive and relational functions of collaboration and adjustment in dealing with Type 1 Diabetes. Journal of Family Psychology, 22(6), 865-874.

Berg, C. A., Skinner, M., Ko, K., Butler, J. M., Palmer, D. L., Butner, J., \& Wiebe, D. J. (2009). The fit between stress appraisal and dyadic coping in understanding perceived coping effectiveness for adolescents with Type 1 Diabetes. Journal of Family Psychology, 23(4), 521-530.

Bielawska-Batorowicz, E., \& Kossakowska-Petrycka, K. (2006). Depressive mood in men after the birth of their offspring in relation to a partner's depression, social 
support, fathers' personality and prenatal expectations. Journal of Reproductive and Infant Psychology, 24 (1), 21-29.

Blonder, L.X., Langer, S.L., Pettigrew, L.C., \& Garrity, T.F. (2007). The effects of stroke disability on spousal caregivers. Neurorehabilitation, 22, 85-92.

Bookwala, J., \& Schulz, R. (1996). Spousal similarity in subjective well-being: The cardiovascular health study. Psychology and Aging, 11, 582-590.

Boss, P. (1977). A clarification of the concept of psychological father presence in families experiencing ambiguity of boundary. Journal of Marriage and the Family, 39, 141-151.

Boylstein, C., Rittman, M., \& Hinojosa, R. (2007). Metaphor shifts in stroke recovery. Health Communications, 21 (3), 279-287.

Brereton, L., Carroll, C., \& Barnston, S. (2007). Interventions for adult family carers of people who have had a stroke: A systematic review. Clinical Rehabilitation, 21(10), 867-884.

Bury, M. (1982). Chronic illness as biographical disruption. Sociology of Health and Illness, 4 (2), 167-182.

Bury, M. (1991). The sociology of chronic illness: A review of research and prospects. Sociology of Health and Illness, 13 (4), 451-468.

Busby, D. M., Christensen, C., Crane, D. R., \& Larson, J. H. (1995). A revision of the dyadic adjustment scale for use with distressed and nondistressed couples" Construct hierarchy and multidimensional scales. Journal of Marital and Family Therapy, 21 (3), 3289-3308. 
Buunk, B. P., Berkhuysen, M. A., Sanderman, R., Nieuwland, W., \& Ranchor, A. V. (1996). Actieve betrokkenheid, beschermend bufferen en overbescherming: Meetinstrumenten voor de rol van de partner bij hartrevalidatie. [The role of the partner in heart disease: Active engagement, protective buffering, and overprotection]. Gedrag \& Gezondheid, 24, 304-313.

Carod-Artal, F.J., Trizotto, D.S., Coral, L.F., Moreira, C.M., (2009). Determinants of quality of life in Brazilian stroke survivors. Journal of Neurological Sciences, 284(1-2), 63-68.

Centers for Disease Control and Prevention. (2006). Advancing the nation's health: A guide to public health research needs, 2006-2015. Retrieved from http://www.cdc.gov/od/science/PHResearch/cdcra/AdvancingTheNationsHealth.p df)

Centers for Disease Control and Prevention. (2007). Outcomes from Stroke. Retrieved from http://www.cdc.gov/stroke/stroke_outcomes.htm

Centers for Disease Control and Prevention. (2009). Health Protection Goals. Retrieved from http://www.cdc.gov/about/stateofcdc/html/2008/Intro-Protection.htm

Chapman, D. P., Perry, G. S., \& Strine, T. W. (2005). The vital link between chronic disease and depressive disorders. Preventing Chronic Disease, Public Health Research, Practice, and Policy, 2(1), 1-10.

Clark, M.S., Rubenach, S, \& Winsor, A. (2003). A randomized controlled trial of an education and counseling intervention for families after stroke. Clinical Rehabilitation, 17, 703-12. 
Clark, S.L. \& Stephens, M.A.P. (1996). Stroke patients' well-being as a function of caregiving spouses' helpful and unhelpful actions. Personal relationships, 3(2), $171-184$.

Cohen, J., Cohen, P., West, S. G., \& Aiken, L. S. (1992). Applied multiple regression/correlation analysis for the behavioral sciences (3rd Ed.). New Jersey: Lawrence Erlbaum Associates.

Corcoran, K. \& Fischer, J. (1987). Measures for clinical practice: A sourcebook. New York: Free Press.

Coyne, J. C., \& Smith, D. A. (1991). Couples coping with a myocardial infarction: A contextual perspective on wives' distress. Journal of Personality and Social Psychology, 61 (3), 404-412.

Dafer, R.M., Rao, M., Shareef, A., \& Sharma, A. (2008). Poststroke depression. Topics in Stroke Rehabilitation, 15(1), 13-21.

Dickson, A., Allan, D., \& O'Carroll, R (2008). Biographical disruption and the experience of loss following a spinal cord injury: An interpretative phenomenological analysis. Psychology \& Health, 23 (4), 407-425.

Duncan, P.W., Wallace, D., Lai, S.M., Johnson, D., Embretson, S., \& Laster, L.J., (1999). The Stroke Impact Scale Version 2.0 : Evaluation of reliability, validity, and sensitivity to change. Stroke, 30, 2131-2140.

Epstein-Lubow, G.P., Beevers, C.G., Bishop, D.S., \& Miller, I.W. (2009). Family functioning is associated with depressive symptoms in caregivers of acute stroke survivors. Archives of Physical Medicine and Rehabilitation, 90, 947-55. 
Epstude, k. \& Mussweiler, T. (2009). What you feel is how you compare: How Comparisons Influence the Social Induction of Affect. Emotion, 9(1), 1-14.

Everson, S. A., Roberts, R. E., Goldberg, D. E., \& Kaplan, G. A. (1998). Depressive symptoms and increased risk of stroke mortality over a 29-year period. Archives of Internal Medicine, 25(158), 1133-1138.

Faircloth, C. A., Boylstein, C., Rittman, M., Young, M. E., \& Gubrium, J. (2004). Sudden illness and biographical flow in narratives of stroke recovery. Sociology of Health and Illness, 26 (2), 242-261.

Falconer, J. A., Naughton, B. J., Strasser, D. C., \& Sinacore, J. M. (1994). Stroke inpatient rehabilitation: A comparison across age groups. Journal of the American Geriatric Society, 42, 39-44.

Franzen-Dahling, A., Billing, E., Nasman, P., Martensson, B., Wredling, R., \& Murray, V. (2006). Post-stroke depression - effect on the life situation of the significant other. Scandinavian Journal of Caring Science, 20, 412-416.

Gagliese, L,., Jovellanos, M., Zimmermann, C., Shobbrook, C., Warr, D., \& Rodin G. (2009). Age-related patterns in adaptation to cancer pain: A mixed-method study. Pain Medicine, 10(6), 1050-1061.

Gilbody, S., Richards, D., Brealey, S., \& Hewiitt, C. (2007). Screening for depression in medical settings with the Patient Health Questionnaire (PHQ): A diagnostic metaanalysis. Journal of General Internal Medicine, 22 (11), 1596-1602.

Gisquet, E. (2008). Cerebral implants and Parkinson's disease: A unique form of biographical disruption? Social Science \& Medicine, 67 (11), 1847-1851. 
Giunta, C. T., \& Compas, B. E. (1993). Coping in marital dyads: Patterns and associations with psychological symptoms. Journal of Marriage and Family, 55, 1011-1017.

Gold-Spink, E., Sher, T. G., \& Theodos, V. (2000). Uncertainty in illness and optimism in couples with multiple sclerosis. International Journal of Rehabilitation and Health, 5 (3), 157-164.

Goodman, C. R., \& Shippy, R. A. (2002). Is it contagious? Affect similarity among spouses. Aging and Mental Health, 6 (3), 266-274.

Grant, J. S., Bartolucci, A. A., Elliot, T. R., \& Giger, J. N. (2000). Sociodemographic, physical, and psychosocial characteristics of depressed and non-depressed family caregivers of stroke survivors. Brain Injury, 14 (12), 1089-1100.

Green, G., Todd, J., \& Pevalin, D. (2007). Biographical disruption associated with multiple sclerosis: Using propensity scoring to assess the impact. Social Science and Medicine, 65 (3), 524-535.

Greenberg, P., Kessler, R., Nelss, T., Finkelstein, S., \& Berndt, E. (1996). Depression in the workplace: An economic perspective. In J. P. Feighner, \& W. F. Boyer, (Eds.), Selective serotonin reuptake inhibitors:Advances in basic research and clinical practice (pp. 321-258). Chichester: John Wiley \& Sons.

Hackett, M. L., Yapa, C., Parag, V., \& Anderson, C. S. (2005). Frequency of depression after stroke: A systematic review of observational studies. Stroke, 36, 1330-1340. Hagedoorn, M., Kuijer, R. G., Buunk, B. P., Wobbes, T., \& Sanderman, R. (2000). Marital satisfaction in patients with cancer: Does support from intimate partners benefit those who need it the most? Health Psychology, 19 (3), 274-282. 
Han, B., \& Haley, W. E. (1999). Family caregivers of patients with stroke: Review and analysis. Stroke, 30,1478-1485.

Hatfield, E., Cacioppo, J. L., \& Rapson, R. L. (1993). Emotional contagion. Current Directions in Psychological Sciences, 2, 96-99.

Herrmann, N., Black, S. E., Lawreance, J., Szekely, C., \& Szalai, J. P. (1998). The Sunnybrook stroke study: A prospective study of depressive symptoms and functional outcome. Stroke, 29, 618-624.

Hosking, S. G., Marsh, N. V., \& Friedman, P. J. (2000). Depression at 3 months poststroke in the elderly: Predictors and indicators of prevalence. Aging, Neurology, and Cognition, 7 (4), 205-216.

Hughes, S. L., Giobbie-Hurder, A., Weaver, F. M., Kubal, J. D., \& Henderson, W. (1999). Relationship between caregiver burden and health-related quality of life. The Gerontologist, 39 (5), 534-545.

Jacobs, B. S., Boden-Albala, B., Lin, I. F., \& Sacco, R. L. (2002). Stroke in the young in the northern Manhattan stroke study. Stroke, 33, 2789-2793.

Kaplan, L., \& Boss, P. (1999). Depressive symptoms among spousal caregivers of institutionalized mates with Alzheimer's: Boundary ambiguity and mastery as predictors. Family Process, 38 (1), 85-103.

Kappelle, L. J., Adams, H. P., Heffner, M. L., Torner, J. C., Gomez, F., \& Biller, J. (1994). Prognosis of young adults with ischemic stroke: A long-term follow-up study assessing recurrent vascular events and functional outcomes in the Iowa Registry of Stroke in Young Adults. Stroke, 25 (7), 1360-1365. 
Karasek, R.A. \& Theorell, T. (1990). Healthy work. Stress, Productivity, and the Reconstruction of Working Life. New York: Basic Books.

Kenen, R., Ardern-Jones, A., \& Eeles, R. (2003). Living with chronic risk: healthy women with a family history of breast/ovarian cancer. Health, Risk \& Society, 5 (3), 315-331.

Kenny, D. A., Kashy, D. A., \& Cook, W. L. (2006). Dyadic data analysis. New York: Guilford Press.

Kessler, D., Dubouloz, C., Urbanowski, R., \& Egan, M. (2009). Meaning perspective transformation following stroke: the process of change. Disability \& Rehabilitation, 31(13), 1056-1065.

King, R.B., Carlson, C.E., Shade-Zeldow, Y., Bares, K.K., Roth, E.J., \& Heinemann, A.W. (2001). Transition to home care after stroke: depression, physical health, and adaptive processes in support persons. Research in Nursing and Health, 24, 307-23.

Klinedinsk, N. J., Clark, P. C., Blanton, S., \& Wolf, S. L. (2007). Congruence of depressive symptom appraisal between persons with stroke and their caregivers. Rehabilitation Psychology, 52 (2), 215-225.

Knapp, P., Young, J., House, A., \& Foster, A. (2000). Non-drug strategies to resolve psycho-social difficulties after stroke. Age and Ageing, 29, 23-30.

Ko, J. K., Aycosk, D.M ., \& Clark, P. C. (2007). A comparison of working versus nonworking family caregivers of stroke survivors. Journal of Neuroscience Nursing, 39 (4), 217-225. 
Kroenke, K., Spitzer, R. L., \& Williams, J. B. W. (2001).The PHQ-9: validity of a brief depression severity measure. Journal General Internal Medicine, 16, 606-613. Kyrozis, A., Potagas, C., Ghika, A., Tsimpouris, P. K., Virvidaki, E. S., \& Vemmos, K. N. (2009). Incidence and predictors of post-stroke aphasia: The Arcadia Stroke Registry. European Journal of Neurology, 16(6), 733-739.

Lai, S. M., Perera, S., Duncan, P. W., \& Bode, R. (2003). Physical and social functioning after stroke: Comparison of the Stroke Impact Scale and Short Form-36. Stroke, 34 (2), 488-493.

Larson, J., Franzen-Dahling, A., Billing, E., von Arbin, M., Murray, V., \& Wredling, R. (2008). The impact of gender regarding psychological well-being and general life situation among spouses of stroke patients during the first year after the patient's stroke event: A longitudinal study. International Journal of Nursing Studies, 45, 257-265.

le Carricaburu, D., \& Pierret, J. (1995). From biographical disruption to biographical reinforcement: The case of HIV-positive men. Sociology of Health \& Illness, 17 (1), 65-88.

Lecrubier, Y., Sheehan, D. V., Weiller, E., Amorim, P., Bonora, I., Harnett Sheehan, K., Janavs, J., \& Dunbar, G. C. (1997). The mini international neuropsychiatric interview (MINI). A short diagnostic structured interview: Reliability and Validity according to the CIDI. European Psychiatry, 12, 224-231.

Lenth, R. V. (2006). Java Applets for power and sample size [Computer software]. Retrieved from http://www.stat.uiowa.edu/ rlenth/Power. 
Low, J. T. S., Payne, S., \& Roderick, P. (1999). The impact of stroke on informal carers: A literature review. Social Science and Medicine, 49, 711-725.

Lyons, K. S., Stewart, B. J., Archbold, P. G., \& Carter, J. H. (2009). Optimism, pessimism, mutuality, and gender: Predicting 10-year role strain in Parkinson's Disease spouses. Gerontologist, 49(3), 378-387.

Macnamara, S. E., Gummow, L. J., Goka, R., \& Gregg, C. H. (1990). Caregiver strain: Need for late poststroke intervention. Rehabilitation Psychology, 35, 71-77.

Mahoney, F. I., \& Barthel, D. W. (1965). Functional evaluation: The barthel index. Maryland State Medical Journal, 14, 61-65.

Mant, J., Carter, J., Wade, D.T., \& Winner, S. (2000). Family support for stroke: a randomized controlled trial. Lancet, 356, 808-13.

Martire, L. M., Schulz, R., Wrosch, C., \& Newsom, J. T. (2003). Perceptions and implications of received spousal care: Evidence from the caregiver health effects study. Psychology and Aging, 18 (3), 593-601.

Marshall, A. J. \& Harper-Jaques, S. (2008). Depression and family relationships. Journal of Family Nursing, 14(1), 56-73.

Mishel, M. H. (1981). The measurement of uncertainty in illness. Nursing Research, 30 (5), 258-263.

Mishel, M. H. (1996). Uncertainty in illness scales manual. Chapel Hill, NC: Author. Montagne, B., Nys, G.M.S., van Zandvoort, M. J. E., Kappelle, J. L., de Haan, E.H. F., \& Kessels, R.P.C. (2007). The perception of emotional facial expressions in stroke patients with and without depression. Acta Neuropsychiatrica, 19(5), 279-283. 
Monteparte, J. M. (1996). An assessment of adults perceptions of their psychological, physical, and social ages. Journal of Clinical Geropsychology, 2 (2), 117-128. Montgomery, S.A., Ashberg, M., (1979). A new depression scale designed to be sensitive to change. British Journal of Psychiatry, 134, 382-389.

Moreno-Rosset, C., Jurado, R. A., Rio, C. J. (2009). Validation of the questionnaire of emotional maladjustment and adaptive resources in infertility (DERA). Psicothema, 21(1), 118-123.

Morris, P. L., Robinson, R. G., Andrzejewski, P., Samuels, J., \& Price, T. R. (1994). Association of depression with 10-year poststroke mortality. American Journal of Psychiatry, 151(1), 124-129.

Mosovich, S. A., Boone, R. T., Reichenberg, A., Bansilal, S., Shaffer, J., Dahlman, K., Harvey, P. D., \& Farkouh, D. (2007). New insights into the link between cardiovascular disease and depression. International Journal of Clinical Practice, 62, 355-357.

Naess, H., Nyland, H. I., Thomassen, L., Aareth, J., \& Myhr, K. M. (2005). Mild depression in young adults with cerebral infarction at long-term follow-up: A population-based study. European Journal of Neurology,12, 194-198.

Navon, L. \& Morag, A. (2004). Liminality as biographical disruption: Unclassifiability following hormonal therapy for advanced prostate cancer. Social Science \& Medicine, 58 (11), 2337-2348.

Neal, M., Hammer, L., \& Morgan, D. (2006). Using mixed methods in research related to work and family. In M. Pitt-Cassouphes, E. Kossek, \& S. Sweet (Eds.), The work 
and family handbook: Multidisciplinary perspectives and approaches. Mahwah, NJ: Lawrence Erlbaum.

Neugarten, B. L. (1979). Time, age, and the life cycle. American Journal of Psychiatry, 136, 887-894.

Oschwald, M., Renker, P., Hughes, R., Arthur, A., Powers, L., \& Curry, M.A. (2009). Development of an accessible audio computer-assisted self-interview (A-CASI) to screen for abuse and provide safety strategies for women with disabilities. Journal of Interpersonal Violence, 24 (5), 795-818. doi:10.1177/0886260508317175

Palmer S, \& Glass, T.A. (2003). Family function and stroke recovery: a review. Rehabilitation Psychology, 48, 255-265.

Paolucci S, Gandolfo C, Provinciali L, Torta R, et al. (2005). Quantification of the risk of post stroke depression: the Italian multicenter observational study DESTRO. Acta Psychiatrica Scandinavica 112(4):272-8.

Paranthaman, R., \& Baldwin, R. C. (2006). Treatment of psychiatric syndromes due to cerebrovascular disease. International Review of Psychiatry, 18 (5), 453-470.

Parsons, T. (1951). The Social System. New York: Free Press

Patten, S. B., Newman, S., Becker, M., Riddell, C., Metz, L. (2007). Disease management for depression in an MS clinic. International Journal Of Psychiatry In Medicine, 37 (4), 459-473.

Peterson, B. D., Pirritano, M., Christensen, U., Boivin, J., Block, J., \& Schmidt, L. (2009). The longitudinal impact of partner coping in couples following 5 years of unsuccessful fertility treatments. Human Reproduction, 24(7), 1656-1664. 
Pound, P., Gompertz, P., \& Ebrahim, S. (1998). Illness in the context of older age: The case of stroke. Sociology of Health and Illness, 20 (4), 489-506.

Pruchno, R., Wilson-Genderson, M., Cartwright, F. (2009). Self-rated health and depressive symptoms in patients with end-stage renal disease and their spouses: A longitudinal dyadic analysis of late-life marriages. Journal of Gerontology Series B - Psychological Sciences and Social Sciences, 64(2), 212-221.

Quittner, A. L., Barker, D. H., Snell, C., Grimley, M. E., Marciel, K., \& Cruz, I. (2008). Prevalence and impact of depression in cystic fibrosis. Current Opinion in Pulmonary Medicine, 14(6), 582-588.

Rabkin, J. G., McElhiney, M., Moran, P., Acree, M., \& Folkman, S. (2009). Depression, distress and positive mood in late-stage cancer: A longitudinal study. PsychoOncology, 18, 79-86.

Rajaram, S. S., \& Hill, J. (1997). A biographical disruption: The case of an abnormal pap smear. Health Care for Women International, 18 (6), 521-523.

Ritchie, J., \& Lewis, J. (2003). Qualitative research practice: A guide for social science students and researchers. Thousand Oaks, CA: Sage.

Riolo, S. A., Nguyen, T. A., Greden, J. F., \& King, C. A. (2005). Prevalence of depression by race/ethnicity: Findings from the National Health and Nutrition Examination Survey III. American Journal of Public Health, 95 (6), 998-1000.

Rochette, A., Bravo, G., Desrosiers, J., St. Cyr-Tribble, D., \& Bourget, A. (2007). Adaptation process, participation and depression over six months in first-stroke individuals and spouses. Clinical Rehabilitation, 21, 554-562. 
Roding, J., Lindstrom, B., Malm, J., \& Ohman, A. (2003). Frustrated and invisible young stroke patients' experiences of the rehabilitation process. Disability and Rehabilitation, 25 (15), 867-874.

Salter, K., Sanjit, K., Bhogal, N.F., Jutai, J., \& Teasell, R. (2007). The assessment of poststroke depression. Topics in Stroke Rehabilitation, 14(3), 1-24.

Santus, G., Ranzenigo, A., Caregnato, R., \& Inzoli, M.R. (1990). Social and family integration of hemiplegic elderly patients 1 year after stroke. Stroke, 21, 10191022.

Saxena, S. K., Ng, T. P., Yong, D., Fong, N. P., \& Koh, G. (2008). Subthreshold depression and cognitive impairment but not demented in stroke patients during their rehabilitation. Acta Neoroligica Scandinavia, 117, 133-140.

Scheff, T.J., (1984). Being Mentally Ill (2nd ed). Piscataway: Aldine Transaction.

Schneider, A. T., Kissela, B., Woo, D., Kleindorfer, D., Alwell, K., Miller, R., et al. (2004). Ischemic stroke subtypes: a population-based study of incidence rates among blacks and whites, Journal Of Cerebral Circulation 35 (7), 1552-1556.

Scott, J. L. \& Kayser, K. (2009). A review of couple-based interventions for enhancing momen's sexual adjustment and body image after cancer. Cancer Journal, 15(1),48-56.

Segrin, C.; Powell, H. L., Givertz, M., \& Brackin, A. (2003). Symptoms of depression, relational quality, and loneliness in dating relationships. Personal Relationships, 10 (1), 25-36.

Shamay-Tsoory, S.G., Tomer R., Goldsher D., Berger B. D., \& Aharon-Peretz, J. (2004). Impairment in cognitive and affective empathy in patients with brain lesions: 
anatomical and cognitive correlates. Journal of Clinical And Experimental Neuropsychology,26(8), 1113-1127.

Shen, J.J., Lin, F. \& Jackson, T (2010). Risk of prenatal depression: Differences by race. Ethnicity and Disease, 20, 35-39.

Silverman, D. (2005). Doing qualitative research: a practical handbook (2nd ed.). London: Sage.

Smith, J., Forster, A., \& Young, J. (2004). A randomized trial to evaluate an education programme for patients and careers after stroke. Clinical Rehabilitation, 18, 72636.

Soares, J.C. \& Mann, J.J. (1997). The anatomy of mood disorders: A review of structural neuroimaging studies. Biological Psychiatry, 41, 86-106.

Spanier, G. B. (1976). Measuring dyadic adjustment: New scales for assessing the quality of marriage and similar dyads. Journal of Marriage and the Family, 38, 15-28.

Spillmann, L., Laskowski, W., Lange, K.W.., Kasper, E., \& Schmidt, D. D. (2000). Stroke-blind for colors, faces and locations: Partial recovery after three years. Restorative Neurology \& Neuroscience, 17(2/3).

Starr L.B., Robinson R.G., Price T.R. (1983). Reliability, validity and clinical utility of the Social Functioning Exam in the assessment of stroke patients. Experimental Ageing Research, 9, 101-106.

Stenager, E.N., Madsen, C., Stenager, E., \& Boldsen, J. (1998). Suicide in patients with stroke: Epidemiological study. BMJ, 316, 1206-1210. 
Stone, S. D. (2007). Patient concerns posthaemorrhagic stroke: A study of the Internet narratives of patients with ruptured arterivenous malformation. Neurological Nursing, 16, 289-297.

Strating, M. M. H., Van Duijn, M. A. J., Van Schuur, W. H., \& Suurmeijer, T. P. B. M. (2007). The differential effects of rheumatoid arthritis on distress among patients and partners. Psychology and Health, 22 (3), 361-379.

Strauss, A. and Corbin, J. (1994). Grounded Theory methodology: An overview, In: Handbook of Qualitative Research (Denzin, N., K. and Lincoln, Y.,S., Eds.). London: Sage.

Suls, J., Green, P., Rose, G., Lounsbury, P., \& Gordon, E. (1997). Hiding worries from one's spouse. Associations between coping via protective buffering and distress in male post-myocardial infarction patients and their wives. Journal of Behavioral Medicine, 20 (4), 333-349.

Tabachnick, B. G. \& Fidell, L. S. (2007). Using multivariate statistics (5 ${ }^{\text {th }}$ Ed.). Boston: Pearson..

Teasell, R. W., McRae, M. P., \& Finestone, H. M. (2000). Social issues in the rehabilitation of younger stroke patients. Archives of Physical Medicine and Rehabilitation, 81, 205-209.

Thomas, A. J., Kalaria, R. N., \& O'Brien, J. T. (2004). Depression and vascular disease: What s the relationship? Journal of Affective Disorders, 79, 81-95.

Tiegs, T., Heesacker, M., Ketterson, T. U., Pekich, D. G., Rittman, M. R., Rosenbek, J. C., Stidham, B. S., \& Gonzalez-Rothi, L. J. (2006). Coping by stroke caregivers: Sex similarities and differences. Topics in Stroke Rehabilitation, 13 (1), 52-62. 
Thompson, A. \& Bolger, n. (1999). Emotional transmission in couples under stress. Journal of Marriage and the Family, 61(1), 38-48.

Tower, R. B., \& Kasl, S. V. (1996). Depressive symptoms across older spouses: Longitudinal influences. Psychology and Aging, 11, 683-697.

Turner-Stokes, L., \& Hassan, N. (2002). Depression after stroke: a review of the evidence base to inform the development of an integrated care pathway. Part 1: Diagnosis, frequency and impact. Clinical Rehabilitation, 16, 231-247.

U.S. Census Bureau. (2006, May). Americans with disabilities: 2002. Available: http://www.census.gov/prod/2006pubs/p70-107.pdf

van Swieten, J. C., Koudstaal, P. J., Visser M. C., Schouten H. J., \& van Gijn, J. (1988). Interobserver agreement for the assessment of handicap in stroke patients. Stroke, 19 (5), 604-607.

Visser-Meily, A., Post, M., Gorter, J. W., Berlekom, S. B. V., Van Den Bos, T., \& Lindeman, E. (2006). Rehabilitation of stroke patients needs a family-centered approach. Disability and Rehabilitation, 28(24), 1557-1561.

Visser-Meily, A., Post, M., van de Port, I., Maas, C., Forstberg-Warleby, G., \& Lindeman, E. (2009). Psychosocial functioning of spouses of patients with stroke from initial inpatient rehabilitation to 3 years poststroke: Course and relations with coping strategies. Stroke, 40, 1399-1404.

Wade, D. T., Leigh-Smith, J., \& Hewer, R. L. (1986). Effects of living with and looking after survivors of stroke. British Medical Journal, 293, 418-420.

Wang, P.P., Badley, E.M., \& GiGnac (2006). Exploring the role of contextual factors in disability models. Disability and Rehabilitation, 28(2), 135-140. 
White, J.H., Magin, P., Attia, J., Pollack, M.R., Sturm, J., \& Levi, C.R. (2008). Exploring poststroke mood changes in community-dwelling stroke survivors: a qualitative study Archives Of Physical Medicine And Rehabilitation, 89(9), 1701-7.

Williams, S. J. (2000). Chronic illness as biographical disruption or biographical disruption as chronic illness? Reflections on a core concept. Sociology and Health \& Illness, 22(1), 40-67.

Williams, A. M. (1993). Caregivers of persons with stroke: Their physical and emotional wellbeing. Quality of Life Research, 2, 213-220.

Williams, L. S., Brizendine, E. J., Plue, L., Bakas, T., Tu, W., Hendrie, H, \& Kroenke, K. (2005). Performance of the PHQ-9 as a screening tool for depression after stroke. Stroke, 36, 635-638.

Williams, L. S., Shoma-Ghose, S., \& Swindel, R. W. (2004). Depression and other mental health diagnoses increase mortality risk after ischemic stroke. American Journal of Psychiatry, 161(16), 1090-1095.

Wilson, J. T. L., Hareendran, A., Hendry, A., Potter, J., Bone, I., \& Muir, K. W. (2005). Reliability of the Modified Rankin Scale across multiple raters: Benefits of a structured interview. Stroke; 36, 777-781.

Wilson, S. (2002). The health capital of families: an investigation of the inter-spousal correlation in health status, Social Science and Medicine, 55, 1157-1172.

Wilson, S. (2007). When you have children, you're obliged to live: Motherhood, chronic illness and biographical disruption. Sociology of Health \& Illness, 29 (4), 610-26. 
Winkens, I., Van Heugten, C.M., Fasotti, L., Duits, A.A., Wade, D.T. (2006).

Manifestations of mental slowness in the daily life of patients with stroke: a qualitative study. Clinical Rehabilitation, 20(9), 827-834.

World Health Organization. (2003). The world health report 2003: Shaping the future. Geneva: Author.

Wright, L. K., Hiskey, J. V., Buckwalter, K. C., Kelechi, T., \& Hendrix, S. A. (1998). Spousal interactions in Alzheimer's disease and stroke caregiving: Relationship to care recipients' functional abilities and physical and emotional health. Journal of the American Psychiatric Nurses Association, 4, 169-181.

Yeung, S., Lui, M. H., Ross, F., \& Murrells, T. (2007). Family carers in stroke care: Examining the relationship between problem-solving, depression, and general health. Journal of Clinical Nursing, 16, 344-352. 


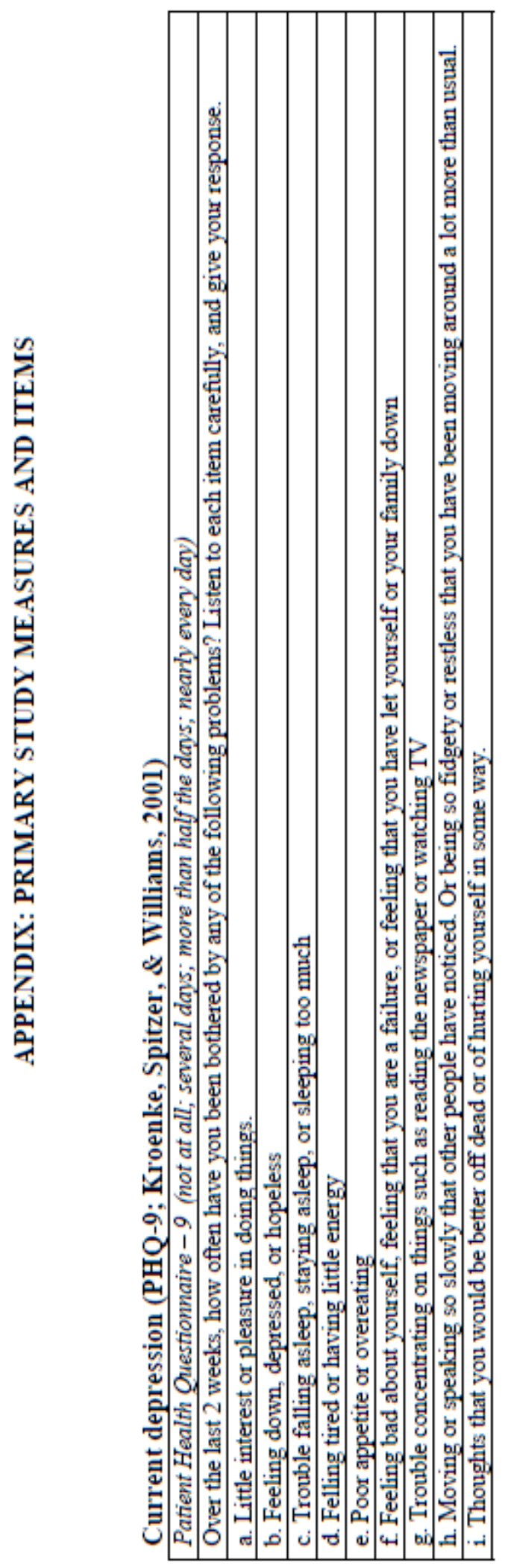




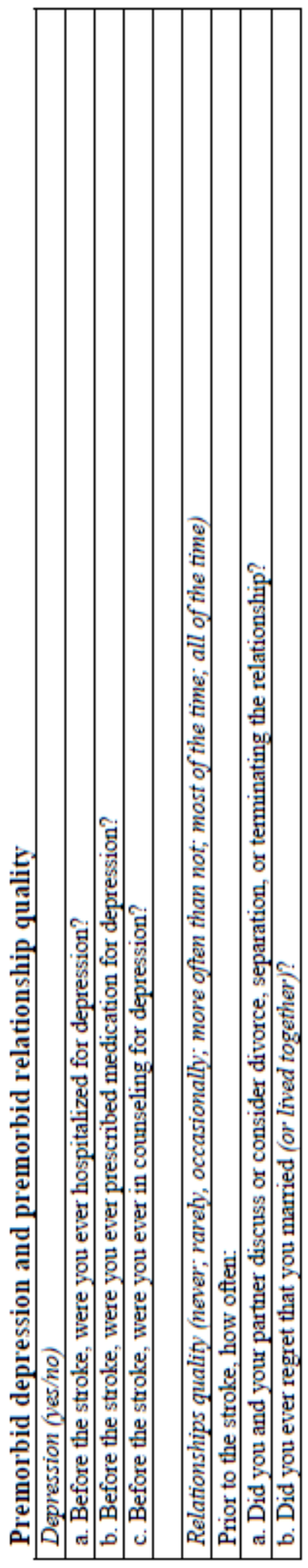




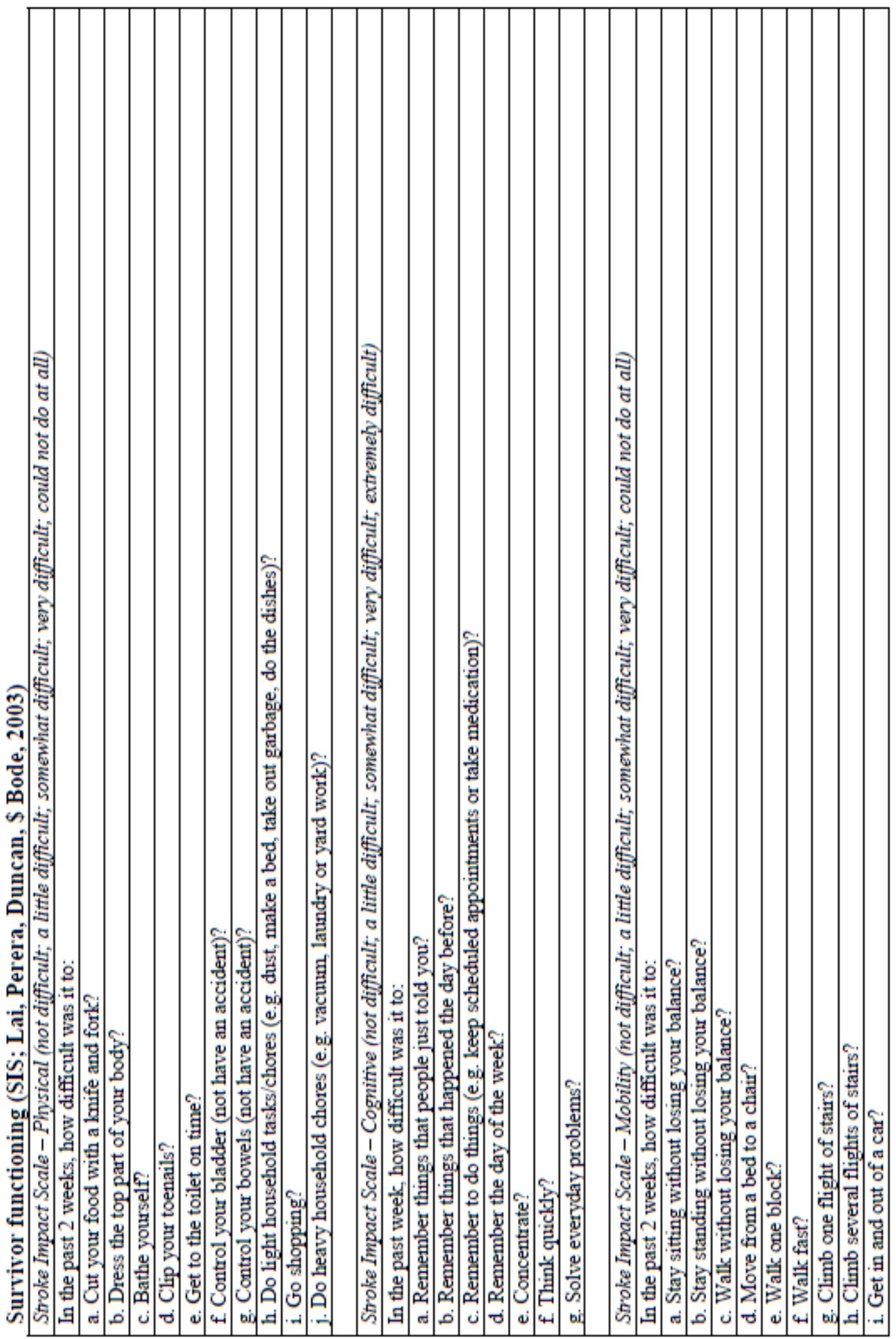




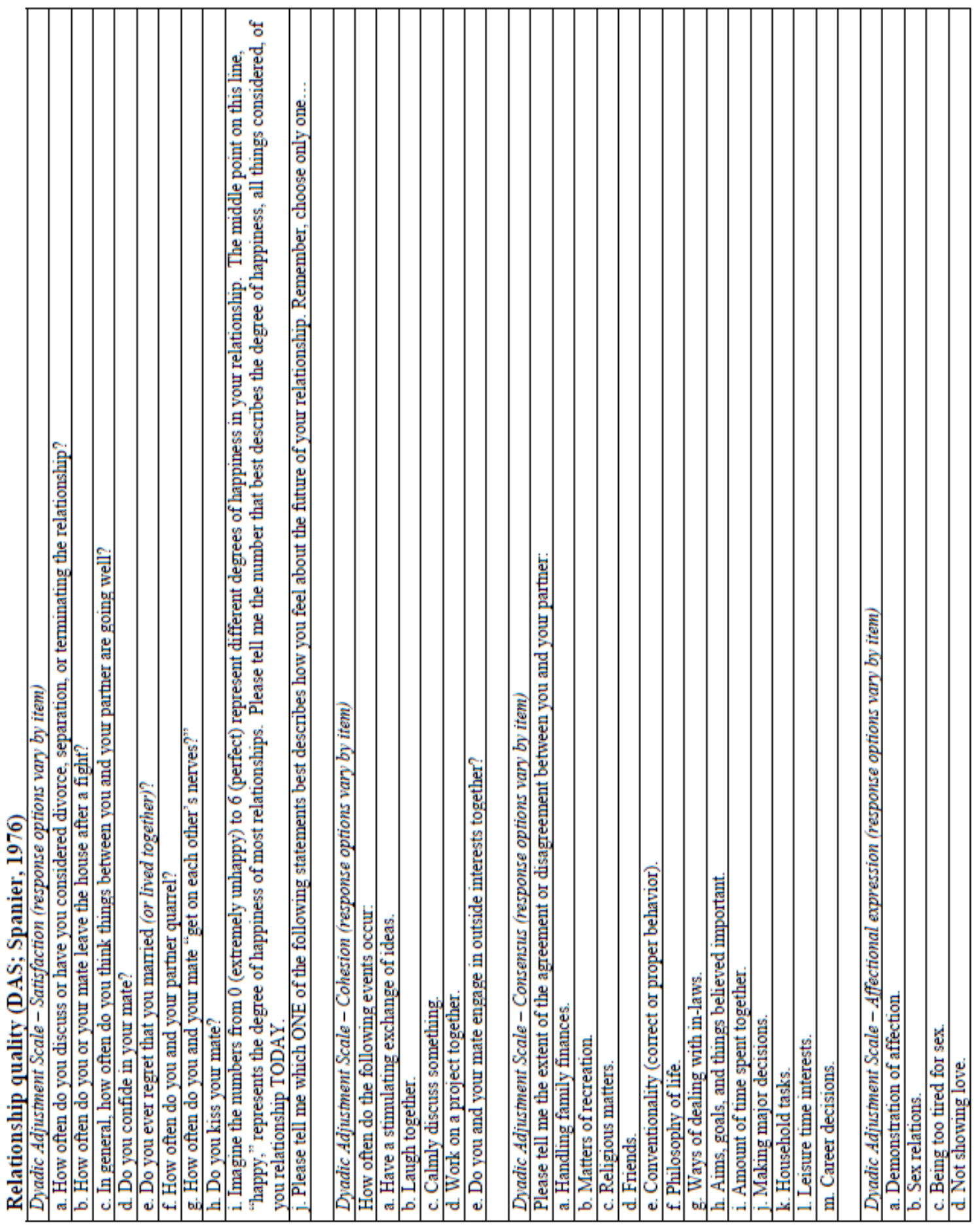




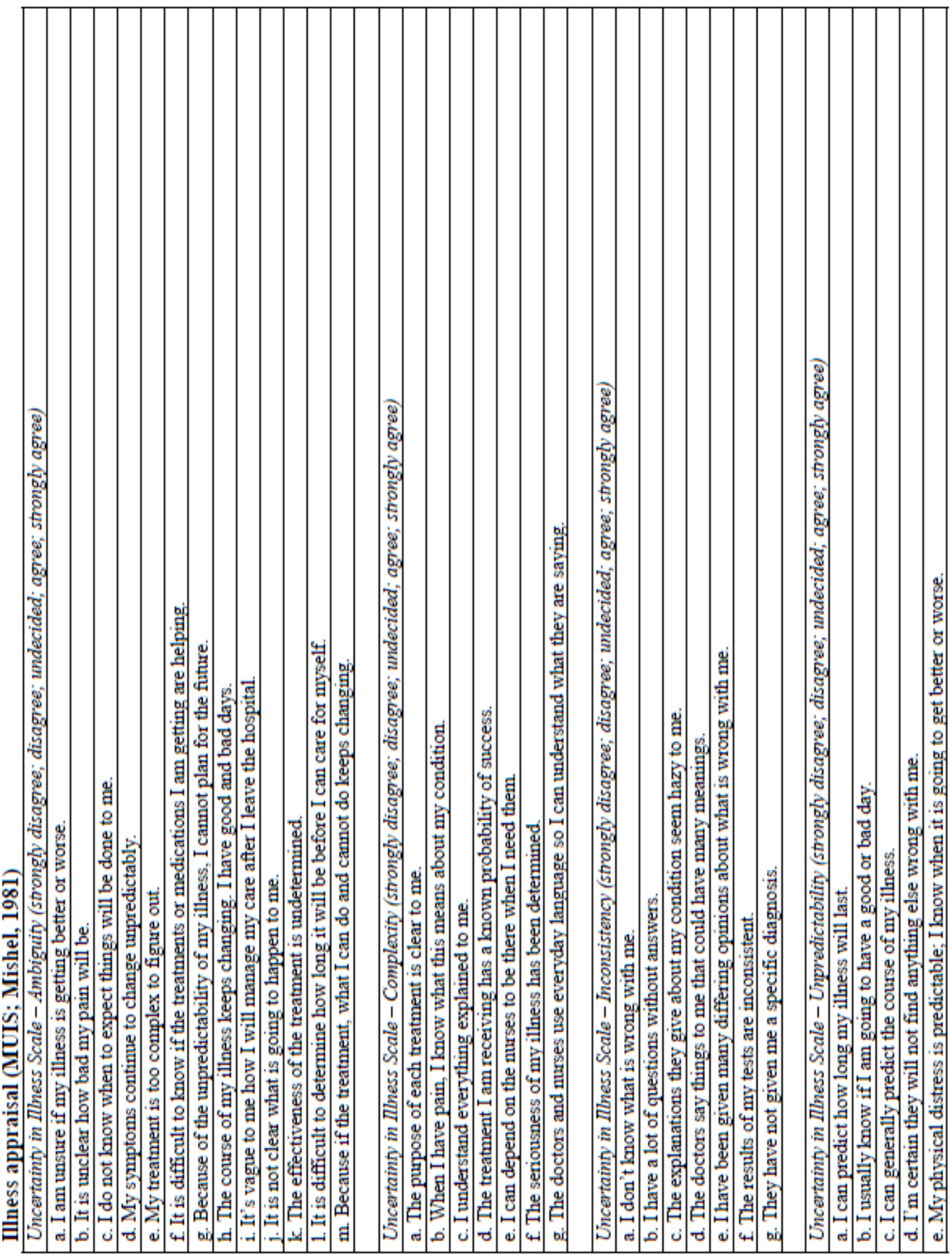




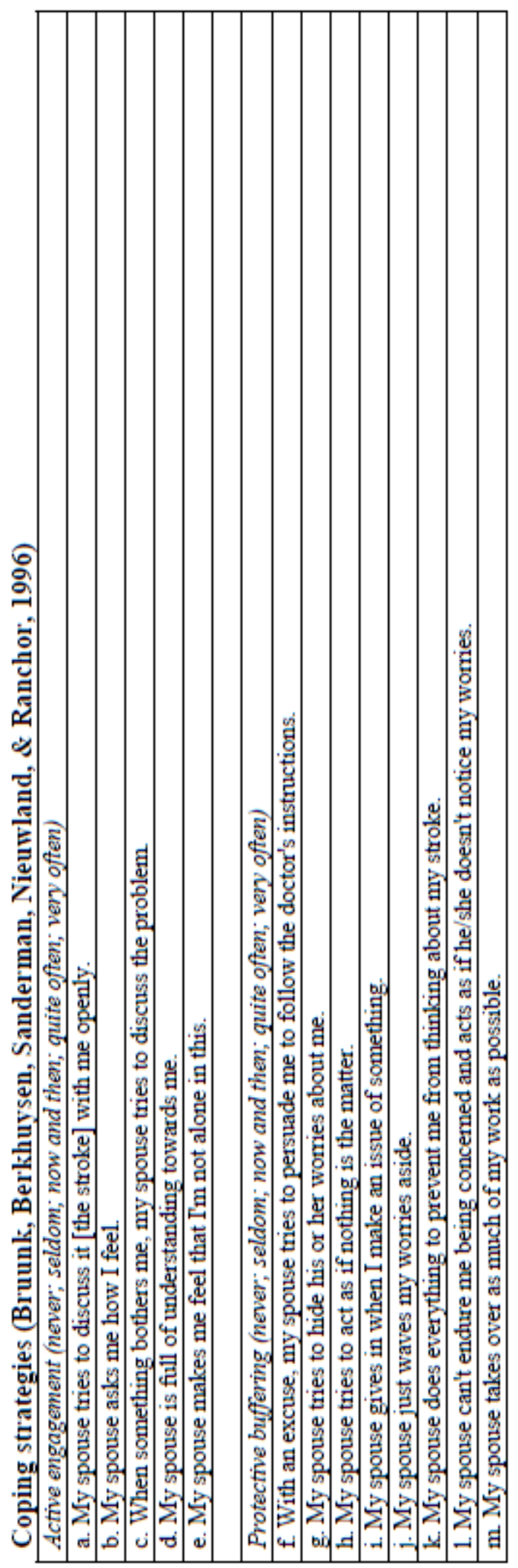




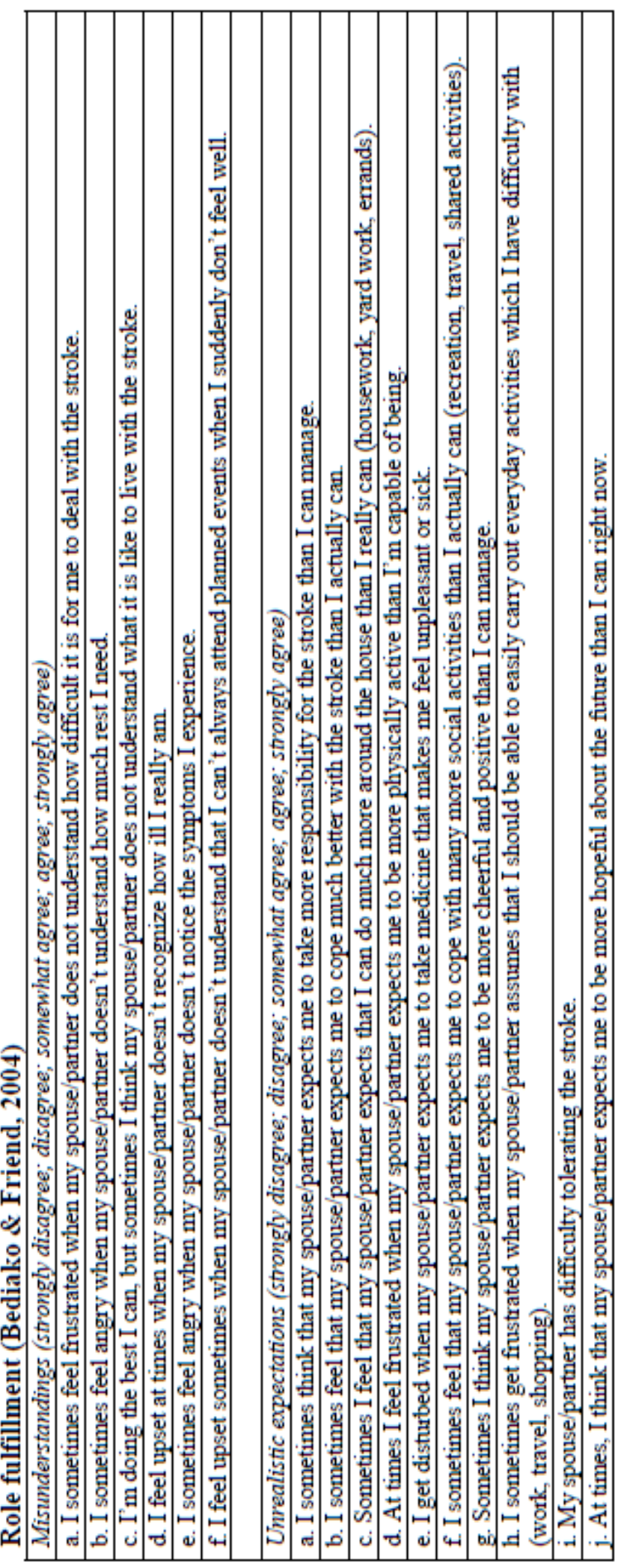




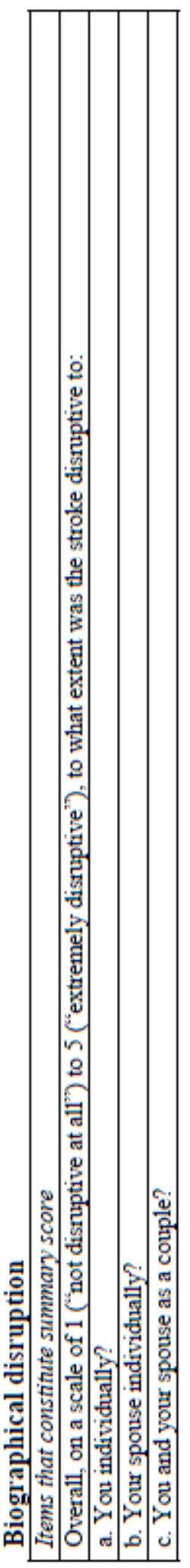

